\title{
Functional proteome analysis of age associated PrPC knockout mice liver along with regulatory response of cytoskeleton associated tau protein and fatty liver disease.
}

\author{
Dissertation \\ For the award of the degree \\ "Doctor rerum naturalium (Dr. rer. nat.)" \\ in the Molecular Medicine Study Program \\ at the Georg-August-University Göttingen
}

Submitted by

Amandeep Singh Arora

From SAS Nagar (Punjab - India)

Göttingen, 2015 


\section{Members of the Thesis Committee:}

Supervisor:

Name, Institute: Prof. Dr. Mathias Bähr, Department of Neurology, University Medical Center, Georg-August University, Göttingen

Second member of the thesis committee:

Name, Institute: Prof. Dr. Karsten Hanisch, Department of Neuropathology, University Medical Center, Georg-August University, Göttingen

Third member of the thesis committee:

Name, Institute: Prof. Dr. Mikael Simons, Max Planck Institute for Experimental Medicine, Göttingen

Date of Disputation: 14-04-2015 


\section{DECLARATION}

Here I declare that my doctoral thesis entitled "Functional proteome analysis of age associated PrPC knockout mice liver along with regulatory response of cytoskeleton associated tau protein and fatty liver disease" has been written independently with no other sources and aids than quoted.

Amandeep Singh Arora

Göttingen, January 2015 


\section{Acknowledgments}

A long journey of more than three years has been interesting and adventurous but it would not have been possible to complete it without the blessings and support of my father Sr. Parlad singh and my mother Smt. Surinder kaur. So, I dedicate my PhD degree to my parents.

Firstly, I would like to thanks my direct supervisor prof. Dr. Inga Zerr for giving me opportunity to do PhD in the prion research group and for her scientific and moral support during failures and successful of experiments. Secondly, I thanks to Dr. Saima Zafar for her support in this challenging project which finally gave an interesting and a new outcome. It was a great experience of learning new innovative techniques like $C E$ and executes new challenging ideas, which had not been possible without the support of Dr. Matthias Schmitz. I thanks to Dr. Franc Llorenz, from whom I learnt how to be more productive and efficient during performing of experiments. It was a great help of Prof. Dr. Sabine Mihm from the department of gastroenterology in analyzing the liver disease samples. I would also like to acknowledge the names of Prof. Dr. kollmar and Dr. Katrin Eckermann for their helping contribution in my PhD project.

I thanks to my family of labmates and friends, Waqas, Maria, Mohsin, Nadine, Tobias, Neelam, katrin dittmar, Ulla, Siri and our new Portuguese girls, Susana and Angela for their kind help and support during this journey of up and downs. I specially thanks to the funniest creature of our lab and my friend Thüne for making the cool and easy environment for research over the last year. It was a great experience to learn the lab work by our senior lab technician Barbara and I have no words to thanks for the excellent administrative help that I got from our secretaries, Maja and Jolanthe.

It was a great help of all kinds from Dr. Prateek kumar, especially during the challenging phases of PhD. I also thank to my friends Dr. Ashish Arora, Dr. Bharat and Dr. Anirban dutta for helping me in taking the right decisions during this journey. There has been a lot of contributions from the long list of my best friends including Rose, Simar, Ashish Rajput, katharina luellmann, Svetlana, Yves, Ali, Irmi Spiess, Jeoffery, Anurag Sankhayan, Gaurav patharia, Johannes, Ranjai sir, Pantalis, Arpit, Nonu and my brother monu, my cousins, Arun, Dipu and Kittu. 


\section{Table of contents}

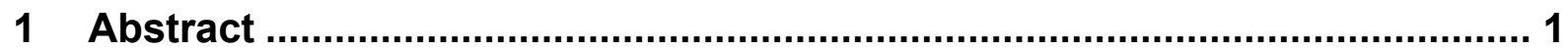

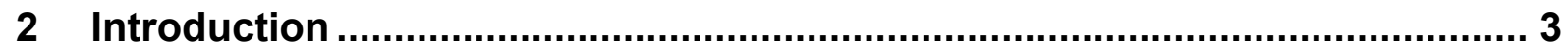

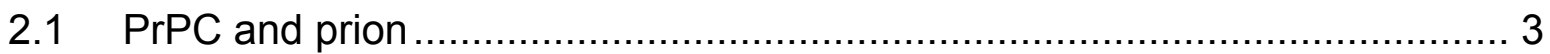

2.1 Structural features and expression of PrPC …..................................... 3

2.2 Phenotypic interpretation of PrPC knockout mouse models......................... 4

2.3 PrPC function and significance of sequence ............................................... 6

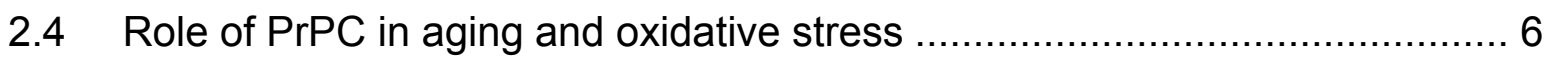

2.5 Change in behavioral phenotypes during aging ……........................... 8

2.6 Change in biochemical properties of PrPC in aging ……......................... 8

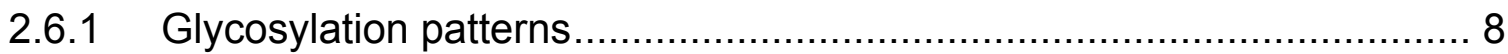

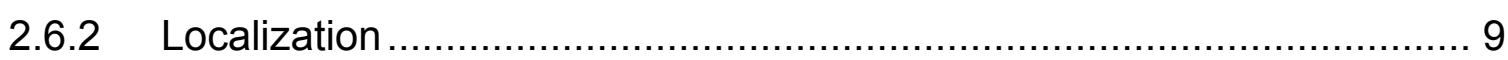

2.7 Role of PrPC in age related neurodegenerative diseases ......................... 9

2.8 Role of PrPC in peripheral tissues ........................................................ 9

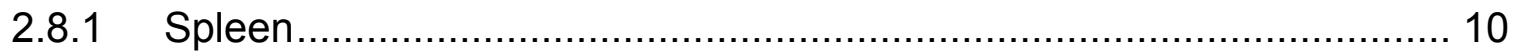

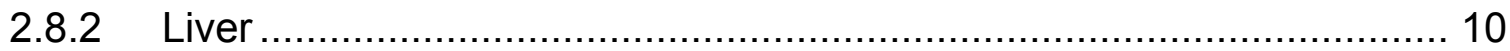

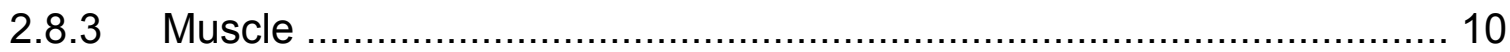

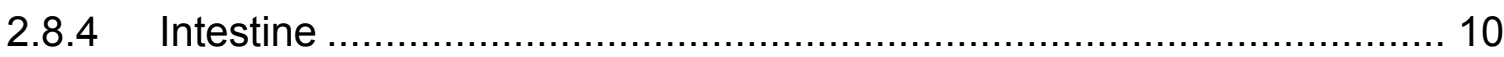

2.9 Liver: A model tissue to study PrPC function .......................................... 11

2.10 PrPC knockout mouse models: Importance of Zurich I............................. 12

2.11 Proteome/genome wide functional analysis of PrPC ................................ 14

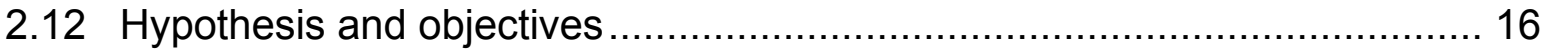

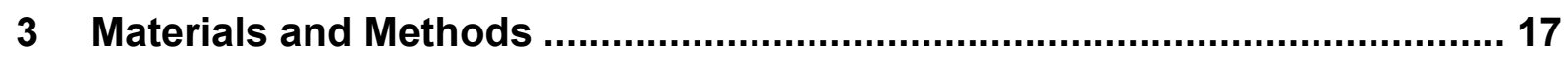

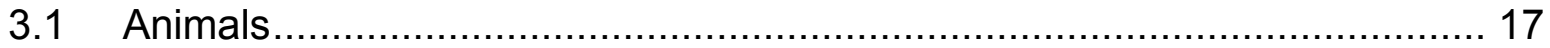

3.2 2 Dimensional (D) gel electrophoresis ............................................... 17

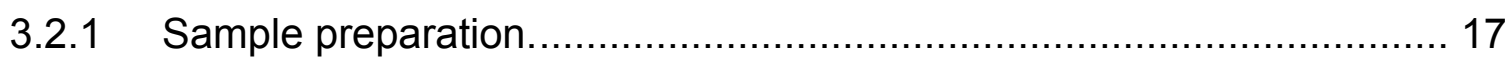

3.2.2 2D gel electrophoresis, staining and Image Analysis .......................... 17

3.3 In gel digestion and mass spectrometry identification ............................. 18

3.4 Screening of mass spectrometry data ............................................... 18

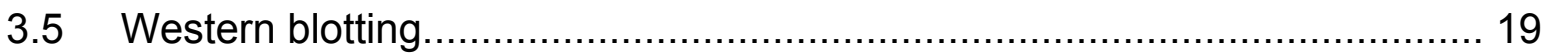

3.5.1 Preparation of mice liver samples ................................................. 19 


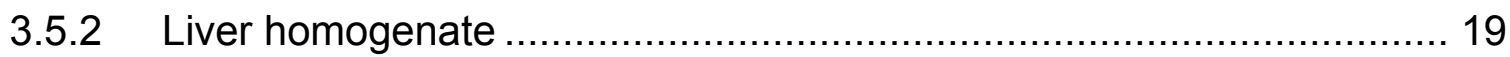

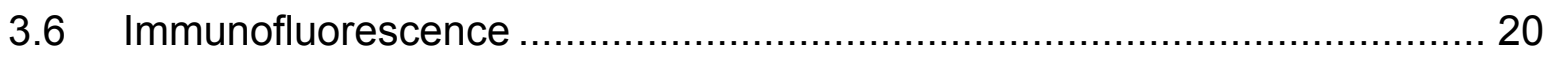

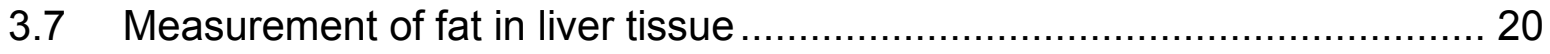

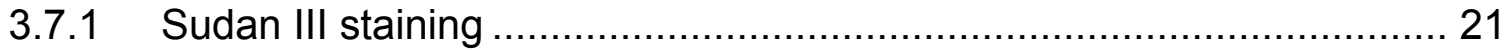

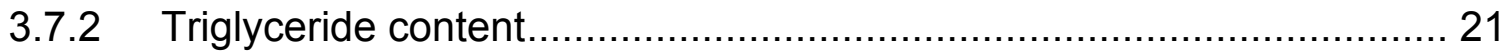

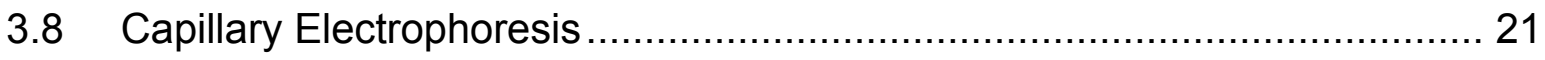

3.8.1 Sample preparation and capillary immunoassay............................... 22

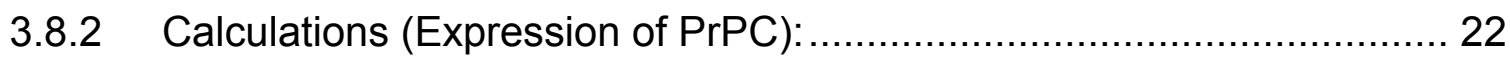

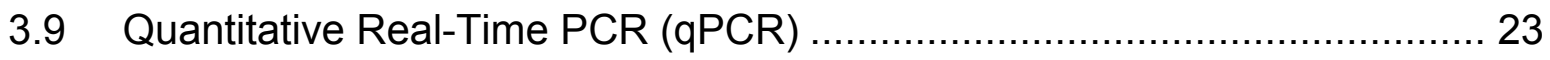

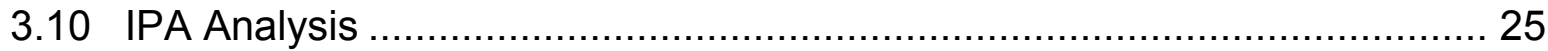

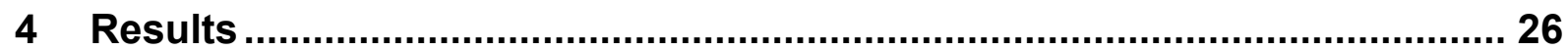

4.1 Age and gender specific PrPC expression in mice liver .......................... 26

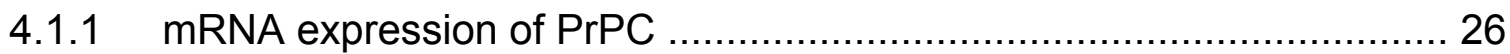

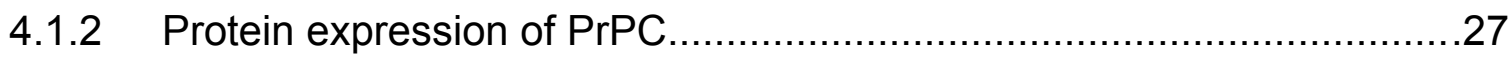

4.1.3 Analysis of PrPC expression by Capillary electrophoresis (CE)........... 27

4.1.4 Analysis of PrPC expression by Western blot .................................. 27

4.2 Age and gender specific differential proteome analysis in PrPC knockout

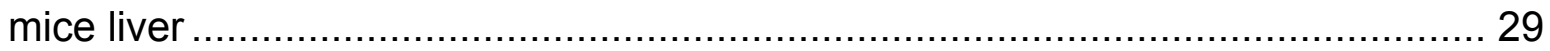

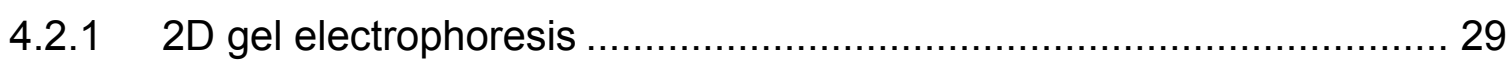

4.3 Bio-informatics based functional network analysis .................................. 37

4.3.1 IPA analysis (Liver as a reference tissue) ...................................... 38

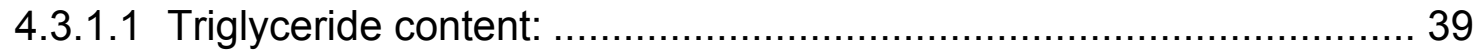

4.3.1.2 Fat globules in PrPC knockout mice liver .................................... 40

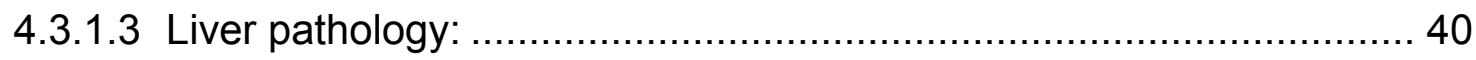

4.3.2 IPA analysis (Brain as a reference tissue) …..................................... 43

4.3.2.1 Altered Tau/Ptau expression in mice liver by Western blot............... 44

4.3.2.2 Altered Tau/Ptau expression in mice liver by immunofluorescence... 45

4.3.2.3 Cyclin dependent kinase 5 (CDK5)/p25 fragment expression by

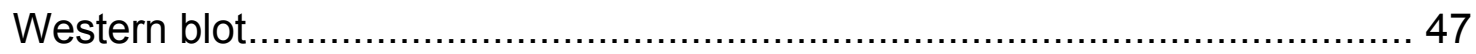

4.3.2.4 Gsk3Beta/P-gsk3Beta expression by Western blot ......................... 47

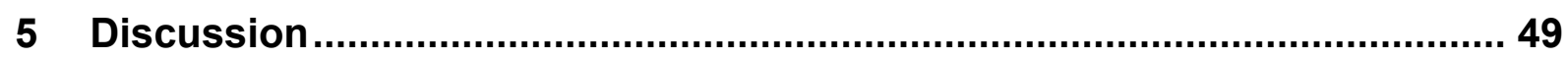

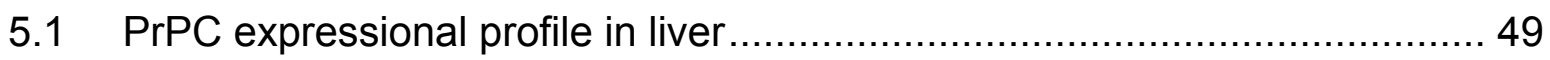




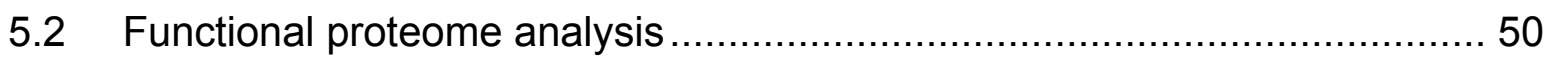

5.2.1 Protein/Amino acid metabolism...................................................... 51

5.2.1.1 3-hydroxyanthranilate 3, 4-dioxygenase (HAAO-3) ......................... 51

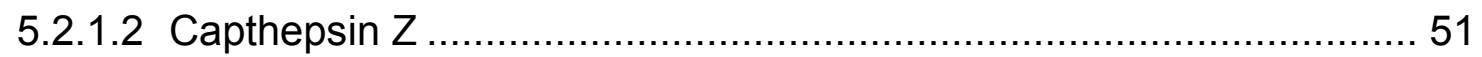

5.2.2 Bioenergetics/Glucose metabolism .............................................. 52

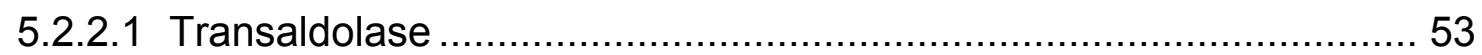

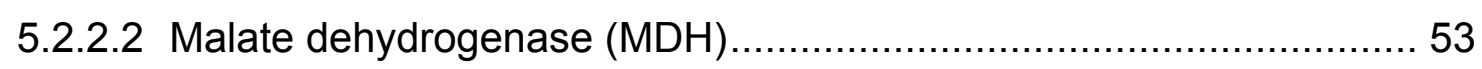

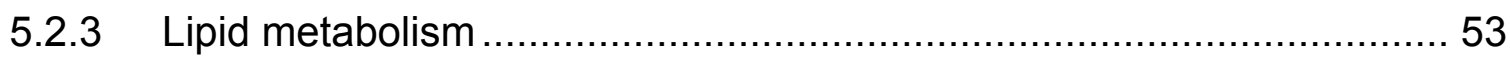

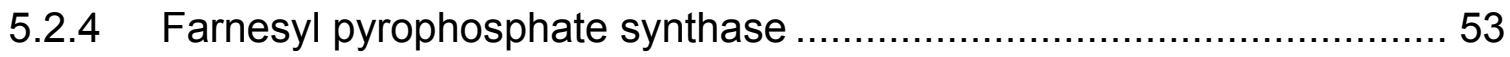

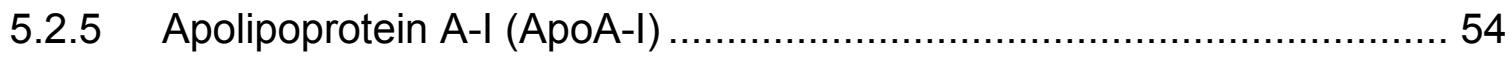

5.2.6 Delta(3,5)-Delta(2,4)-dienoyl-CoA isomerase(DI) ............................. 54

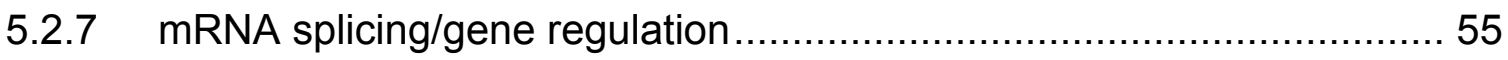

5.2.7.1 Serine-threonine kinase receptor-associated protein (STRAP) ......... 55

5.2.7.2 U5 small nuclear ribonucleoprotein $200 \mathrm{kDa}$ helicase ..................... 55

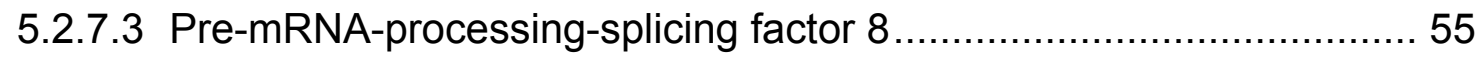

5.2.7.4 $116 \mathrm{kDa}$ U5 small nuclear ribonucleoprotein component.................. 56

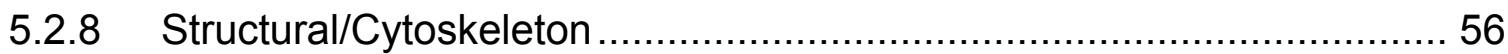

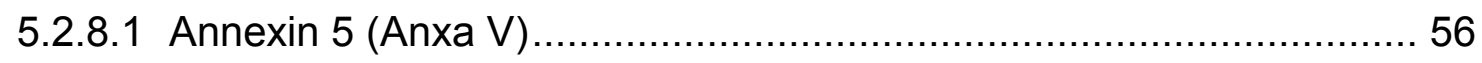

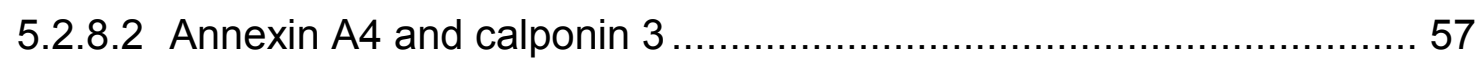

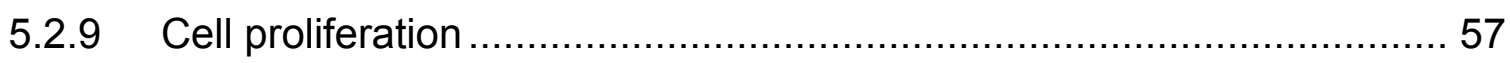

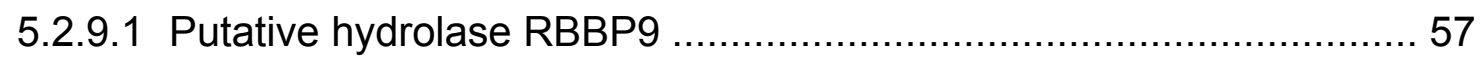

5.2.9.2 P27/cyclin dependent kinase inhibitor 1B ..................................... 57

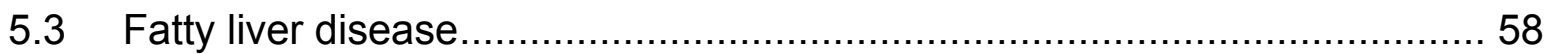

5.3.1 Pathology associated with liver steatosis ........................................ 60

5.3.2 Change in cytoskeleton function in liver disease ................................ 62

5.3.3 Markers of liver steatosis (Proteomics dataset) ................................ 62

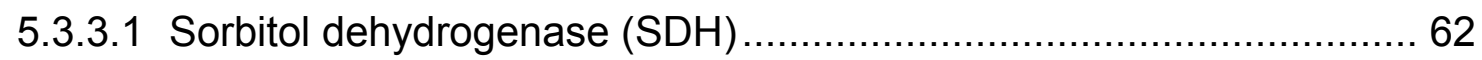

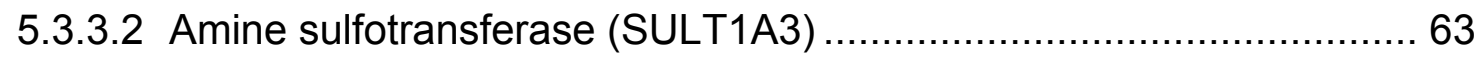

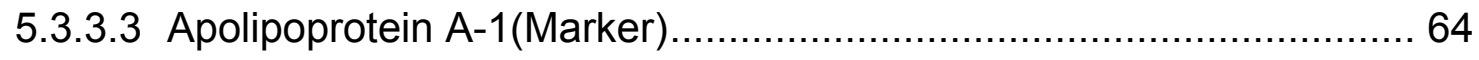

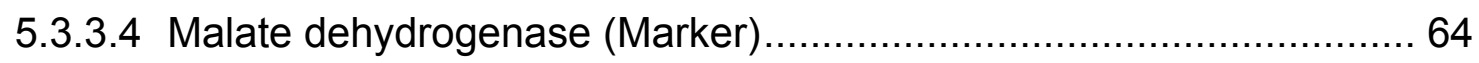

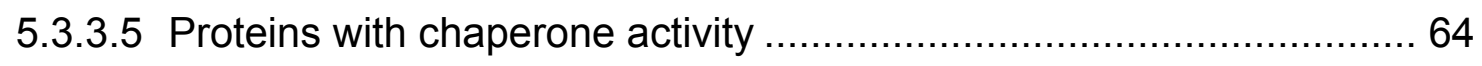

5.4 Age and PrPC dependent altered tau/ptau pathway................................6 66

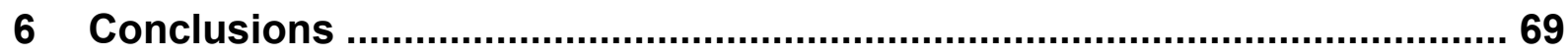




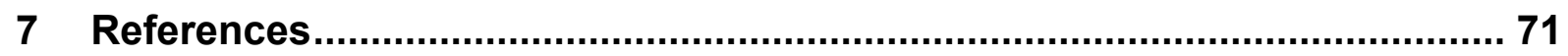

8 INDEX

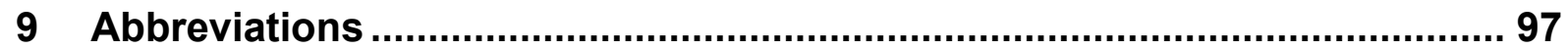

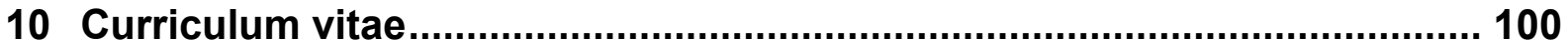




\section{Abstract}

PrPC is a membrane associated cellular glycoprotein. Its mis-folded form, PrPSc causes a set of neurodegenerative diseases called transmissible spongiform encephalopathies (TSEs). PrPC is abundantly expressed in the brain tissue and a relatively lower expression has been reported in the peripheral tissues. It has contradictorily been described to be involved in multiple functions beside the consensually accepted function as an anti-oxidant. PrPC has evolutionary conserved sequence and it shows that it should have some fundamental functions. The functional studies of PrPC in the peripheral tissues could be useful to elucidate its fundamental function and to better understand its role in the disease mechanism. Among the peripheral tissues, the liver has low PrPC expression, but interestingly its expression increases in oxidative stress during the activation of hepatic stellate cells (HSCs), which have role in liver diseases. In addition, our first set of results have shown a significant up-regulation of PrPC expression in the liver of aging mice (14 months) as compared to the 3 and 9 months old mice with a differential expression in the male and female groups.

To understand the age and gender dependent altered expression of PrPC and to find out that if there was any manifestation of liver diseases, 2D gel electrophoresis based proteomics analysis was performed in the liver of PrPC knockout mice (Zürich I). Proteins differentially regulated in the liver of PrPC Knockout mice were identified by the tandem mass spectrometry (MS/MS). Further, the functional analysis of proteomics dataset was performed by using bioinformatics tool called Ingenuity pathway analysis (IPA). IPA predicted the manifestations of the liver diseases including the fatty liver disease along with the regulation of insulin receptor (INSR) and PPARa transcriptional factor. The biochemical measurement of triglycerides and the staining of liver tissue by Sudan III confirmed the fatty liver disease in the liver of aging PrPC knockout mice. Further, the regulation of apoptotic markers by the Western blot indicated the progression of fatty liver disease into non-alcoholic steatohepatitis (NASH).

As majority of the research work in the PrPC knockout mouse models has been performed in the brain tissue. Thus, we further performed an additional IPA analysis from the same proteomics dataset by setting brain as a reference tissue. This 
analysis included the broader PrPC relevant literature information stored in the ingenuity Pathways Knowledge Base (IPKB). It predicted the role of PrPC in cellular development, cell signaling, cellular growth and proliferation including the role of microtubule associated tau protein (MAPT). Further, by using Western blot analysis we observed an age dependent decrease in tau expression and an increase of ptau expression in the liver of old age mice. Furthermore, we showed the PrPC dependent regulation of ptau by gsk3beta, which is an already known mechanism during prion infection. Fatty liver disease has already been described to be associated with the imbalance of liver cytoskeleton by the regulation of tau protein expression. Hence, our study showed that the absence of PrPC causes the fatty liver disease along with associated change in cytoskeleton function in the aging mice liver. In conclusion, from this current study, by using PrPC knockout mice, we showed a critical role of PrPC in the liver of aging mice by regulating the glucose/lipid metabolism, which further seems to be associated with its cytoskeleton function. 


\section{Introduction}

\subsection{PrPC and prion}

$\operatorname{PrPC}(c-$ cellular form) is a cellular glycoprotein and expressed in all the tissues with abundant expression in the central nervous system. PrPC protein was discovered due to its misfolded disease causing isoform called PrPSc (Sc - scrapie form), which has a high beta sheet content compared to its physiological form (PrPC). PrPSc is involved in a set of neurodegenerative diseases known as prion (Protein infectious particles) diseases or transmissible spongiform encephalopathies (TSE) in humans as well as in animals. TSE has been classified based on the infectious, sporadic and familial forms. These diseases include Kuru, Creutzfeldt-Jakob disease (CJD) and Fatal familial insomnia (FFI) in humans, bovine spongiform encephalopathy (BSE) in bovine and scrapie in sheep. All subtypes affect the brain with different pathological phenotypes. Prevalence of prion diseases is low, but are incurable and invariably fatal (Johnson et al., 2007).

\subsection{Structural features and expression of PrPC}

PrPC is a plasma membrane associated glycoprotein. It is attached to the lipid bilayer of the cellular plasma membrane by C-terminal glycosyl phosphatidylinositol anchor (GPI) (Stahl et al., 1987). It is synthesized in the endoplasmic reticulum attached ribosomes and transported to the cell surface via Golgi apparatus (Harris et al., 2003). It is attached with two N-linked oligosaccharide chains of high-mannose type oligosaccharide at Asn181lleThr and Asn197PheThr of human PrP; asparagine residues 180 and 196 of mouse PrP. In addition, there is a single disulphide bond in between two cysteines at the C-terminus (Lawson et al., 2005). The cellular PrPC is synthesized in three forms: secreted, carboxyl-terminal transmembrane forms $\left(\operatorname{PrP}^{\mathrm{ctm}}\right)$, and amino-terminal transmembrane forms $\left(\operatorname{PrP}^{\mathrm{ntm}}\right)$. The secreted form is the main GPI anchor form, which is fully translocated to the ER. With removal of $\mathrm{COOH}$ terminal signal peptide, GPI anchor is added to immature PrPC in the ER and then processed for further transport (Stahl et al., 1987). PrPC is also found in the cytoplasm in variable amounts usually after proteasomal inhibition or prnp over expression (Alexander et al., 2003). 
In the endoplasmic reticulum, PrPC appears to be associated with the lipid rafts and this association has been described to be implicated for the correct folding of PrPC (Sarnataro et al., 2004). Certain amounts of PrPC are also transferred to the clathrincoated pits, where it is subjected to constitutive endocytosis and recycling (Kristiansen et al., 2005).

PrPC is abundantly expressed in the brain and comparatively low expression in nonneuronal tissues such as lymphoid cells, lung, heart, kidney, gastrointestinal tract, muscle, liver, and mammary glands has been found. (Ford et al., 2002, Isaacs et al., 2006, Zomosa-Signoret et al., 2007).

The expression of PrPC starts during embryogenesis (Manson et al.,1992) and its transcripts are found at different days of embryogenesis in brain, spinal cord, specific non-neuronal cell population such as multi-nucleated cells in the liver parenchyma at day 27 (Peralta et al., 2012). The cell specific variant expression of PrPC indicates a pleiotropic role of PrPC during development.

\subsection{Phenotypic interpretation of PrPC knockout mouse models.}

Reverse genetics is the first approach to discover the function of a protein by knocking out the gene and analyzing phenotypic effects.

First PrPC knockout mice had been generated in 1992 (Bueler et al., 1992). There was great expectation to elucidate the function of PrPC by interpreting the phenotype of knockout mice. Unfortunately, PrPC knockout model has not provided any clear hint to reveal its fundamental function due to lack of any overt or pathogenic phenotype except resistant to prion infection. The resistance to prion infection is technically a lack of phenotype. Although, excess amount of literature with diverse phenotypes has been accumulated over the years but the results are contradictory. Some of these phenotypes are under intensive investigation and many of these are subtle (Table 1). As we can see in the table that many phenotypes which have been reported are inconsistent among different labs.

Critical question arise, that which of these phenotypes are related to the primary functions of PrPC due to deletion of prnp gene and which could be due to artifacts?

Unfortunately, PrPC sequence has also not provided any information to predict its physiological function. Interestingly, the broad homology conservation of PrPC 
sequence among mammalian and avian species (Fig. 2), expression of the protein in almost all tissues during entire lifespan with its high turnover rate gives evidence that PrPC have important physiological functions.

Table 1 - Number of reports describing phenotypes from PrPC knockout mice with parallel reports with similar experiments, which are either confirming or opposing the phenotype reported in the literature.

\begin{tabular}{|c|c|c|c|}
\hline Phenotype in PrP KO & Reported & Confirmed? & Opposing ? \\
\hline \multicolumn{4}{|l|}{ Circadian/Sleep regulation } \\
\hline Abnormal circadian rhythm & Tobler et al., 1996 & & \\
\hline Interrupted sleep patterns & Tobler et al., 1996 & & \\
\hline \multicolumn{4}{|c|}{ Oxidative stress: copper binding, SOD-activity and mitochondria } \\
\hline Decreased copper content in brain & Brown et al., 1997 & & Waggoner et. al., 2000 \\
\hline $\begin{array}{l}\text { Decreased SOD activity; increased } \\
\text { oxidative damage }\end{array}$ & $\begin{array}{l}\text { Wong et al., } 2001 \\
\text { Brown et al., } 2002\end{array}$ & Klamt et al., 2001 & $\begin{array}{l}\text { Waggoner et. al., } \\
\text { 2000, Hutter et al., } \\
\text { 2003, Lobao-Soares } \\
\text { et. al., 2005 }\end{array}$ \\
\hline Reduction/abnormal mitochondria & Miele et al., 2002 & & $\begin{array}{l}\text { Lobao-Soares et. al., } \\
2005\end{array}$ \\
\hline \multicolumn{4}{|c|}{ Immune system, phagocytosis and as a microbial receptor } \\
\hline Increased phagocytosis 47 & $\begin{array}{l}\text { de Almeida et al., } \\
2005\end{array}$ & & \\
\hline Resistance to infection with B. abortus & Watarai et al., 2003 & & Fontes et. al., 2005 \\
\hline Resistance to infection with HSV-1 & $\begin{array}{l}\text { Thackray et al., } \\
2003\end{array}$ & Thackray et al., 2005 & \\
\hline Immune synapse, $\mathrm{T}$ cell response & Ballerini et al., 2006 & & \\
\hline Interleukin expression & \begin{tabular}{|l} 
Kubosaki et al., \\
2003 \\
\end{tabular} & & \\
\hline \multicolumn{4}{|l|}{ Neuronal excitability } \\
\hline Impaired long term potentiation & Collinge et al., 1994 & $\begin{array}{l}\text { Criado et. al., 2005, } \\
\text { Asante et al., 2004, } \\
\text { Carleton et. al., 2001, } \\
\text { Curtis et al., 2003, } \\
\text { Herms et al., 2001, } \\
\text { Manson et al., 1995, } \\
\text { Whittington et al., } 1995\end{array}$ & $\begin{array}{l}\text { Herms et al., 1995, } \\
\text { Lledo et al., 1996, } \\
\text { Maglio et la., 2004, } \\
\text { Maglio et al., 2006 }\end{array}$ \\
\hline Increased susceptibility to seizures & Walz et al., 1999 & Rangel et al., 2007 & \\
\hline $\begin{array}{l}\text { Mossy fiber disorganization in } \\
\text { hippocampus }\end{array}$ & Colling et al., 1997 & & \\
\hline \multicolumn{4}{|l|}{ Behavioral phenotypes } \\
\hline Cognitive defects/memory impairment & $\begin{array}{l}\text { Criado et al., } 2005 \\
\text { Coitinho et al., } 2003 \\
\text { Schmitz etz al.., } \\
2014 \\
\end{array}$ & & $\begin{array}{l}\text { Bueler et al., } 1992 \\
\text { Manson et al., } 1994\end{array}$ \\
\hline $\begin{array}{l}\text { Increased locomotor / exploratory } \\
\text { activity }\end{array}$ & Roesler et al., 1999 & Criado et al., 2005 & \\
\hline $\begin{array}{l}\text { Increased hyperlocomotion induced by } \\
\text { MK-801 }\end{array}$ & Coitinho et al., 2002 & & \\
\hline Decreased anxiety & Nico et al., 2005 & & \\
\hline \multicolumn{4}{|l|}{ Neuroprotection } \\
\hline Susceptible to Dpl toxicity & $\begin{array}{l}\text { Sakaguchi et al, } \\
1996\end{array}$ & $\begin{array}{l}\text { Moore et. al., 1999, Li et } \\
\text { al., 2000, Nishida et. al., } \\
\text { 1999, Valenti et. al., } \\
2001\end{array}$ & \\
\hline
\end{tabular}




\begin{tabular}{|l|l|l|l|}
\hline $\begin{array}{l}\text { Susceptible to "DF" PrP induced } \\
\text { toxicity }\end{array}$ & $\begin{array}{l}\text { Shmerling et al., } \\
1998\end{array}$ & $\begin{array}{l}\text { Flechsig et. al., 2003, } \\
\text { Radovanovic et. al., } \\
2005\end{array}$ & \\
\hline Enhanced susceptibility to ischemia & $\begin{array}{l}\text { McLennan et al., } \\
2004\end{array}$ & $\begin{array}{l}\text { Sakurai-Yamashita et. } \\
\text { al., 2005, Weise et. al., } \\
2006, \text { Spudich et. al., } \\
2005\end{array}$ & \\
\hline $\begin{array}{l}\text { Enhanced susceptibility to ethanol } \\
\text { induced apoptosis }\end{array}$ & Gains et al., 2006 & & \\
\hline $\begin{array}{l}\text { Enhanced susceptibility to traumatic } \\
\text { brain injury }\end{array}$ & Hoshino et al., 2003 & & \\
\hline Stem/precursor cells & & \\
\hline $\begin{array}{l}\text { Impaired self-renewal of hematopoietic } \\
\text { stem cells }\end{array}$ & Zhang et al., 2006 & & \\
\hline $\begin{array}{l}\text { Decreased proliferation of neural } \\
\text { precursors }\end{array}$ & Steele et al., 2006 & & \\
\hline Miscellaneous & $\begin{array}{l}\text { Schneider et al., } \\
2007\end{array}$ & \\
\hline Abnormality in dentin in teeth
\end{tabular}

\subsection{PrPC function and significance of sequence}

It has been described that PrPC has multiple functions but exact function of PrPC is unknown. It is not certain, if loss of function or gain of pathogenic dysfunction of PrPSc causes prion diseases. So, exact overlap between gain of pathogenic dysfunction of PrPSc and normal physiological function of PrPC is still to be determined (Fig. 1).

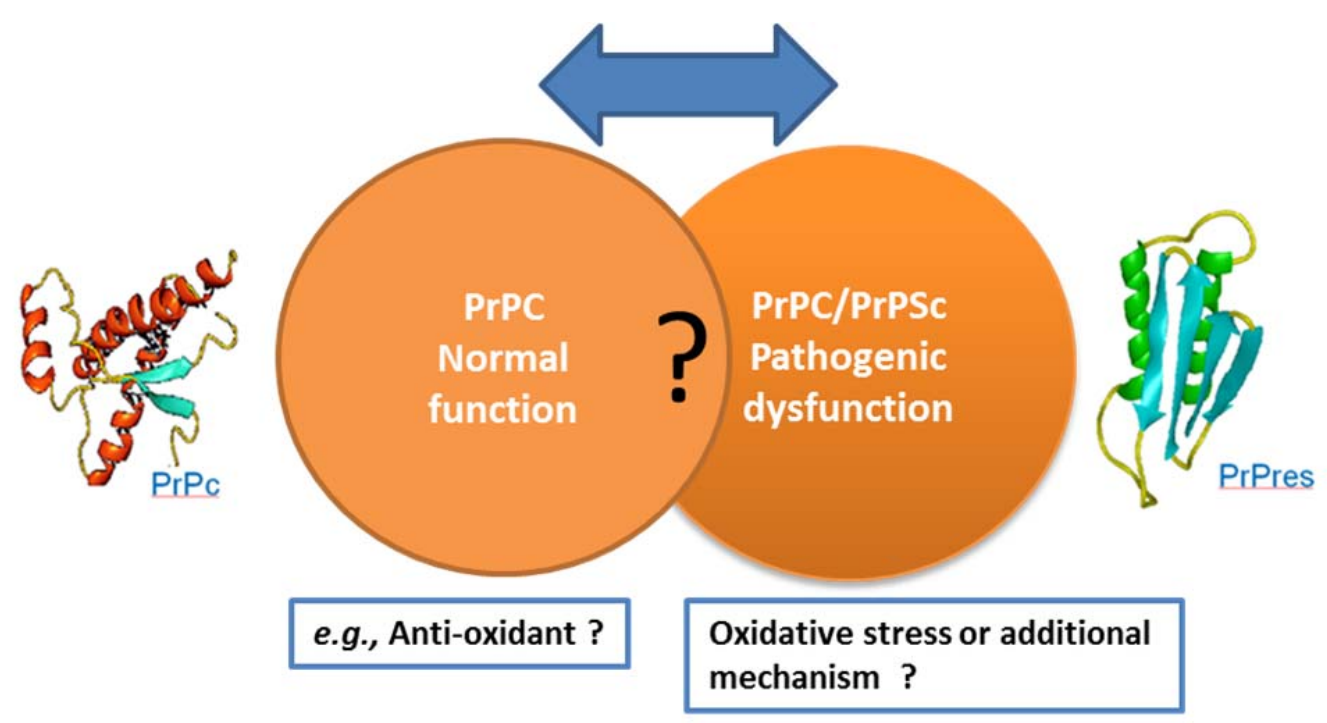

Fig. 1. The overlapping of region associated with normal physiological function of PrPC and pathogenic dysfunction of PrPSc in neurodegeneration.

\subsection{Role of PrPC in aging and oxidative stress}

Although PrPC function is not completely understood, but the role of PrPC as an antioxidant and as a neuroprotectant, are among the well characterized and 
consensually accepted functions. Both are linked to the neurodegeneration and aging (Vassallo and Herms et al., 2003; Roucou and LeBlanc et al., 2005; Steele et al., 2008). Recently, the role of PrPC during aging has been described in detail (Gasperini et al., 2014). The role of PrPC in aging and oxidative stress is further supported by its functional involvement in age related disorders (in addition to CJD) such as Alzheimer diseases (Kellett et al., 2009). Thus, it is critical to understand the PrPC dependent events during aging such as oxidative stress, changes in PrPC expression, localization, biochemical properties, and effect of PrPC knockout on phenotypes.

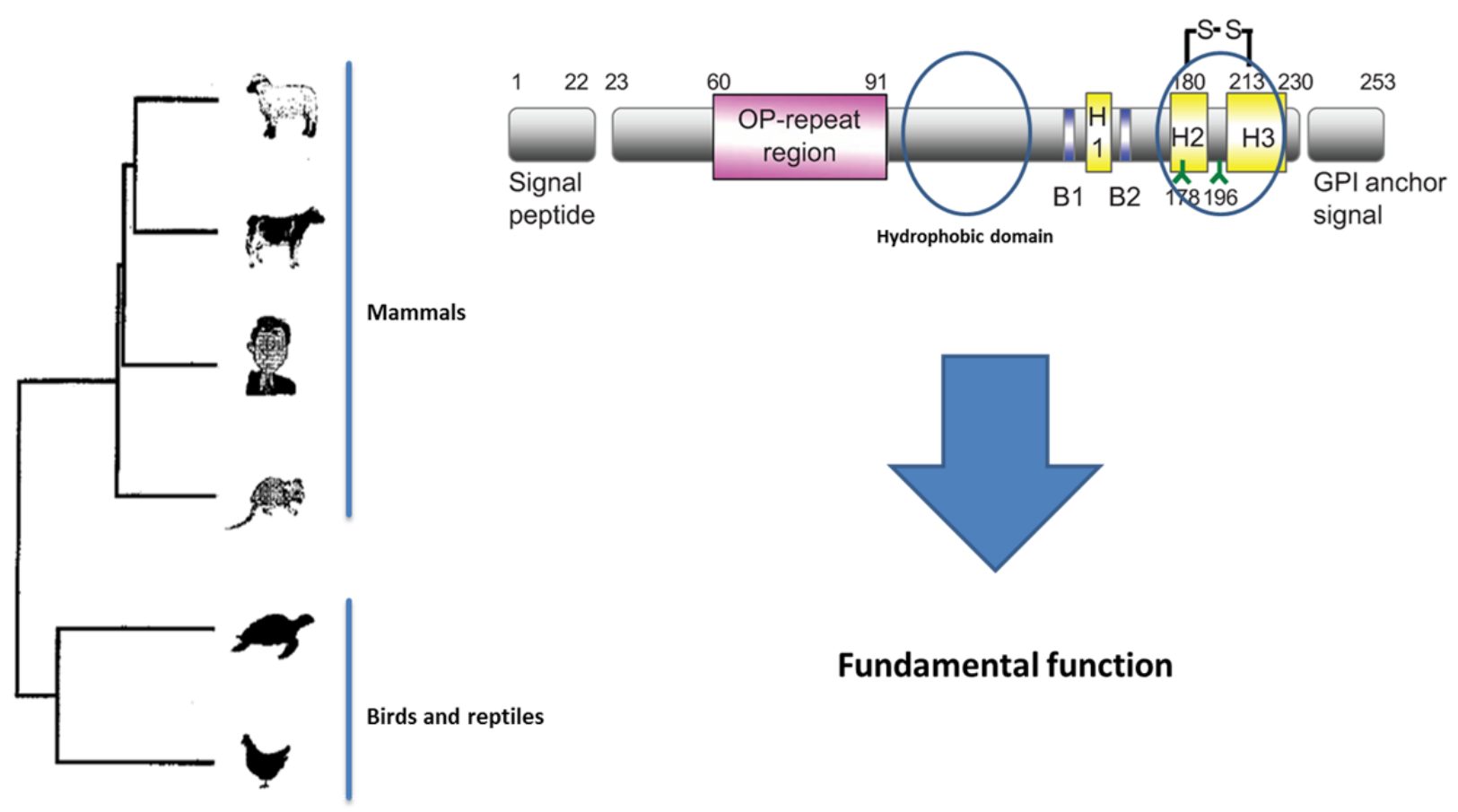

Fig. 2. A) Phylogenetic tree of prnp gene, showing sequence homology conservation among mammals and avian species. B) PrPC sequence with conserved regions: hydrophobic region, residues with disulphide bonds and glycosylation sites.

Furthermore, PrPC reduces the formation of reactive oxygen species (ROS) due its ability to catalyze the reduction of $\mathrm{Cu}^{2+}$ into $\mathrm{Cu}^{+}$(Gasperini et al., 2014). Further, it has been reported that PrPC knockout mice possess high sensitivity to the neurons due to oxidative stress (Brown et al., 1997, Rachidi et al., 2003). Another report described the impairments in copper incorporation in PrPC knockout mice due to alterations of superoxide dismutase (SOD I) enzyme activity (Brown and Besinger et al., 1998, Kralovicova et al., 2009). One experimental approach on neuronal cell lines devoid of PrPC has shown the trigger of apoptosis after serum removal. In addition, neuronal cell lines were more sensitive to oxidative stress due to mitochondrial 
dysfunction compared wild type, indicating a neuro-protective function of PrPC (Kim et al., 2004). PrPC knockout mouse has also been reported to have higher levels of lipid and protein oxidation, which are the marker of cellular damage due to oxidative stress (Wong et al., 2001). At molecular level, beta cleavage of PrPC protein has been linked with role of PrPC against oxidative stress (Watt et al., 2005).

\subsection{Change in behavioral phenotypes during aging}

The role of PrPC in learning has been associated due to two major observations: 1) PrPC expresses predominantly in neurons with highest expression in hippocampus (De Armond et al., 1987; Benvegnu et al., 2010), 2) The expression of PrPC increases in the brain during aging (Williams et al., 2004). One comparative study in PrPC knockout, wild type and PrPC over expressing mice have shown that PrPC has a role in regulating age dependent alterations in anxiety like responses, in locomotion and defects in short-term social recognition memory.

Further, our group showed the drop in anxiety and decline in associative learning in the aging PrPC knockout mice. We have reported that the PrPC dependent alterations in cytoskeleton protein expressions could be responsible for change in the learning process (Schmitz et al., 2014).

In conclusion, PrPC dependent change in cognitive learning and behavioral activities in aging mice could be linked to the increase of oxidative stress and decrease of neuroprotective function of PrPC.

\subsection{Change in biochemical properties of PrPC in aging}

\subsubsection{Glycosylation patterns}

PrPC is glycosylated at two specific sites, which represents three different bands in Western blot: di-glycosylated (35 KDa), mono-glycosylated (32 KDa) and unglycosylated (28 KDa) (Khalili-Shirazi et al., 2005; Pan et al., 2002). It has been reported that during aging, $\mathrm{N}$-terminally truncated and under glycosylated (mono- and un-glycosylated) full length PrPC species increase with the age (Goh et al., 2007). Further, the accumulation of under-glycosylated and N-terminally truncated PrPC in both aging and prion infection suggests the functional relevance of PrPC glycosylation in aging processes. 


\subsubsection{Localization}

PrPC is a GPI-anchored protein and it has been associated with lipid rafts. PrPC protein is transported from the detergent soluble membrane fractions to lipid rafts compartments in aged mouse hippocampus (Agostini et al., 2013). During normal aging brain or in neurodegenerative diseases like $A D$, there has been a change in cholesterol/sphingolipid ratio (Martin et al., 2010). Hence, the localization of PrPC might potentially be affected due to age dependent changes in the membrane composition and hence it may also modulate the function of PrPC.

\subsection{Role of PrPC in age related neurodegenerative diseases}

PrPC expression increases in brain with age, which could be linked with its functional role as an anti-oxidant against increased oxidative stress in the old age (Williams et al., 2004).

In neurodegenerative diseases such as CJD and AD, it has been reported that PrPC expression decreases in the brain and CSF, which could be associated with an increase in oxidative stress due to low PrPC expression or the other way, neurodegenerative diseases could be one of the cause which leads to low PrPC expression. At molecular level, it is known that PrPC regulates the processing of amyloid precursor protein and production of $A \beta$, a hallmark of $A D$ (Parkin et al., 2007). In addition, higher production of $A \beta$ has been reported in the brains of PrPC knockout mice (Parkin et al., 2007). So, decrease in PrPC expression in neurodegenerative disorders could be part of the mechanism which has been linked with the higher $A \beta$ synthesis in disease.

So, based on expressional profiles of PrPC during aging and its involvement in age associated neurodegenerative diseases, it seems that PrPC has an important role in aging.

\subsection{Role of PrPC in peripheral tissues}

Most of the PrPC functional research has been performed in the brain or neuronal cell lines. To elucidate the fundamental function of PrPC, it is important to consider its functional relevance in the peripheral tissues as well because it is ubiquitously expressed in almost all the tissues. Not much attention has been given to explore the 
role of PrPC in peripheral organs. There are some reports based on PrPC functional studies in peripheral tissues with a brief following outlook:

\subsubsection{Spleen}

PrPC is highly expressed in follicular dendritic cells (FDC) of spleen. But no effect on the development or maturation of FDC cells has been reported in the PrPC knockout mice. Further, it has been reported that the knockout of PrPC has no effect on the immune function neither to bind immune complexes on the surface nor to produce antigen-specific antibodies. This also implies that PrPC function is beyond its expression levels which might be related to a specific cell type or specific physiological conditions. (McCulloch et al., 2013).

\subsubsection{Liver}

Among peripheral tissues, the expression of PrPC in liver is comparatively low but interestingly, it has been reported that PrPC expression increases during oxidative stress conditions such as $\mathrm{CCl}_{4}$ induced liver fibrosis due to the activation of hepatic stellate cells (lkeda et al., 1998).

\subsubsection{Muscle}

One study has been done on skeletal and cardiac muscle tissue in the PrPC knockout mice. It showed that PrPC might has an important role in mitochondrial dependent locomotory activity especially during exercises (Nico et al., 2005). This shows that PrPC has a role in muscle physiology and possible involvement in the neuromuscular pathologies.

\subsubsection{Intestine}

PrPC knockout mice showed greater paracellular permeability in the intestine as cellcell junctions and monolayer shape were altered in the PrP knock down cells. Further, E-cadherin, plakoglobin, claudin-4, desmoplakin, occludin, zonula occludens 1 , and tricellulin were decreased at cell contacts while re-introduction of PrPC restored cell shape and junctions, which shows that PrPC may regulate intestinal barrier and epithelial cell-cell junctions functions (Petit et al., 2012). Another study in mucous epithelial cells of stomach and intestine has shown the localization of PrPC in the secretary globules of digestive tract which emphasize the role of PrPC in the secretary function of digestive tract (Fournier et al., 1998). 


\subsection{Liver: A model tissue to study PrPC function}

As emphasized above, not much research has been done in peripheral tissues. The current project is to define the role of PrPC in peripheral tissues with liver as a model due to following reasons: Liver is the most important metabolic organ with highest ability of proliferation and regeneration. It is physiologically and functionally linked with almost all the tissues of the body. In addition, there are a large number of sexdependent regulated proteins influenced by hormones in the liver (Waxman et al., 2009), so it could also be a useful organ to explain, if any gender specific role of PrPC. The relationship between the brain and liver in relevance to physiological function and neurological disorders has been known for years (Lewis et al., 2003). Interestingly, the presence of prion infectivity in the liver of sheep, experimentally infected with BSE and the presence of prion deposits in the liver of inherited human prion disease has been reported (Everest et al., 2011, Mead et al., 2013). In addition, liver has also been shown to be a significant source of $A \beta$ synthesis and linked with brain pathology in the mouse model of Alzheimer's disease (Sutcliffe et al., 2011).

In literature, it has been described that the expression of PrPC in liver is low, which might be due to the fact that most of the previously published reports in the liver had been done in the embryonic stage, young or adult mice (Ford et al., 2002, Horiuchi et al., 1995; Moudjou et al., 2001; Peralta et al., 2012). Interestingly, the proliferation of hepatic stellate cells (HSCs) during $\mathrm{CCl}_{4}$ induced fibrosis results in the up-regulation of PrPC expression both at mRNA as well as protein level due to increase in oxidative stress (Ikeda et al., 1998). This indicates that PrPC has some important functional link with hepatic stellate cell activation. The precise function of hepatic stellate cells is not known. Notably, HSCs have been described to be activated during various liver diseases which are associated with liver injury, such as fatty liver disease (Washington et al., 2000). The role of PrPC during oxidative stress in the aging mice via regulation of SOD1 has already been known (Vassallo and Herms, 2003; Roucou and LeBlanc, 2005; Steele et al., 2008, Gasperini et al., 2014) and activation of HSCs has also been linked with increased oxidative stress during liver injuries. Interestingly, the liver is the tissue with the highest SOD1 enzyme expression (De Haan JB et al., 1994). It implies that PrPC might have an important function, linked with pathophysiological conditions in the liver due to increased 
oxidative stress. Recently, our group has reported the higher latency in open field test in the aging PrPC knockout mice as compared to the wild type possibly due to alterations in the cytoskeleton function (Schmitz et al., 2014).

Interestingly, similar changes in the anxiogenic effects has been reported in the rat model due to liver damage induced by lipopolysaccharide (LPS) in which rats spent more time in the closed arms of open field test (Anjali et al., 2006).

In addition, another study has reported the reduced anxiety in the rat model due to cafeteria (CFA) induced increased triglycerides deposition in the liver and increased insulin resistance (Lalanza et al., 2014). So, alterations in behavioral activities in the PrPC knockout mice model at least could partially be linked with the change in liver function because any alterations of liver function may potentially affect the central nervous system functions including behavioral manifestations (Nguyen et al. , 2012).

Based on the above evidences, we hypothesized that PrPC expression should be increased during aging process in the liver due to its role as an anti-oxidant and it might also be linked with the liver disease pathology due to its reported role in HSCs activation and altered behavioral activities.

\subsection{PrPC knockout mouse models: Importance of Zurich I}

To study the mammalian gene function, gene-targeting and transgenic mouse models are often generated. This strategy has also facilitated the in vivo study of PrPC function. The gene knockdown technology expected to show changes in the phenotypes of mouse such as appearance, behavior and biochemical characteristics, so observing any differences from normal behavior or physiology, researchers can infer its probable function. Over the three decades of intensive research, a number of different mice and other animal models have been employed to understand the disease mechanisms and function of PrPC itself. Among the notable models, mice with PrPC over-expression and PrPC knockout mouse model are of central importance. The interpretation of the PrPC function gave a contradictive outcome when PrPC knockout mice showed no obvious phenotype. PrPC is encoded by a single-copy gene (Basler et al., 1986) that comprises three exons, with the entire reading frame contained in the third exon (Fig. 3). A number of mice lines devoid of PrPC have been generated using two strategies: 1) Conservative strategy and 2) Radical strategy. 
Conservative strategy: It involves the truncation modifications only to the open reading frame (ORF). PrPC knockout mice with a conservative strategy develop normally without any pathological phenotype and are resistant to prion infection.

Radical strategy: In this strategy, in addition to the reading frame, it also involves the deletion of flanking region, particularly, splice acceptor site of the third exon. Mice with this strategy also develop normally, but exhibits severe ataxia and Purkinje cell loss in later stage life (Sakaguchi et al., 1996, Moore et al., 1999, Silverman et al., 2000, Rossi et al., 2001). However, later on it was found that phenotype associated with the radical strategy was due to ectopic expression of Dopple product, caused by transcription of prnd gene which is $16 \mathrm{bp}$ downstream of prnp gene. The ectopic expression of Dopple was likely to be caused by the deletion of sequences flanking the prnp ORF. Deletion of splice acceptor site of the third prnp exon caused the formation of chimeric transcripts that placed prnd transcription under control of prnp promoter. So all three PrPC knockout mice generated by radical strategy: Nagasaki, Zürich II and Rcm0 are not reliable because of the fact that generated phenotype was not caused by the absence of prnp gene but due to the expression of Dopple gene product.

Mice generated with conservative strategy: Zurich I and Edinburg are the most reliable models compared to models generated by radical strategy. Zurich I is the well characterized and easily available model while Edinburg has breeding problems due to pure background (Payne et al., 1998). So, based on its advantages, we have used Zurich I mice in the current study. 

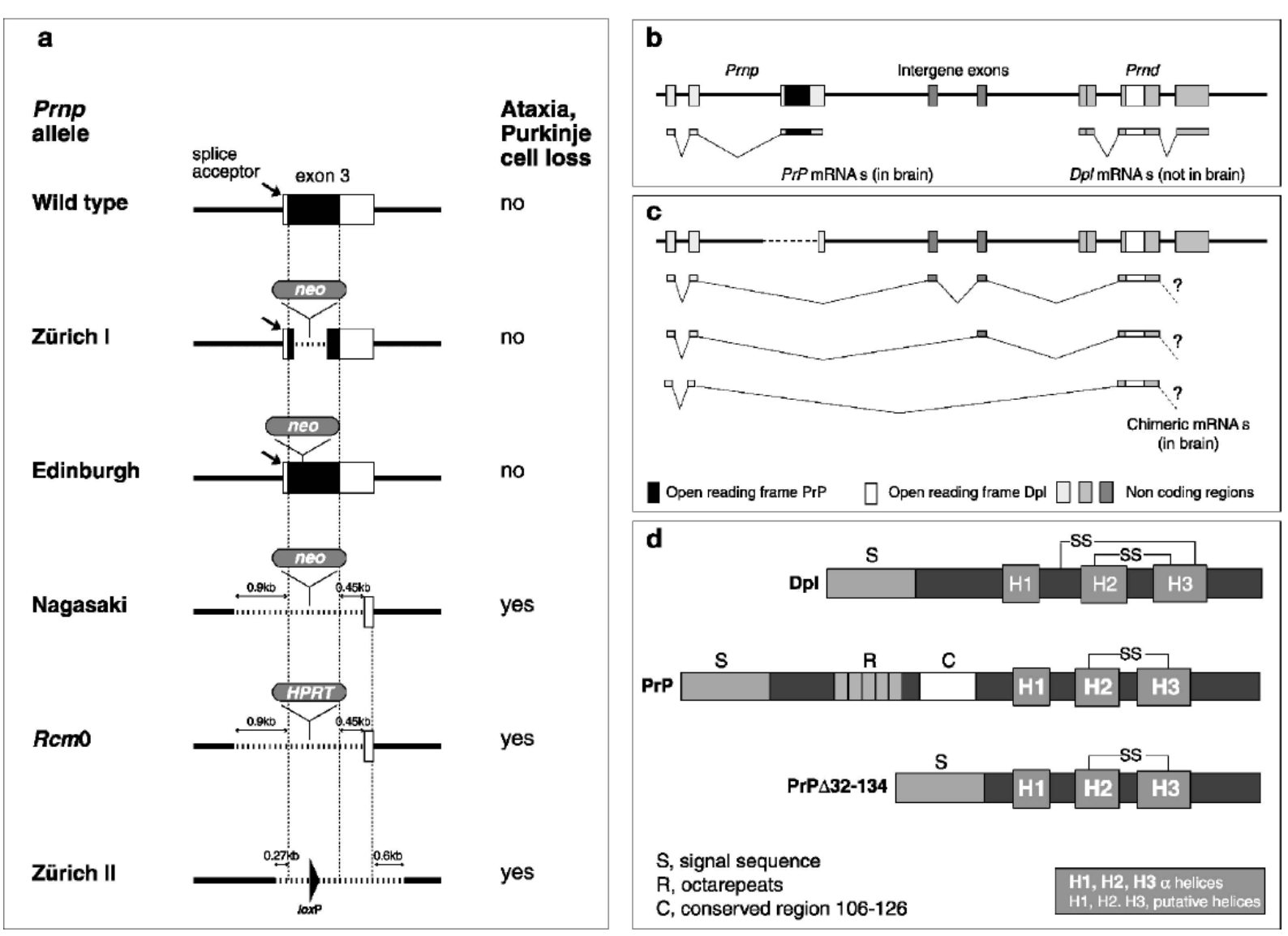

Fig. 3. Strategies of PrPC knockout mouse and their phenotypes: (a) various ways of gene targeting by homologous recombination. Black boxes shows ORFs of PrP; white boxes - non coding regions of the gene; grey boxes - insert sequences; dotted line - removed regions; neo stands for neomycin phosphotransferase; HPRT for hypoxanthine phosphoribosyltransferase; loxP is represented with black arrow-head is a 34 bp site of recombination from phage P1. (b) Different coding and noncoding sequences of Prnd, Prnd and intergenic coding sequences of unknown function. (c) Doppel expression under Prnp promoter by exon skipping. (d) Comparison of different regions of Doppel (Dlp) to the full sequence of PrP and PrP sequence that lacks 32-134 residues (Figure was obtained from the reference - Weissmann et al., 2003).

\subsection{Proteome/genome wide functional analysis of PrPC}

Most of the proteomics or genomics based PrPC functional studies have been done in brain or cell lines. One proteomics based approach implying 2D gel electrophoresis technique to compare brain proteome of the Zurich I PrPC knockout mice has shown no significant differences between PrPC knock out and wild type mice. This study has shown that proteome of PrPC knockout mice compared with wild type mice is highly conserved unlike transcriptome studies which have shown a significant amount of gene regulation between PrPC knockout mice as compared to wild type mice. Contrary to study in the brain, an another study based on proteomics using PrPC 
deficient human embryonic kidney (HEK) cell line and transient PrPC expressional levels in PrPC deficient cells was performed. The results from this study showed the regulation of proteins involved in energy metabolism, cellular homeostasis, oxidative stress and apoptosis.

Interestingly, this proteomics based approach has first time shown PrPC dependent regulation of several proteins involved in the pathogenesis of Alzheimer disease (Ramljak et al., 2007).

Further, one genomics study involving microarray in PrPC knockout mouse model has shown a number of regulated genes which are related to neurodegenerative pathways such as Alzheimer disease. This report has described 18 up-regulated genes and 12 down regulated genes among which Ch25h, S100a9, Kcnip3, Grin2b, Cdk5r1, Cdk5, Psen1, and Sod2 were up regulated, whereas genes such as Gsk3 were down regulated in the developmental stages of Prnp0/0 mice (Benvegnù et al., 2011). Further bioinformatics interpretation of the genomics data has shown a link of PrPC function in amyloid processing pathways, specifically the genes involved in tau phosphorylation (Benvegnù et al., 2011). Tau protein is a microtubule associated protein which stabilizes the microtubule and its hyper phosphorylation causes misfolding of tau protein molecules. It forms paired helical filaments (PHF), which are very well known to be the structural constituents of neuro-fibrillary tangles in neurodegenerative Alzheimer disease (AD) (Fig. 4). Tau protein is highly phosphorylated in normal developing brain (Mawal-Dewan et al., 1994), probably to maintain microtubule polymerization-depolymerization dynamics during brain development. It has been reported that there is age dependent decrease in total tau protein and phosphorylated tau both in PrPC knockout and wild type mice (Benvegnù et al., 2011). The levels of phosphorylation are known to be higher in the brain of newborn PrPC knockout mice as compared to the wild type mice. But there has been no PrPC specific regulation in the adult mice. Studies have shown that PrPC regulates the phosphorylation levels of tau during post natal developing brain (Caiati et al., 2013). This involvement of PrPC in tau pathways indicated the role of PrPC during development and shed a light on a correlation between AD and prion biology.

Specifically, genomic and proteomic studies investigating PrPC knockout mice and cell lines have given new insights to explore PrPC function. 


\subsection{Hypothesis and objectives}

Finally based on the above evidences, we hypothesized:

1. Age dependent altered regulatory response of PrPC expression in liver.

2. Potential gender specific outlook to the PrPC function due to high sex dependent hormonal influence of the liver tissue.

3. PrPC knockout mice liver might have some pathological manifestations due to its reported role, specifically in the hepatic stellate cells (HSCs) activation.

4. Proteomics based approach could generate correlative functional links with previous proteomics/genomics based studies in the brain of PrPC knockout mice and may help to elucidate its fundamental role.

So, first we used livers from 3, 9 and 14 months old wild type mice (C57BL/6) to see the age and gender dependent expressional profile of PrPC. Second, based on previous reports from proteomics and genomics studies, we performed 2D gel electrophoresis based protein profiling in the liver of Zürich I PrPC knockout mice from the same three age groups. 


\section{Materials and Methods}

\subsection{Animals}

We used Zürich I PrPC knockout and wild type mice with C57BL/6 background. Three different age groups ( 3 months, 9 months and 14 months old of male and female) were used in this study. All experiments with the involved animals were performed in accordance with the relevant laws and institutional guidelines of Central Animal Facility, UMG, Göttingen.

\subsection{Dimensional (D) gel electrophoresis}

\subsubsection{Sample preparation.}

After mice being sacrificed, liver tissue were dissected and were snap frozen into liquid nitrogen and stored at $-80^{\circ} \mathrm{C}$ until further use. The tissues were lysed in tissue lyses buffer (7M urea, $2 \mathrm{M}$ thio-urea, $4 \%$ CHAPS, $20 \mu \mathrm{l} / \mathrm{ml}$ ampholytes, $10 \mathrm{mg} / \mathrm{ml}$ DTT, protease and phosphatase inhibitors) for 5 minutes at 50 hertz frequency and kept at $4^{\circ} \mathrm{C}$ for overnight. Lysed tissue samples were centrifuged at $14000 \mathrm{rpm}$ for 20 minutes at $4^{\circ} \mathrm{C}$ and supernatant was obtained for further protocols.

\subsubsection{D gel electrophoresis, staining and image Analysis}

Protein concentrations were measured by the Bradford protein estimation method (Bio-Rad standard protocol) and lysates volume containing $120 \mu \mathrm{g}$ of protein were diluted into $325 \mu \mathrm{L}$ rehydration buffer (7M urea, $2 \mathrm{M}$ thio-urea, $4 \%$ CHAPS, $0.2 \% 3-10$ bio- Lytes and 65mM DTT) and loaded on a ReadyStrip (IPG nonlinear pH 3-10, 17 $\mathrm{cm}$ strip - Bio-Rad). After $12 \mathrm{~h}$ of active rehydration at 50 volt $(\mathrm{V})$, isoelectric focusing was started at $500 \mathrm{~V}$ for $1 \mathrm{~h}$, followed by ramping at $1000 \mathrm{~V}$ for $1 \mathrm{~h}$ and $5000 \mathrm{~V}$ for 2 h. The final focusing was conducted at $8000 \mathrm{~V}$, reaching the total of $60,000 \mathrm{~V}$ hours (PROTEAN IEF CELL, Bio-Rad). Then, the strips were equilibrated 2 times for 20 minutes in buffer containing $6 \mathrm{M}$ urea, $2 \%$ SDS, $30 \%$ glycerin, and $0.375 \mathrm{M}$ Trisph, $\mathrm{pH}$ 8.8, supplemented with $2 \%$ DTT in the first and with $2.5 \%$ lodoacetamide (IAA) in the second equilibration step. SDS-PAGE was performed overnight at $4^{\circ} \mathrm{C}$ with homogeneous $12 \%$ polyacrylamide gel using a PROTEAN II XL Vertical Electrophoresis Cell (Bio-Rad).

2D gels were stained with silver staining - Gels were placed in fixative $(50 \%$ methanol, 12\% acetic acid), washed with 50 and $30 \%$ ethanol, sensitization with 
$1.26 \mathrm{mM}$ sodium thio-sulphate, staining of gels with the silver nitrate $(1 \mathrm{~g} /$ liter silver nitrate, $700 \mu \mathrm{l}$ formaldehyde/liter), developing (60g/liter Sodium carbonate, $500 \mu \mathrm{l}$ Formaldehyde/liter, $40 \mu \mathrm{l}$ of $10 \%$ sodium thio-sulphate), and finally stopping of the reaction with fixative. The images were scanned at 300 dpi with canon LiDe 110 scanner. Protein spot abundances from 48 liver proteome gel images $(3,9,14$ months, wild type and PrPC knockout from both gender) were analyzed using the Delta2D software (v. 3.6) (DECODON). The differences in spot abundance detected by Delta2D densitometry analysis were statistically evaluated using unpaired Student's t-test. Means and standard deviations were calculated from four sets of experiments. A protein spot was considered as differentially regulated when its densitometric analyses showed at least 1.5 -fold change in abundance and when the $p$-value was $<0.05$ in unpaired Student's t-test.

\subsection{In gel digestion and mass spectrometry identification}

2D gel spot plugs containing proteins (differentially regulated spots) were manually excised from the silver stained gels and subjected to in-gel digestion. The detailed protocol of this procedure has been described by Ramljak (Ramljak et al., 2007). Ingel digested peptides were chromatographically separated (C18 pepMap100 Nano Series analytical column, LC Packings) and analyzed by an ESI-Q-TOF Ultima Global mass spectrometer (Micromass). Data acquisition were performed using the MassLynx (v. 4.0) software and further processed on Protein- Lynx-Global-Server (v. 2.1) (Micromass). The acquired data was searched against MSDB and SwissProt 2010_08 databases through the Mascot search engine using a peptide mass and MS/MS fragment mass tolerance of 0.5 Da. The searching criteria were set with one missed cleavage by trypsin allowed and protein modifications included methionine oxidation and carbamidomethyl cysteine when appropriate.

\subsection{Screening of mass spectrometry data}

Raw files in the scaffold software format were further screened to remove false positive results based on the following criteria:

a) Molecular mass - As each protein has its unique molecular mass, therefore identified protein was confirmed, if it was from the excised spot by comparing the theoretical molecular mass of the protein with the experimental molecular mass on the gel map with help of a maker. 
b) Isoelectric $\mathrm{pH}(\mathrm{pl})$. - As each protein has its unique isoelectric $\mathrm{pH}$, so the theoretical pl was compared with the experimental pl on the gel maps.

c) Score/peptide count - Peptide count is the number which represents the number of times a peptide has been detected by the mass spectrometer. We set up a criteria minimum of 5 counts to be considered for the further functional analysis.

d) Sequence coverage - It is the percentage of the sequence covered by the peptide identified, out of the full sequence of the protein. We set up minimum sequence coverage of $15 \%$ to include the identified protein in our study.

\subsection{Western blotting.}

\subsubsection{Preparation of mice liver samples}

Mice were sacrificed and liver tissue was frozen in liquid nitrogen. Liver tissue was lysed with Urea/thio-urea lysis buffer (7M urea, 2M thio-urea, $4 \%$ CHAPS, $20 \mu \mathrm{l} / \mathrm{ml}$ ampholytes, $10 \mathrm{mg} / \mathrm{ml}$ DTT, protease and phosphatase inhibitors) and kept at $4^{\circ} \mathrm{C}$ overnight before centrifugation at 14000 rpm for 20 minutes.

\subsubsection{Liver homogenate}

Liver samples were homogenized and lysed with the similar protocol as described earlier for 2D gel electrophoresis. Liver tissue lysates containing $75 \mu \mathrm{g}$ of protein samples were separated on $12 \%$ SDS-PAGE gels and transferred to PVDF membranes. The membranes were blocked with $5 \%$ skimmed milk in phosphate buffer saline with $0.2 \%$ Triton X-100 (PBST) for $1 \mathrm{~h}$ at room temperature. Subsequently, the membranes were incubated overnight at $4^{\circ} \mathrm{C}$ with the following primary antibodies: mouse anti-PrPC SAF32 (SPI-BIO), rabbit anti-Tau (1:1000, Abcam), mouse anti-Ptau-199 (1:1000, Abcam), mouse anti-Beta-actin (1:2000, Abcam), mouse anti-Gsk3beta (1:10000, Santa Cruz), mouse anti-Pgsk3beta (1:1000, Milipore), rabbit anti-CDK5 (1:1000, Santa Cruz), rabbit anti-P25 (1:1000, Cell Signalling) mouse anti-Bax (1:1000, Cell Signalling), mouse anti-Bcl2 (1:1000, Cell Signalling). Thereafter, membranes were washed with PBST and incubated for 1 $\mathrm{h}$ at room temperature with the corresponding horseradish peroxide-conjugated secondary antibodies: (goat anti-mouse; 1:10,000, Abcam, anti-rabbit; 1:7500, Jackson Immunoresearch). The immunoreactivity was detected after immersing the membranes in enhanced chemiluminescence (ECL) solution (Index) and the membranes were scanned with ChemiDoc fluorescent device (Bio-Rad). Films were 
scanned, densitometry and statistical analysis were performed with the Image Lab Software. The protein regulation was considered significant when the $P$-value was lower than 0.05 in student's t-test.

\subsection{Immunofluorescence}

Frozen liver tissues were embedded in cryomatrix and $5 \mu \mathrm{m}$ thick sections were sliced using cryostat (Leica cryostat 3050). These sections were mounted on histological glass slides, fixed in acetone (1 minute), washed with methanol (10 minutes), and air dried. Slides were kept at $-20^{\circ} \mathrm{C}$ until further use. Immunofluorescence staining was performed using the following protocol:

- The tissue glass slides containing liver tissue sections were thawed at room temperature for 10-20 minutes

- Slides were rehydrated in wash buffer (PBS) for 10 minutes

- Tissue sections were surrounded by drawing a hydrophobic barrier circle using fat PAP pen marker

- To expose the antigenic site in the tissue sections, slides were incubated in PBS supplemented with $0.2 \%$ Triton X-100

- Primary antibodies were applied in appropriate dilutions and slides were incubated overnight at $4{ }^{0} \mathrm{C}$

- Washing was done with PBS (3x, 5 minutes) followed by incubation with secondary antibody for $1 \mathrm{~h}$ at room temperature.

- Washing with PBS (3x, 5 minutes) was done.

- Slides were air dried and mounted with the cover slips using antifade mounting medium

- $\quad$ Slides were visualized using a fluorescence microscope.

\subsection{Measurement of fat in liver tissue}

The analysis of the fat content was performed histochemically by Sudan III staining on liver tissue sections and a quantitative measurement of the total triglycerides content was performed in diagnostic facility at the department of clinical chemistry, UMG, Göttingen. 


\subsubsection{Sudan III staining}

The tissue slices of $5 \mu \mathrm{m}$ thickness from the liver samples were sliced with cryostat and fixed with $4 \%$ paraformaldehyde.

- The tissue glass slides containing liver tissue sections were thawed at room temperature for 10-20 minutes

- The slides were rehydrated in wash buffer (PBS) for 10 minutes

- Tissue sections were surrounded drawing a hydrophobic barrier circle using fat PAP pen marker

- The slides were washed with $50 \%$ ethanol

- After being washed with $50 \%$ ethanol, slides were incubation with ready to use Sudan III dye for 5 minutes.

- The slides were washed again with $50 \%$ ethanol for 10 seconds, followed by washing with distilled water for 10 seconds.

- After being washed, slides were incubated with ready to use hematoxylin for 5 minutes followed by washing with tap water for 10 minutes.

- Slides were air dried and mounted with cover slip using anti fade mounting medium

- Slides were visualized using a bright field microscope.

\subsubsection{Triglyceride content}

Liver tissue was homogenized in PBS. The homogenates were centrifuged at 14000 rpm for half an hour and supernatant was obtained. The supernatant from the liver homogenates were then analyzed for the triglyceride measurement $(\mathrm{mg} / \mathrm{dl})$ by the diagnostic facility at the department of clinical chemistry, UMG, Göttingen.

\subsection{Capillary Electrophoresis}

Free-zone Capillary electrophoresis (CE) was performed on a Beckman P/ACE MDQ Capillary Electrophoresis System controlled by 32 Karat 7.0 Software (Beckman Instruments). LIF detection was performed by an air-cooled argon laser (Beckman Instruments) with excitation at $488 \mathrm{~nm}$ and emission at $520 \mathrm{~nm}$. The untreated fusedsilica capillaries (Beckman Coulter) with an inner diameter of $50 \mathrm{~mm}$ and a total length of $30 \mathrm{~cm}\left(20 \mathrm{~cm}\right.$ to the detector) were preconditioned with, $0.1 \mathrm{M} \mathrm{NaOH}, \mathrm{H}_{2} \mathrm{O}$ and $5 \mathrm{mg} / \mathrm{ml} \mathrm{CM}-\beta-C D$ running buffer. The peptide was labeled during synthesis through a gamma butyric bridge. Rabbit antibodies were produced to peptide and 
affinity purified by passing over an affinity column prepared with the corresponding peptide. Peptides and antibodies were obtained from Ames Laboratory, USDOE, lowa State University, Ames, IA, USA. The dilutions of antibodies and peptides were made to determine the concentration that gave the ratio equal to 1.00 and were prepared in the $25 \mathrm{mM}$ TAPS ( $\mathrm{pH} 8.8$ ) buffer with $0.1 \%$ BSA.

\subsubsection{Sample preparation and capillary immunoassay}

After mice being sacrificed, liver tissues were excised into liquid nitrogen and immediately stored at $-80^{\circ} \mathrm{C}$. Tissues were lysed in lyses buffer containing $3 \mathrm{ml} 1 \mathrm{M}$

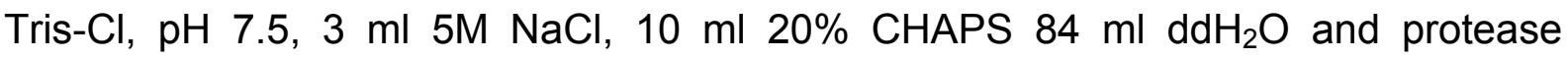
inhibitors for 5 minutes at 50 hertz frequency and kept at $4^{\circ} \mathrm{C}$ for overnight. Lysed tissue samples were centrifuged at $14000 \mathrm{rpm}$ for 30 minutes at $4^{\circ} \mathrm{C}$ and supernatant was obtained. Analysis was performed within half an hour after samples were prepared to load. Running method was described in the literature (Yang et al., 2005). Peak areas for the free FITC-peptide and immunocomplex (antibody+tissue lysate) in electrophoretograms were measured and their ratio was calculated. The ratio was multiplied by peak area of the control immunocomplex (antibody+buffer) to obtain the normalized values for different set of experiments.

\subsubsection{Calculations (Expression of PrPC):}

We observed a variation in the peak area with the same set of antibody dilutions from one set of experiment compared to another. Therefore, to compare different experiments performed on different types of tissues, we normalized the different set of immunoassays by calculating a normalized Ratio $(R)$. It was determined by calculating the area under the peak of the free peptide vs area under the peak of the antibody control (antibody + buffer + free peptide). Ratio obtained was multiplied by area under the peak of PrPC (antibody+tissue lysate+free peptide). This gave the relative amount of PrPC expression (Table 1).

Three types of peaks were obtained as shown in figure 6: (1) Free FITC-peptide peak, (3) Antibody (Ab) control peak and (2) PrPC peak

Normalized ratio (R): Area of free peptide peak (1) /Area of ab control peak (3)

Relative expression of PrPC: Ratio $\times$ Area of PrPC peak (2) 
Table. 2. Calculations to measure the expressional levels of PrPC in brain and liver

\begin{tabular}{|c|c|c|c|c|c|}
\hline Sample & $\begin{array}{c}\text { Area under the } \\
\text { peak (PrPC) } \\
\text { /100000 }\end{array}$ & $\begin{array}{c}\text { Area under the } \\
\text { peak (Free } \\
\text { Peptide)/100000 }\end{array}$ & $\begin{array}{c}\text { Area under the } \\
\text { peak(Ab } \\
\text { Control)/100000 }\end{array}$ & $\begin{array}{c}\text { Normalized } \\
\text { ratio }(\boldsymbol{R})\end{array}$ & $\begin{array}{c}\text { Relative } \\
\text { expression of } \\
\text { PrPC }\end{array}$ \\
\hline Brain & 2.04 & 3.16 & 0.19 & 16.73 & 34.09 \\
\hline Liver & 1.05 & 2.53 & 0.78 & 3.25 & 3.42 \\
\hline
\end{tabular}

A

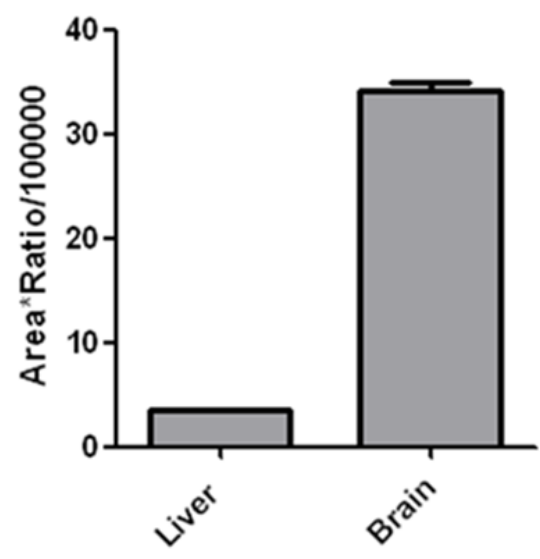

B Peptide dilution $100 \mathrm{~K}=1 / 100000$

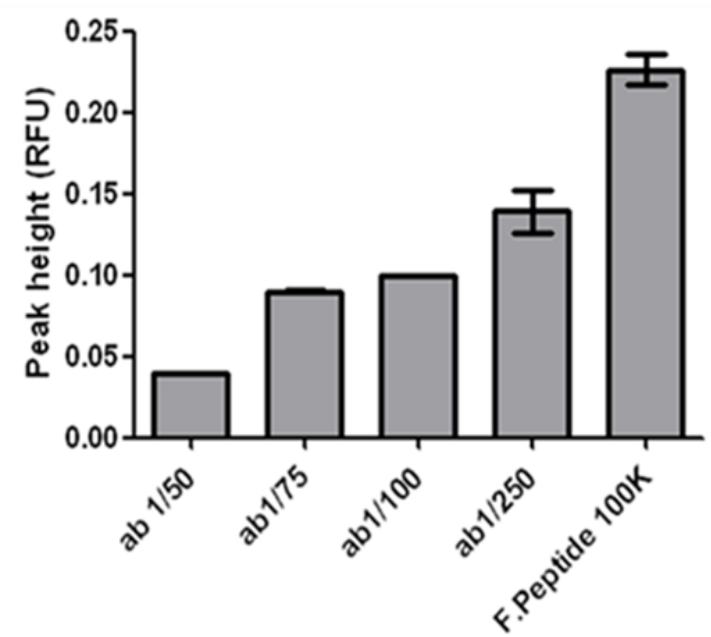

Fig. 5. Relative expression of PrPC and binding of peptide at different dilutions of antibody: (A) PrPC expression in the liver and brain by peak area (Table 2). (B), Different dilutions of the antibody incubated against $1 / 100 \mathrm{~K}$ dilution $(0.5 \mathrm{mg} / \mathrm{ml})$ of the peptide.

\subsection{Quantitative Real-Time PCR (qPCR)}

Sample preparation and total RNA extraction from the liver tissue was done as per instructions from a commercial kit (mirVana isolation kit Ambio, Austin, TX). The retrotranscriptase reaction of the RNA samples was carried out with the High Capacity cDNA Archive kit (Applied Biosystems, US) following the protocol provided by the manufacturer and using the Gene Amp® 9700 PCR System thermocycler (Applied Biosystems, USA). A parallel reaction for an RNA sample was run in the absence of reverse transcriptase to assess the degree of contaminating genomic DNA. Roche LightCycler 480 detector instrument was used for PCR amplification and detection. Parallel amplification reactions for each sample were performed using the $20 \times$ TaqMan Gene Expression Assays (Applied Biosystems) and $2 \times$ TaqMan Universal PCR Master Mix (Applied Biosystems). Different steps were as follows: denaturation-activation cycle $\left(50^{\circ} \mathrm{C}\right.$ for 2 minutes, $95^{\circ} \mathrm{C}$ for 10 minutes) followed by 
40 cycles of denaturation-annealing-extension $\left(95^{\circ} \mathrm{C}, 15\right.$ seconds; $60^{\circ} \mathrm{C}, 1$ minute; $98^{\circ} \mathrm{C}$ ). mRNA levels were calculated using the LightCycler 480 software. Data analysis was done by $\triangle \Delta \mathrm{Ct}$ method to get PrPC gene expression values as fold changes between two genders, which were normalized by the relative expression of a housekeeping gene (HPRT). The probes used in this study:

1. PrPC-TCGGTGGCAGGACTCCTGAGTATAT

(Life technology-Mm01545186_m1)

2. HPRT- GTTAAGGTTGCAAGCTTGCTGGTGA

(Life technology-Mm00446968_m1)

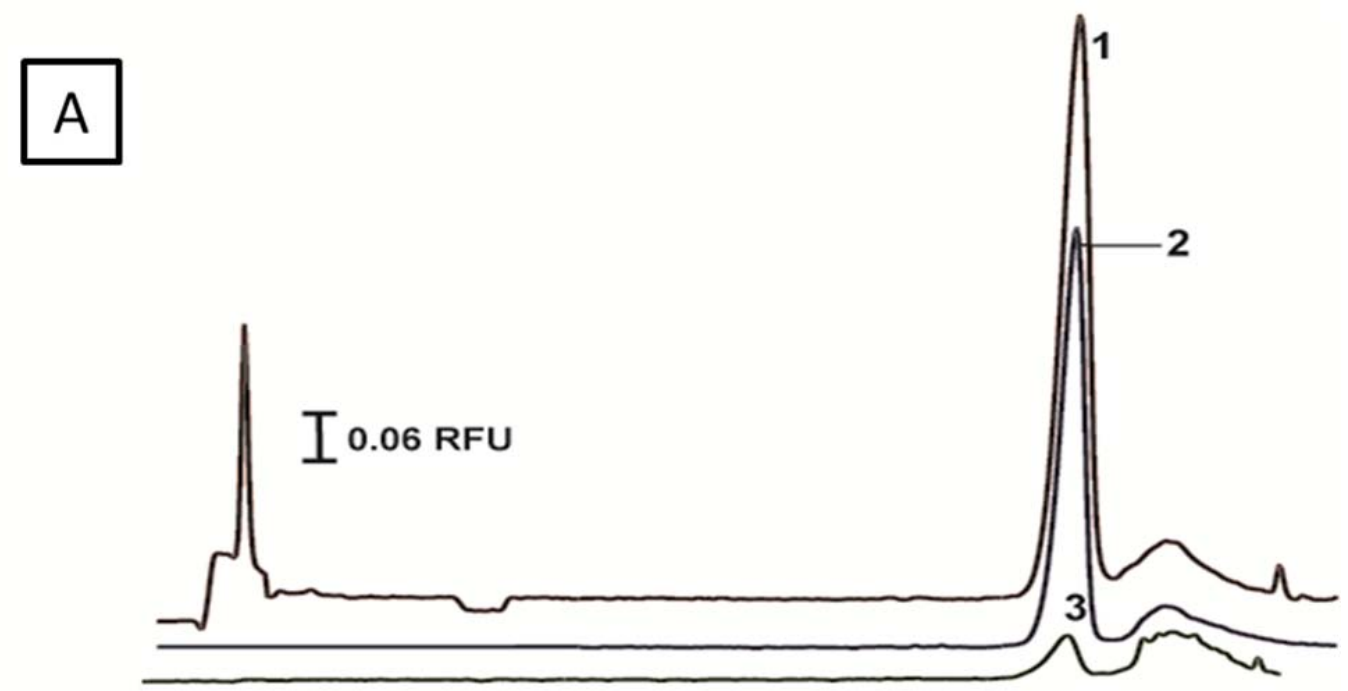

B
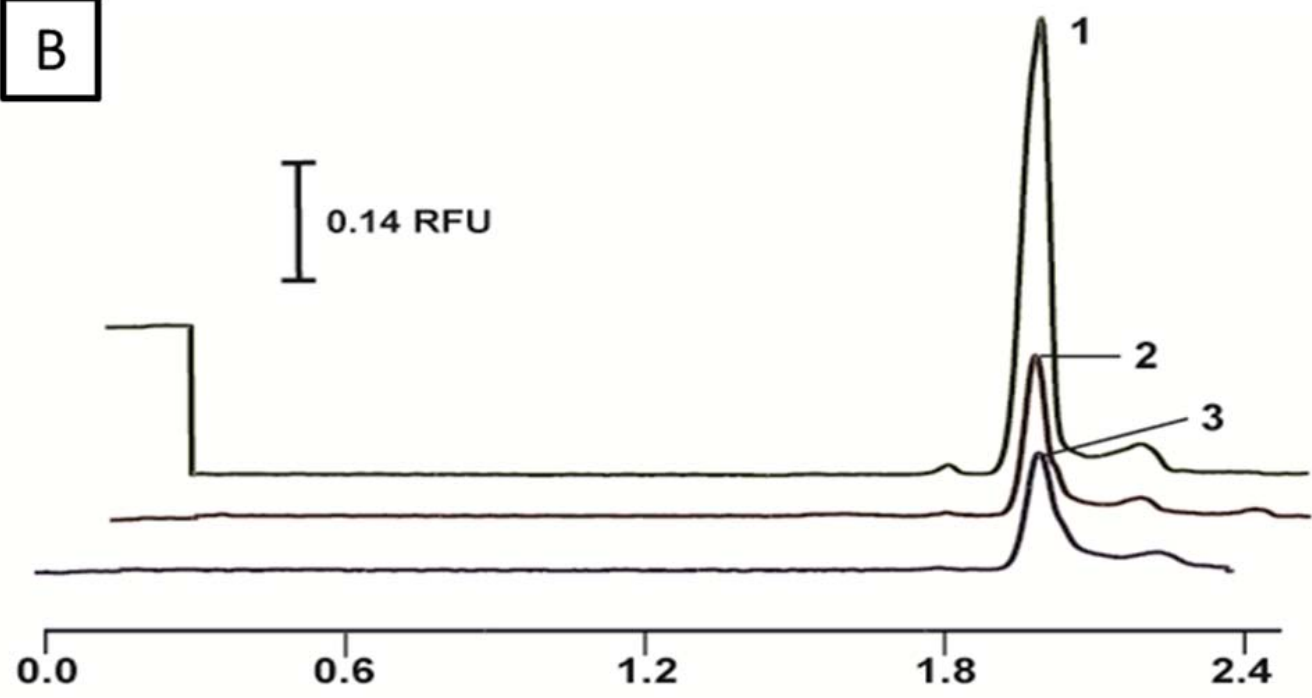

1.2

1.8

2.4

Fig. 6. Electrophoretograms of PrPC expression by capillary electrophoresis (CE) in brain $(A)$ and liver $(B)$ respectively: Peak 1 represents (Free FITC-peptide), peak 2 represents (Antibody + FITC-peptide + tissue lysate) and peak 3 represents antibody control (antibody + FITC peptide). Relative Fluorescence Units (RFU). 


\subsection{IPA Analysis}

Ingenuity Pathway Analysis (IPA) is a web-delivered application (www.ingenuity.com) that transforms a list of proteins/genes (with or without accompanying expression information) into a group of relevant biological networks based on the literature records maintained in the Ingenuity Pathways Knowledge Base (IPKB). This knowledge base has been integrated into a large network, called the Global Molecular Network, composed of thousands of genes and gene products such as proteins or compounds with their interacting partners.

Principle: Each protein identifier such as accession numbers were mapped to its corresponding protein object in the Ingenuity Pathways Knowledge Base (IPKB). The biological networks were generated based upon the identities of the focus proteins and interactions with genes/proteins that were reported in the literature. Each biological network has a significance score, which was created using a $P$-value calculation. The $P$-value indicates the likelihood that assembly of a set of focus proteins in a network could be explained by the random chance ( (Score) p-score = $\log 10$ (P-value)) . For example, a score of 2 indicates that there is 1 in 100 chance that focus proteins are together in a network due to random chance. Therefore, networks with scores of 2 or higher have at least a $99 \%$ confidence of not being generated by random chance alone. Calculation of canonical pathways/biological functions were assigned by using research extracted from scientific literature and stored in the IPKB.

Settings: IPA provided a wide range of settings such as to select species/strain taken (i.e., mouse, human etc.), experimental type (i.e., proteomics, microarray etc.), tissue used (i.e., brain, liver etc.). In our study, we performed two type of analysis: first was performed using liver as a reference tissue and second was an additional analysis with brain as a reference tissue because most of work with prion transgenic mouse models or prion disease human subjects is done in brain and only two reports have been published in liver so far. Therefore, the second analysis was aimed to get the additional information regarding the fundamental function of PrPC. 


\section{Results}

PrPC expression in the liver is very low. Therefore, we used high sensitive capillary electrophoresis (CE) technique along with Western blot to obtain the improved resolution of PrPC expression. Gender dependent expression of PrPC was observed in the liver. In this study, we observed that PrPC expression increased with age and was found maximum in the aging wild type mice liver (14 months old). The proteome profiling of all the age groups from the PrPC knockout mice liver showed 64 differentially regulated proteins. Further IPA software analysis and confirmation by Sudan III (fat globules) staining showed the manifestations of the fatty liver disease. Additional IPA analysis showed the regulation of microtubule associated tau (MAPT) protein which was further confirmed by Western blot and immunofluorescence.

\subsection{Age and gender dependent PrPC expression in mice liver}

\subsection{1 mRNA expression of PrPC}

The mRNA expression of PrPC from all three age groups was quantified by qPCR. The female mice have higher PrPC expression than male mice in the liver of 9 and 14 months. The expression of PrPC was higher in the 14 months old wild type mice liver as compared to the 3 and 9 months of age (Fig. 9). Further, we analyzed the PrPC expression at the protein levels. It was critical to measure the expression of PrPC first at the gene level, because its detection at the protein level could be due to its amounts in the liver from

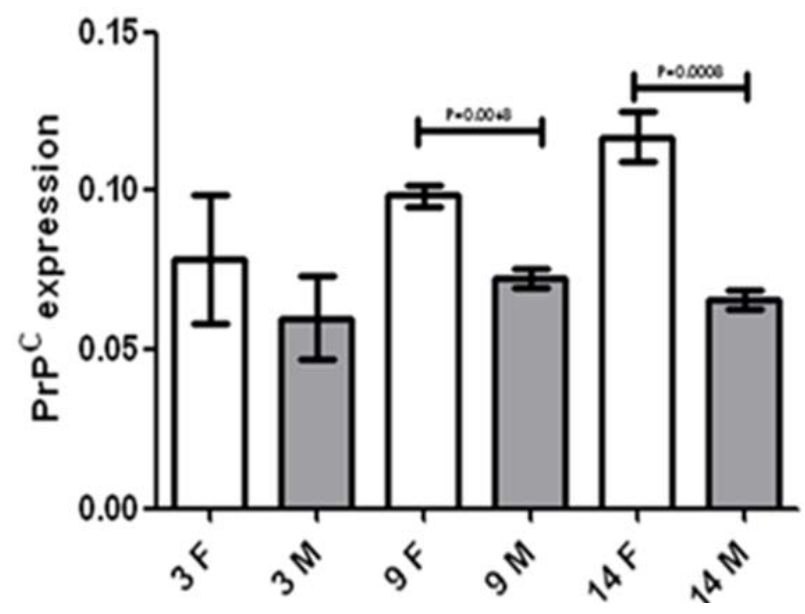

Fig. 9. mRNA expression of PrPC in 3, 9 and 14 months old wild type mice liver: PrPC expression was significantly higher in the female as compared to male wild type mice liver in 
the 9 and 14 months old age and a similar gender dependent trend of PrPC expression in the 3 months old age mice was also observed (F-Female, M-Male).

systemic circulation as liver is physiologically linked to other tissues through hepatic portal system.

\subsubsection{The expression of PrPC at protein level}

The expressional regulation of PrPC at protein level was analyzed by high sensitive technique capillary immunoelectrophoresis (CIE) and Western blot.

\subsubsection{Analysis of PrPC expression by Capillary immunoelectrophoresis (CIE)}

The main advantage of capillary immunoelectrophoresis (CIE) is its high sensitivity, with a detectable limit of $1 \mathrm{pg}$ (Yang et al., 2005), which is difficult to be achieved with the standard techniques like Western blot or ELISA. By implying CIE, we observed a better resolution of PrPC differential expression in the 9 months old age mice liver (Fig. 10B). However, PrPC was barely detectable by standard techniques such as Western blot or ELISA. However, by CIE showed the higher expression of PrPC in the liver of 9 months female mice as compared to the male wild type mice. Identical regulation was observed in the 14 months old mice (Fig. 10C and 10D).
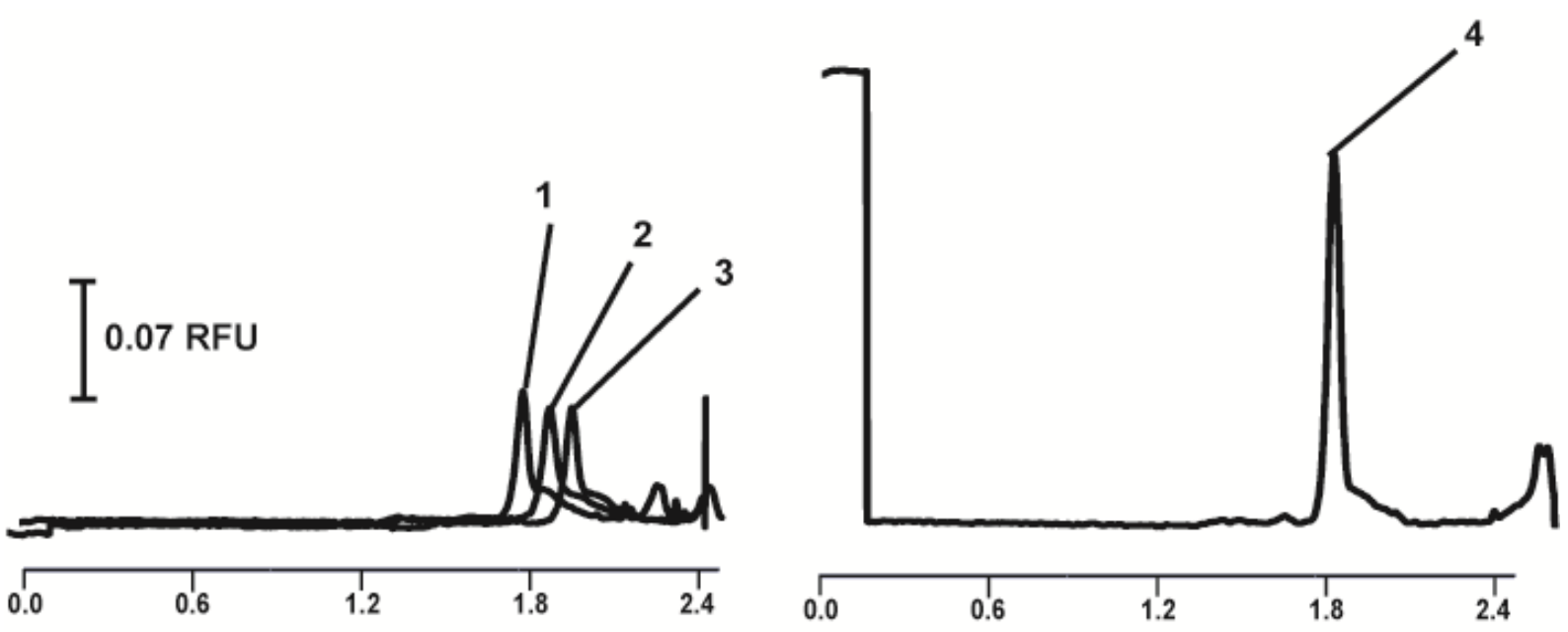

Fig. 8. PrPC expression in wild type compared to the PrPC knockout liver: Expression of PrPC in wild type (peak 1) and PrPC knockout mice (peak 2). PrPC expression in PrPC knockout liver was equivalent to antibody control (peak 3 - antibody + FITC-peptide $+2 \%$ chaps buffer). Peak 4 represents Free-FITC-peptide.

\subsubsection{Analysis of PrPC expression by Western blot}

We further analyzed the PrPC expression by the Western blots and observed upregulation of the PrPC expression in female wild type mice liver but only in the aging 
mice (14 months) but the expressional regulation of PrPC in the 3 and 9 months aged mice liver using Western blot was absent, due to low sensitivity of Western blot
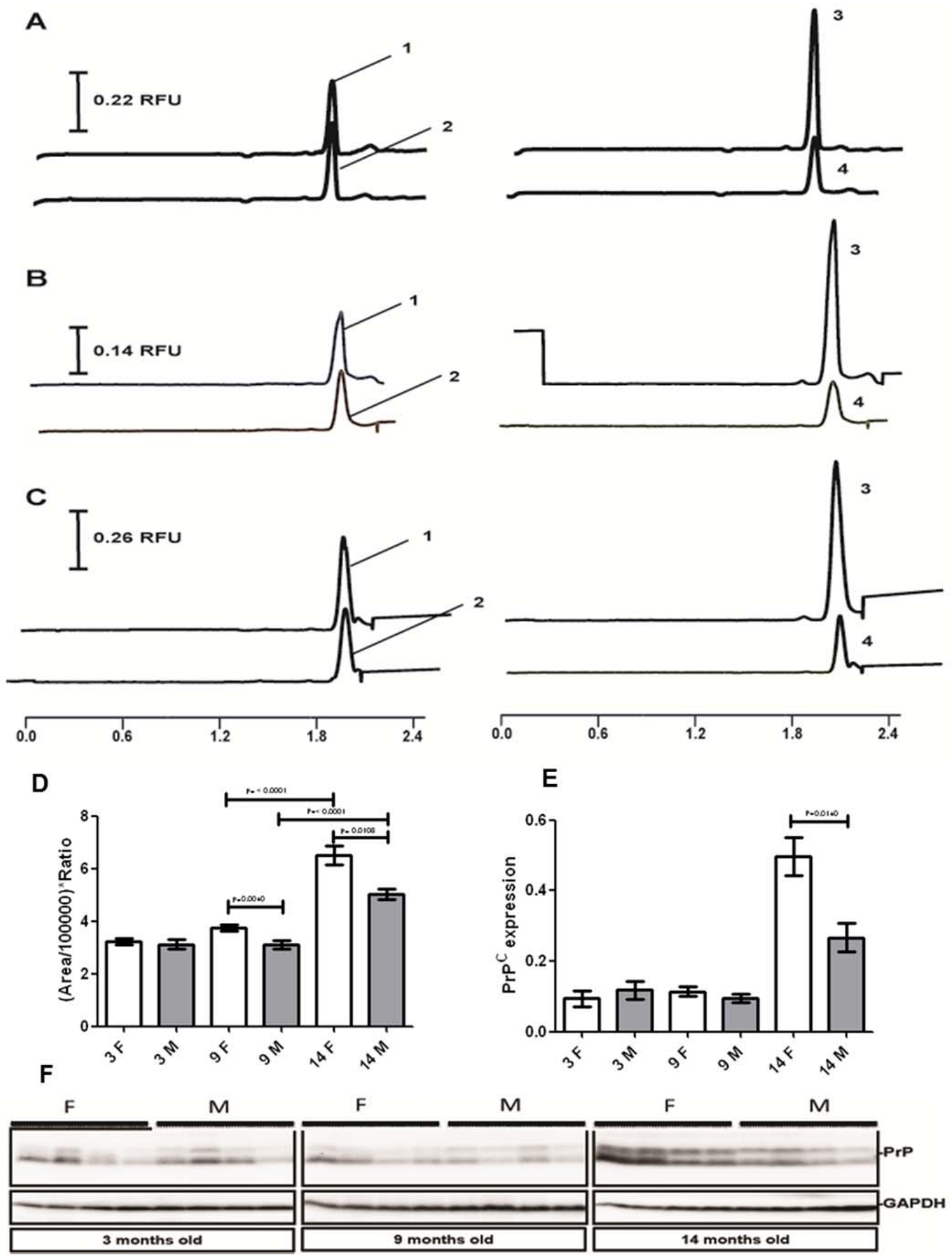

Fig. 10. PrPC expression in liver: PrPC expression in female (peak 1) and male (peak 2) in 3 (A), 9 (B) and 14 months old (C) by Capillary electrophoresis (CE). Peak 3 and 4 represents free FITC-peptide and antibody control (FITC-peptide + Antibody). There was age and gender dependent significant regulation of PrPC expression (D), represented by relative 
differences in Area/100000×Ratio by CE (Calculations in Index-Table-5), (E) and (F), by Western blot.

technique (Fig. 10E and 10F), which clearly indicated an advantage to use CIE for the measurement of the minutely expressed proteins in the tissues.

\subsection{Age and gender specific differential proteome analysis in PrPC knockout mice liver}

As we showed an age and gender dependent regulation of PrPC expression in the liver of wild type mice, therefore, this observation confirmed our first hypothesis that aging could be associated with up-regulation of PrPC expression. Our second hypothesis was the possibility of liver pathology in the PrPC knockout mice liver due to reported role of PrPC in hepatic stellate cells activation. The third hypothesis was based on proteomics and genomics reports in the brain of PrPC knockout mice. Therefore, we were expected to get regulation of liver functions linked with the hepatic stellate cells activation such as liver disease and also regulation of tau/ptau dependent cytoskeleton functions in the liver of PrPC knockout mice.

\subsubsection{Two-dimensional (2D) gel electrophoresis}

To understand age and gender dependent altered expression of PrPC and to prove our further hypothesis, we used liver tissue from Zurich I PrPC knockout mice. Hence, we performed 2D gel electrophoresis based proteomics approach to get the robust functional networks. We used liver samples from 3, 9 and 14 months old age liver with both genders. In total, 48 gels (17 cm width) with well separated spots were obtained by 2D gel electrophoresis. Images of each gel were taken at $300 \mathrm{dpi}$ using Canon LiDE 110 scanner (Fig.11) which was used for further software analysis. Using Delta2D's 100\% spot matching approach, 3035 protein spots were detected on liver 2D gel patterns and each spot was identified with multiple set of proteins. 27 spots were regulated in the liver of PrPC knockout mice compared to the wild type mice which constituted 64 proteins in total (Table 3).

In total, 19 proteins were regulated in the liver of 3 and 14 months old PrPC knockout male mice as compared to the wild type while there was no regulation found in the 9 months male group (Fig. 12). 45 proteins were found to be regulated in the liver of 3 , 9 and 14 months old PrPC knockout female mice as compared to the wild type (Fig. 13). 


\section{D gel electrophoresis}

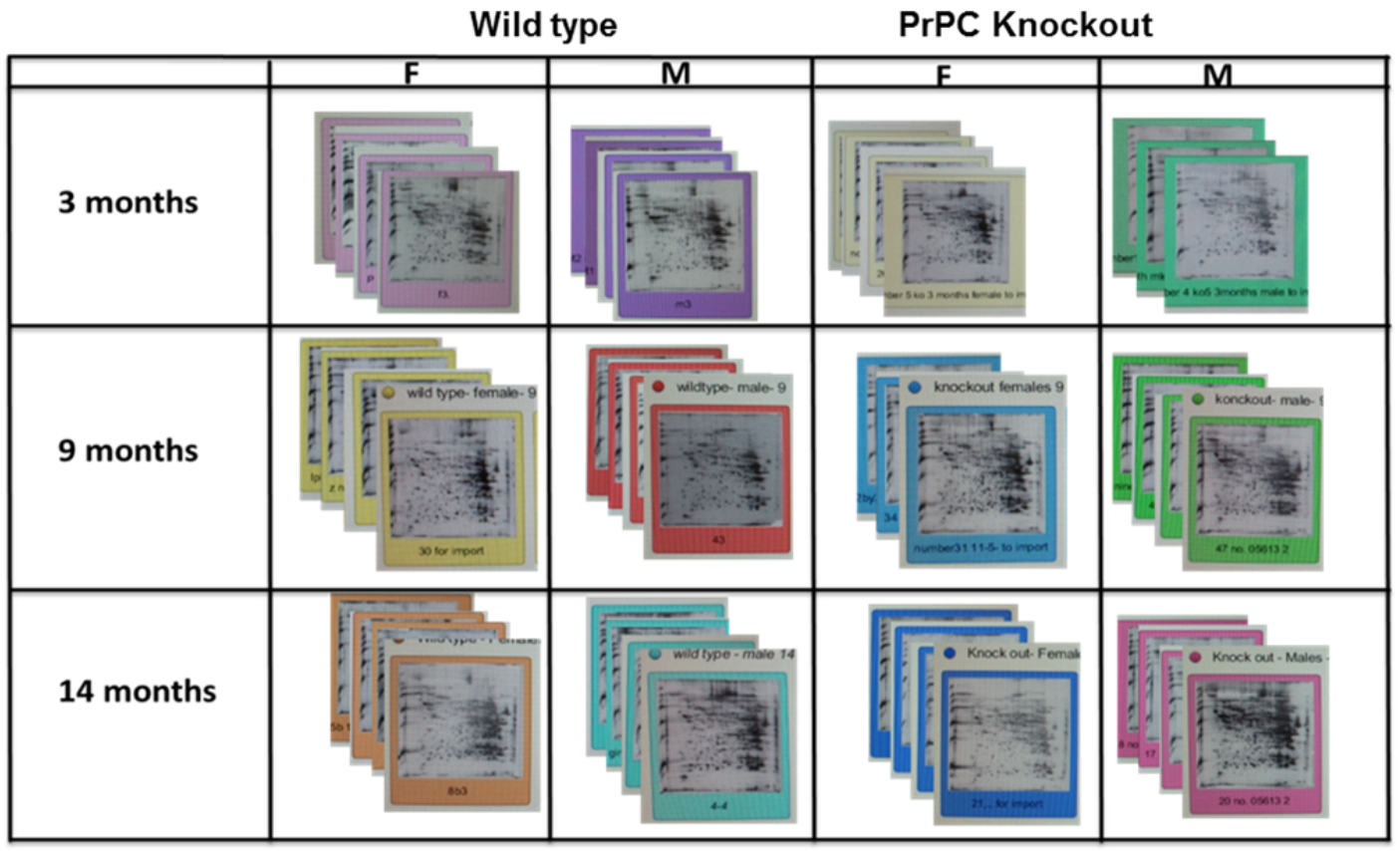

Fig. 11. 2D gels: Gel images from 3, 9 and 14 months old (PrPC knockout and wild type mice liver) age with male and female groups were analyzed by Delta2D DECODON software. 

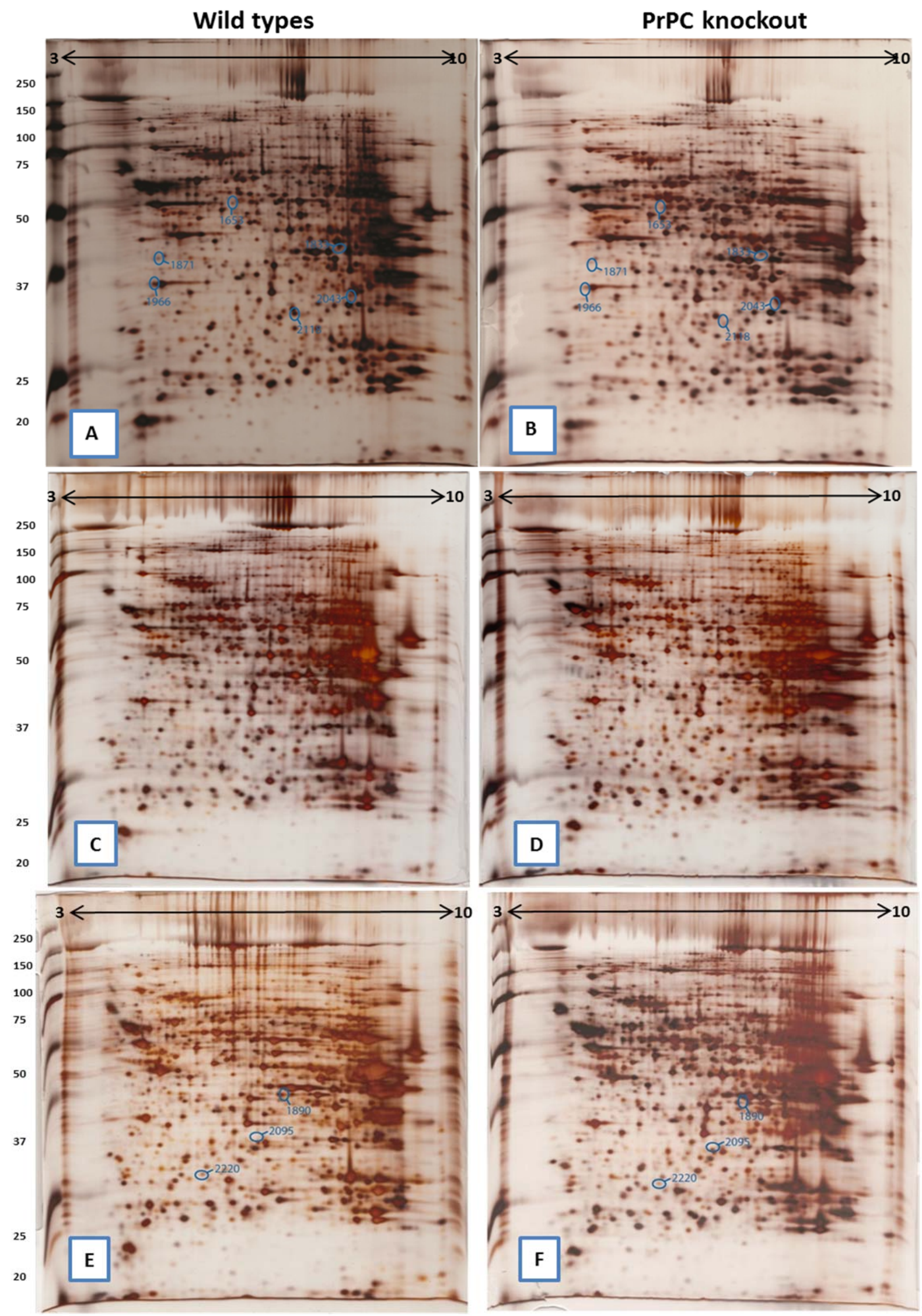

Fig. 12. 2D gel maps of male liver samples: 3 months; wild type (Panel $A)$, PrPC knockout (Panel B), 9 months; wild type (Panel C), PrPC knockout (Panel D), 14 months; wild type (Panel E), PrPC knockout (Panel F) obtained by silver staining of 2D gels. Densitomeric and 
statistical analysis revealed the up-regulation of one spot and down-regulation of 9 spots. No protein was significantly regulated in 9 months male group.
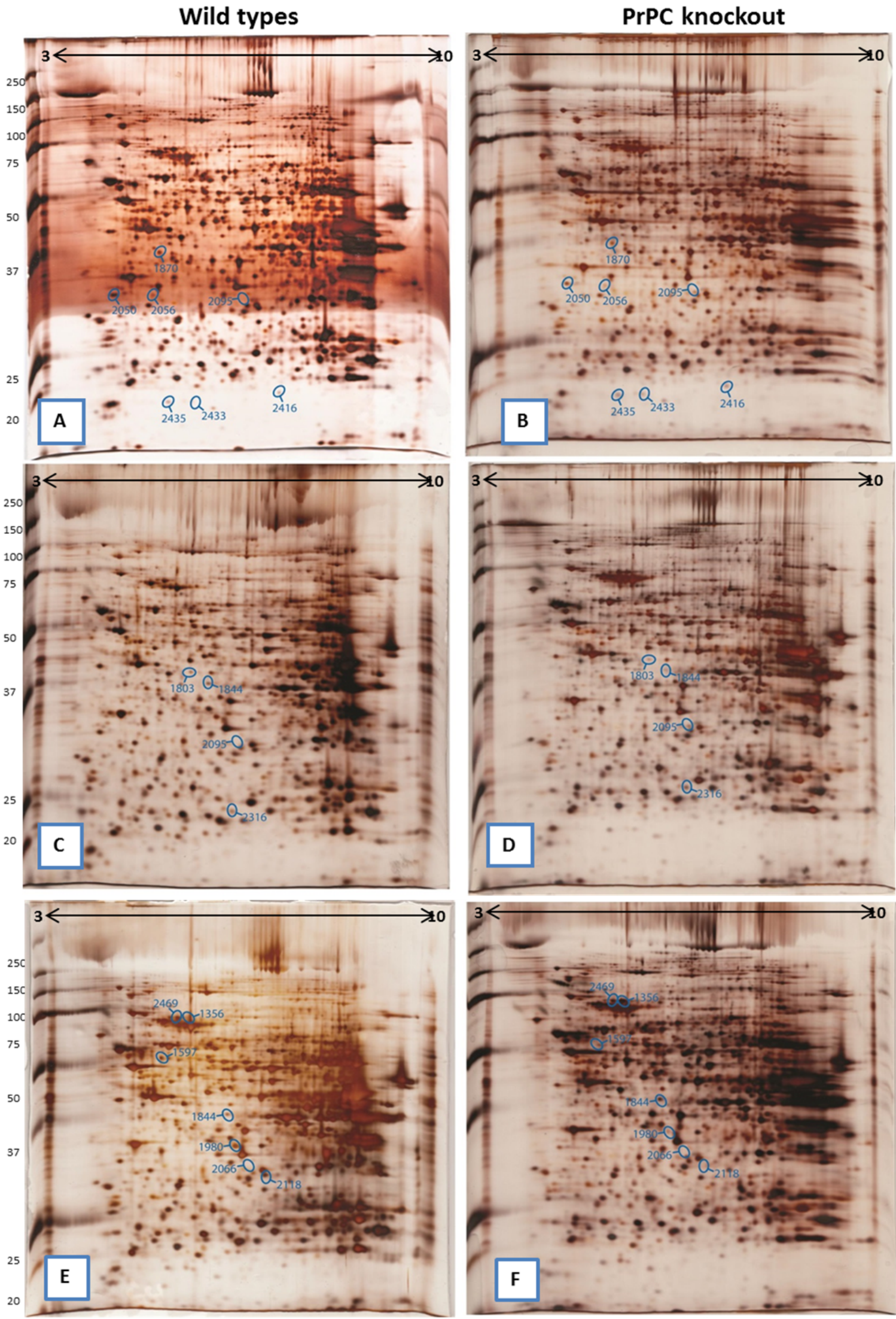

Fig. 13. 2D gel maps of female liver: 3 months; wild type (Panel A), PrPC knockout (Panel B), 9 months; wild type (Panel C), PrPC knockout (Panel D) and 14 months; wild type (Panel 
E), PrPC knockout (Panel F) obtained by silver staining of 2D gels. Densitomeric and statistical analysis revealed the of upregulation of 9 spot and down-regulation of 8 spots.

Table 3 - Detailed list of statistically significant $(P$ value $\leq 0.05)$ dataset from mass spectrometry analysis: List included regulated proteins from 3, 9 and 14 months old in the PrPC knockout mice liver as compared to the wild type (No proteins were found regulated in 9 months male PrPC knockout mice liver). The list is arranged by the protein name with accession numbers and molecular mass with their unique iso-electric $\mathrm{pH}(p /)$. Protein identification is further screened by the score (peptide count), percentage sequence coverage.

\begin{tabular}{|c|c|c|c|c|c|c|c|c|}
\hline $\begin{array}{l}\text { Groups } \\
\text { compared }\end{array}$ & Protein name & $\begin{array}{l}\text { Accessi- } \\
\text {-on } \\
\text { number }\end{array}$ & MW (kDa) & $\begin{array}{c}\text { Coverage } \\
\%\end{array}$ & Score & $\begin{array}{c}\text { Fold } \\
\text { Change }\end{array}$ & $\begin{array}{c}P \text { - } \\
\text { value }\end{array}$ & pl \\
\hline \multicolumn{9}{|c|}{ PrPC knockout vs Wild type (3 months) } \\
\hline 1 & Actin, cytoplasmic 1 & P60710 & $41.737,80$ & $15.70 \%$ & 23 & $2.48 \downarrow$ & 0.01 & 5.29 \\
\hline 2 & Histone $\mathrm{H} 1$ & $\mathrm{P} 15864$ & $21.267,80$ & $18.90 \%$ & 7 & & & 11.0 \\
\hline 3 & $\begin{array}{l}\text { Isoamyl acetate- } \\
\text { hydrolyzing esterase } \\
1 \text { homolog }\end{array}$ & Q9DB29 & $27.975,10$ & $36.90 \%$ & 24 & $1.55 \downarrow$ & 0.018 & 5.34 \\
\hline 4 & $\begin{array}{l}\text { Serine-threonine } \\
\text { kinase receptor- } \\
\text { associated protein }\end{array}$ & Q9Z1Z2 & $38.443,30$ & $40.30 \%$ & 26 & $1.53 \downarrow$ & 0.014 & 4.99 \\
\hline 5 & Regucalcin & Q64374 & $33.407,10$ & $56.90 \%$ & 155 & $1.59 \downarrow$ & 0.031 & 5.16 \\
\hline 6 & $\begin{array}{l}\text { Thioredoxin-like } \\
\text { protein } 1\end{array}$ & Q8CDN6 & $32.237,40$ & $45.70 \%$ & 34 & & & 4.84 \\
\hline 7 & & & & & & $4.65 \downarrow$ & 0.025 & \\
\hline 8 & $\begin{array}{l}\text { Propionyl-CoA } \\
\text { carboxylase alpha } \\
\text { chain, mitochondrial }\end{array}$ & Q91ZA3 & $79.921,90$ & $17.70 \%$ & 17 & $1.58 \downarrow$ & 0.04 & 6.04 \\
\hline \multicolumn{9}{|c|}{ PrPC knockout vs Wild type (14months) } \\
\hline 9 & $\begin{array}{l}\text { U5 small nuclear } \\
\text { ribonucleoprotein } 200 \\
\text { kDa helicase }\end{array}$ & Q6P4T2 & $244.552,50$ & $12.30 \%$ & 36 & $1.77 \downarrow$ & 0.012 & 5.73 \\
\hline 10 & $\begin{array}{l}\text { S-methylmethionine-- } \\
\text { homocysteine S- } \\
\text { methyltransferase } \\
\text { BHMT2 }\end{array}$ & Q91WS4 & $39.871,70$ & $44.60 \%$ & 36 & & & 6.10 \\
\hline 11 & $\begin{array}{l}\text { Pre-mRNA- } \\
\text { processing-splicing }\end{array}$ & Q99PV0 & $273.624,50$ & $6.85 \%$ & 24 & & & 8.95 \\
\hline
\end{tabular}




\begin{tabular}{|c|c|c|c|c|c|c|c|c|}
\hline & factor 8 & & & & & & & \\
\hline 12 & $\begin{array}{l}\text { NADH } \\
\text { dehydrogenase } \\
\text { [ubiquinone] } \\
\text { flavoprotein 2, } \\
\text { mitochondrial }\end{array}$ & Q9D6J6 & $27.285,50$ & $49.20 \%$ & 24 & & & 5.31 \\
\hline 13 & $\begin{array}{l}116 \text { kDa U5 small } \\
\text { nuclear } \\
\text { ribonucleoprotein } \\
\text { component }\end{array}$ & O08810 & $109.362,90$ & $16.10 \%$ & 22 & & & 4.86 \\
\hline 14 & Transaldolase & Q93092 & $37.388,50$ & $24.30 \%$ & 18 & & & 6.57 \\
\hline 15 & $\begin{array}{l}\text { 3-mercaptopyruvate } \\
\text { sulfurtransferase }\end{array}$ & Q99J99 & $33.023,40$ & $67.30 \%$ & 68 & $6.70 \uparrow$ & $\begin{array}{c}\leq \\
0.001\end{array}$ & 6.12 \\
\hline 16 & $\begin{array}{l}\text { Delta(3,5)-Delta(2,4)- } \\
\text { dienoyl-CoA isomer } \\
\text { ase, mitochondrial }\end{array}$ & O35459 & $36.119,20$ & $45.00 \%$ & 54 & & & 6.01 \\
\hline 17 & $\begin{array}{l}\text { 3-hydroxyanthranilate } \\
\text { 3,4-dioxygenase }\end{array}$ & Q78JT3 & $32.804,30$ & $54.90 \%$ & 48 & & & 6.10 \\
\hline \multirow[t]{2}{*}{18} & L-xylulose reductase & Q91X52 & $25.745,40$ & $34.00 \%$ & 16 & & & 6.83 \\
\hline & & & & & & $1.53 \downarrow$ & 0.046 & \\
\hline 19 & $\begin{array}{l}\text { Farnesyl } \\
\text { pyrophosphate } \\
\text { synthase }\end{array}$ & Q920E5 & $40.583,20$ & $42.80 \%$ & 105 & $2.28 \downarrow$ & 0.02 & 5.48 \\
\hline $\begin{array}{l}\text { Groups } \\
\text { compared }\end{array}$ & Protein name & $\begin{array}{c}\text { Accessi- } \\
\text {-on } \\
\text { number }\end{array}$ & MW (kDa) & $\begin{array}{c}\text { Coverage } \\
\%\end{array}$ & Score & $\begin{array}{c}\text { Fold } \\
\text { Change }\end{array}$ & $\begin{array}{c}P \text { - } \\
\text { value }\end{array}$ & pl \\
\hline \multicolumn{9}{|c|}{ Female mice } \\
\hline 20 & $\begin{array}{l}\text { Isocitrate } \\
\text { dehydrogenase } \\
\text { [NAD] subunit alpha, } \\
\text { mitochondrial }\end{array}$ & Q9D6R2 & $39.639,40$ & $\begin{array}{c}34.20 \\
\%\end{array}$ & 18 & & & 5.59 \\
\hline 21 & Calponin-3 & Q9DAW9 & $36.429,60$ & $\begin{array}{c}33.60 \\
\%\end{array}$ & 17 & & & 5.46 \\
\hline 22 & Annexin A5 & $\mathrm{P} 48036$ & $35.754,20$ & $\begin{array}{c}59.90 \\
\%\end{array}$ & 182 & $2,16 \downarrow$ & 0.006 & 4.82 \\
\hline 23 & $\begin{array}{l}\text { Elongation factor 1- } \\
\text { delta }\end{array}$ & P57776 & $31.293,40$ & $\begin{array}{c}21.70 \\
\%\end{array}$ & 12 & & & 4.91 \\
\hline
\end{tabular}




\begin{tabular}{|c|c|c|c|c|c|c|c|c|}
\hline 24 & $\begin{array}{l}\text { Alpha-soluble NSF } \\
\text { attachment protein }\end{array}$ & Q9DB05 & $33,190.8$ & $70.5 \%$ & 146 & $2.14 \downarrow$ & 0.013 & 5.30 \\
\hline 25 & $\begin{array}{l}\text { 40S ribosomal protein } \\
\text { S3a }\end{array}$ & P97351 & $29,885.3$ & $40.2 \%$ & 25 & & & 9.75 \\
\hline 26 & Cathepsin Z & Q9WUU7 & $33,996.3$ & $20.6 \%$ & 22 & & & 5.31 \\
\hline 27 & Annexin A4 & P97429 & $35,917.6$ & $33.5 \%$ & 18 & & & 5.42 \\
\hline 28 & $\begin{array}{l}\text { 3-mercaptopyruvate } \\
\text { sulfurtransferase }\end{array}$ & Q99J99 & $33.023,40$ & $\begin{array}{c}67.30 \\
\%\end{array}$ & 68 & $3.54 \uparrow$ & 0.04 & 6.12 \\
\hline 29 & $\begin{array}{l}\text { Delta(3,5)-Delta(2,4)- } \\
\text { dienoyl-CoA } \\
\text { isomerase, } \\
\text { mitochondrial }\end{array}$ & O35459 & $36.119,20$ & $\begin{array}{c}45.00 \\
\%\end{array}$ & 54 & & & 6.01 \\
\hline 30 & $\begin{array}{l}\text { 3-hydroxyanthranilate } \\
\text { 3,4-dioxygenase }\end{array}$ & Q78JT3 & $32.804,30$ & $\begin{array}{c}54.90 \\
\%\end{array}$ & 48 & & & 6.10 \\
\hline 31 & L-xylulose reductase & Q91X52 & $25.745,40$ & $\begin{array}{c}34.00 \\
\%\end{array}$ & 16 & & & 6.83 \\
\hline 32 & $\begin{array}{l}\text { Vacuolar protein } \\
\text { sorting-associated } \\
\text { protein } 29\end{array}$ & Q9QZ88 & $20.496,10$ & $\begin{array}{c}44.50 \\
\%\end{array}$ & 39 & $2.14 \uparrow$ & 0.006 & 6.29 \\
\hline 33 & $\begin{array}{l}\text { Probable } \\
\text { imidazolonepropionas } \\
\text { e }\end{array}$ & Q9DBA8 & $46.488,80$ & $\begin{array}{c}24.20 \\
\%\end{array}$ & 15 & & & 6.47 \\
\hline 34 & $\begin{array}{l}\text { 14-3-3 protein } \\
\text { gamma }\end{array}$ & P61982 & $28,303.1$ & $36.0 \%$ & 21 & $2.66 \uparrow$ & 0.017 & 4.80 \\
\hline 35 & $\begin{array}{l}\text { 39S ribosomal protein } \\
\text { L12, mitochondrial }\end{array}$ & Q9DB15 & $21.708,80$ & $\begin{array}{c}55.70 \\
\%\end{array}$ & 48 & $2.07 \uparrow$ & 0.004 & 5.35 \\
\hline 36 & Ferritin heavy chain & P09528 & $21.067,20$ & $\begin{array}{c}31.30 \\
\%\end{array}$ & 16 & & & 5.53 \\
\hline \multicolumn{9}{|c|}{ PrPC knockout vs Wild type (9 months) } \\
\hline 37 & $\begin{array}{l}\text { Histidine ammonia- } \\
\text { lyase }\end{array}$ & P35492 & $72.258,90$ & $\begin{array}{c}14.90 \\
\%\end{array}$ & 30 & $2.05 \downarrow$ & 0.039 & 5.94 \\
\hline 38 & Aminoacylase-1 & Q99JW2 & $45.781,20$ & $\begin{array}{c}35.30 \\
\%\end{array}$ & 26 & & & 5.89 \\
\hline 39 & $\begin{array}{l}\text { Leukocyte elastase } \\
\text { inhibitor } \mathrm{A}\end{array}$ & Q9D154 & $42.576,60$ & $\begin{array}{c}44.10 \\
\%\end{array}$ & 59 & $2.19 \downarrow$ & 0.009 & 5.85 \\
\hline 40 & $\begin{array}{l}\text { Sorbitol } \\
\text { dehydrogenase }\end{array}$ & Q64442 & $38.248,80$ & $\begin{array}{c}27.50 \\
\%\end{array}$ & 14 & & & 6.60 \\
\hline
\end{tabular}




\begin{tabular}{|c|c|c|c|c|c|c|c|c|}
\hline 41 & $\begin{array}{l}\text { 3-mercaptopyruvate } \\
\text { sulfurtransferase }\end{array}$ & Q99J99 & $33.023,40$ & $\begin{array}{c}67.30 \\
\%\end{array}$ & 68 & $2.53 \uparrow$ & 0.019 & 6.12 \\
\hline 42 & $\begin{array}{l}\text { Delta(3,5)- } \\
\text { Delta(2,4)-dienoyl- } \\
\text { CoA isomerase, } \\
\text { mitochondrial }\end{array}$ & O35459 & $36.119,20$ & $\begin{array}{c}45.00 \\
\%\end{array}$ & 54 & & & 6.01 \\
\hline 43 & $\begin{array}{l}\text { 3- } \\
\text { hydroxyanthranilate } \\
\text { 3,4-dioxygenase }\end{array}$ & Q78JT3 & $32.804,30$ & $\begin{array}{c}54.90 \\
\%\end{array}$ & 48 & & & 6.10 \\
\hline 44 & $\begin{array}{l}\text { L-xylulose } \\
\text { reductase }\end{array}$ & Q91X52 & $25.745,40$ & $\begin{array}{c}34.00 \\
\%\end{array}$ & 16 & & & 6.83 \\
\hline 45 & $\begin{array}{l}\text { Proteasome subunit } \\
\text { beta type- } 3\end{array}$ & Q9R1P1 & $22.965,50$ & $\begin{array}{c}55.60 \\
\%\end{array}$ & 103 & $2.28 \uparrow$ & 0.04 & 6.13 \\
\hline 46 & $\begin{array}{l}\text { Triosephosphate } \\
\text { isomerase }\end{array}$ & P17751 & $32.191,30$ & $\begin{array}{c}49.80 \\
\%\end{array}$ & 34 & & & 5.56 \\
\hline 47 & $\begin{array}{l}\text { Maleylacetoacetate } \\
\text { isomerase }\end{array}$ & Q9WVL0 & $24.275,70$ & $\begin{array}{c}65.70 \\
\%\end{array}$ & 28 & & & 7.68 \\
\hline 48 & $\begin{array}{l}\text { Ig kappa chain } C \\
\text { region }\end{array}$ & P01837 & $11.777,90$ & $\begin{array}{c}56.60 \\
\%\end{array}$ & 28 & & & 5.56 \\
\hline 49 & $\begin{array}{l}\text { Cyclin-dependent } \\
\text { kinase inhibitor } \\
\text { 1B/P2z }\end{array}$ & P46414 & $22.193,00$ & $\begin{array}{c}33.00 \\
\%\end{array}$ & 6 & & & 6.54 \\
\hline \multicolumn{9}{|c|}{ PrPC knockout vs Wild type (14 months) } \\
\hline 49 & $\begin{array}{l}\text { Stress-70 protein, } \\
\text { mitochondrial }\end{array}$ & P38647 & $73.462,10$ & $\begin{array}{c}69.50 \\
\%\end{array}$ & 507 & $1,56 \downarrow$ & 0.029 & 5.44 \\
\hline 50 & Lamin-B2 & P21619 & $67.318,50$ & $\begin{array}{c}49.30 \\
\%\end{array}$ & 64 & & & 5.36 \\
\hline 51 & $\begin{array}{l}\text { Heat shock cognate } \\
71 \mathrm{kDa} \text { protein }\end{array}$ & P63017 & $70.872,80$ & $\begin{array}{c}29.60 \\
\%\end{array}$ & 25 & & & 5.37 \\
\hline 52 & Glycerol kinase & Q64516 & $61.228,10$ & $\begin{array}{c}27.00 \\
\%\end{array}$ & 19 & & & 5.62 \\
\hline \multirow[t]{2}{*}{53} & $\begin{array}{l}\text { Cytosolic 10- } \\
\text { formyltetrahydrofolate } \\
\text { dehydrogenase }\end{array}$ & Q8R0Y6 & $98.710,50$ & $\begin{array}{c}18.60 \\
\%\end{array}$ & 15 & & & 5.64 \\
\hline & $\begin{array}{l}\text { Protein disulfide- } \\
\text { isomerase A4 }\end{array}$ & P08003 & $71.984,40$ & $\begin{array}{c}24.30 \\
\%\end{array}$ & 19 & & & 5.06 \\
\hline 54 & $\begin{array}{l}\text { Actin, aortic smooth } \\
\text { muscle }\end{array}$ & P62737 & $42.010,10$ & $\begin{array}{c}17.80 \\
\%\end{array}$ & 13 & $4.96 \downarrow$ & $\begin{array}{c}\leq \\
0.001\end{array}$ & 5.24 \\
\hline 55 & Leukocyte elastase & Q9D154 & $42.576,60$ & 44.10 & 59 & $2.23 \uparrow$ & 0.012 & 5.82 \\
\hline
\end{tabular}




\begin{tabular}{|c|c|c|c|c|c|c|c|c|}
\hline & inhibitor A & & & $\%$ & & & & \\
\hline 56 & $\begin{array}{l}\text { Sorbitol } \\
\text { dehydrogenase }\end{array}$ & Q64442 & $38.248,80$ & $\begin{array}{c}27.50 \\
\%\end{array}$ & 14 & & & 6.60 \\
\hline 57 & $\begin{array}{l}\text { Alcohol } \\
\text { dehydrogenase } \\
\text { class-3 }\end{array}$ & P28474 & $39.547,20$ & $\begin{array}{c}16.60 \\
\%\end{array}$ & 12 & & & 7.11 \\
\hline 58 & Apolipoprotein A-I & Q00623 & $30.615,30$ & $\begin{array}{l}16.30 \\
\%\end{array}$ & 6 & & & 5.31 \\
\hline 59 & $\begin{array}{l}\text { Amine } \\
\text { sulfotransferase }\end{array}$ & O35403 & $35,183.0$ & $41.3 \%$ & 201 & $3.01 \downarrow$ & 0.036 & 6.08 \\
\hline 60 & $\begin{array}{l}\text { Nicotinate-nucleotide } \\
\text { pyrophosphorylase } \\
\text { [carboxylating] }\end{array}$ & Q91X91 & $31,530.0$ & $34.8 \%$ & 35 & & & 6.24 \\
\hline 61 & $\begin{array}{l}\text { Malate } \\
\text { dehydrogenase, } \\
\text { cytoplasmic }\end{array}$ & P14152 & $36,512.1$ & $43.7 \%$ & 29 & & & 6.16 \\
\hline 62 & & & & & & $10.94 \uparrow$ & 0.031 & \\
\hline 63 & $\begin{array}{l}\text { Propionyl-CoA } \\
\text { carboxylase alpha } \\
\text { chain, mitochondrial }\end{array}$ & Q91ZA3 & $79.921,90$ & $\begin{array}{c}17.70 \\
\%\end{array}$ & 17 & $5.27 \downarrow$ & 0.003 & 6.04 \\
\hline 64 & $\begin{array}{l}\text { Putative hydrolase } \\
\text { RBBP9 }\end{array}$ & 088851 & $20,911.8$ & $19.4 \%$ & 13 & & & 5.62 \\
\hline
\end{tabular}

\subsection{Bio-informatics based functional network analysis}

As described in methods part that IPA is a bio-informatics tool aimed to analyze the complex proteomics dataset to build functional networks based on the literature information stored in IPKB from a given set of statistical significant dataset.

We used the proteomics dataset with their accession numbers and fold change (up or down-regulated in PrPC knockout mice in comparison to the wild type mice) to analyze with the IPA inguenuity software. The proteomics dataset of male and female groups were combined together to build IPA networks because of the less number of proteins in the male group. Number of proteins in 3,9 and 14 months old groups were not enough to built a significant network by IPA analysis, so we also combined proteomics dataset from all the age groups into one set and analysis was performed to find the functional networks relevant to the PrPC function. 


\subsubsection{IPA analysis (Liver as a reference tissue)}

The IPA ingenuity software gave three pathways with three different functional networks (Fig no. 14)

Network1: Gastrointestinal Disease, Hepatic System Disease, Liver Steatosis (Index - Table 1).

Network2: Lipid Metabolism, Molecular Transport, Small Molecule Biochemistry (Index - Table 2).

Network3: Cellular Function and Maintenance, Cellular Growth and Proliferation, Cellular Movement (Index - Table 3).

We obtained a very diverse forms of functional networks, network 1 had the highest score, which is associated with the liver steatosis and hepatic system disease. Liver steatosis is also known as fatty liver disease, is a reversible condition in which large vacuoles of triglycerides with increased density, gets deposited in the liver cells. In addition, IPA functional networks also indicated the regulation of lipid metabolism (Network2) in the liver of PrPC knockout mice as compared to the wild type mice. Next step was to examine if the liver has any disease pathology including fatty liver disease as predicted by IPA. First, we intended to examine the fat content in the liver and perfomed biochemical measurment of triglyceride levels in the liver of PrPC knockout mice as compared to the wild type mice followed by Sudan III staining to examine the number and intensity of fat globules in the liver of PrPC knockout mice. 


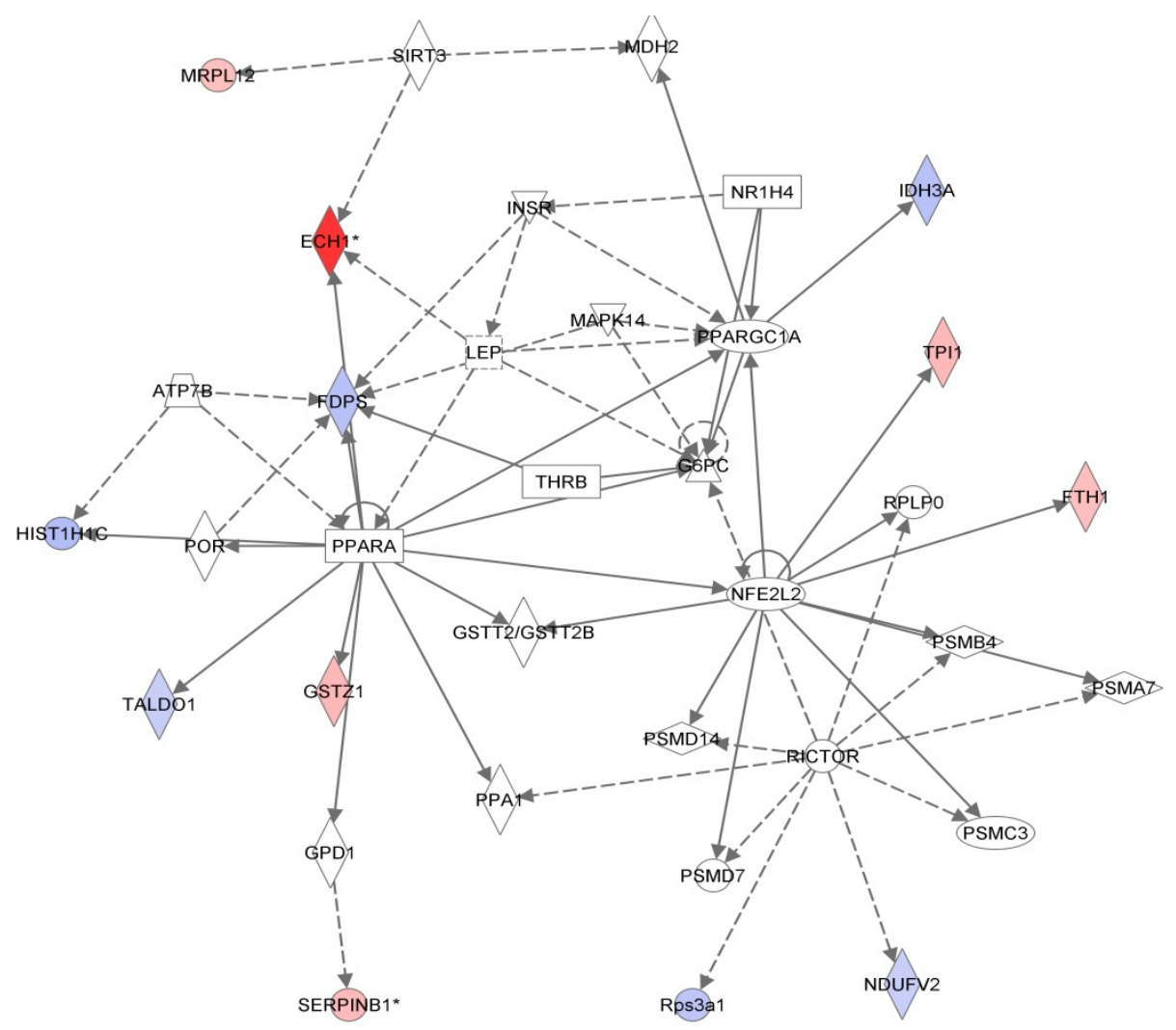

Fig. 14. IPA software Network 1 - Functional network analyzed by comparing the proteomics dataset of PrPC knockout mice liver and wild type (both genders and all age groups). The network was associated with gastrointestinal disease, hepatic system disease, liver steatosis (Detail, Index - Table 1)

\subsubsection{Triglyceride content:}

Triglyceride content was measured in the liver of PrPC knockout mice as compared to the wild type. We found significant up-regulation of triglyceride content $(\mathrm{mg} / \mathrm{dl})$ in 14 months old only which indicated the presence of fatty liver disease in the liver of aging PrPC knockout mice (Fig.15). 
A

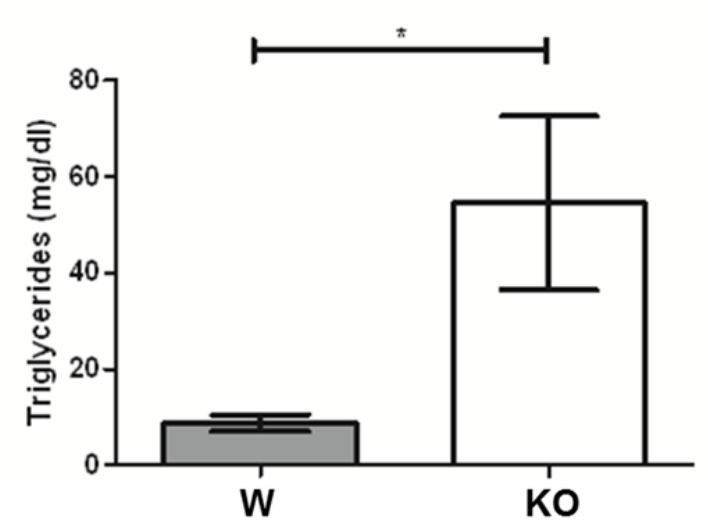

B

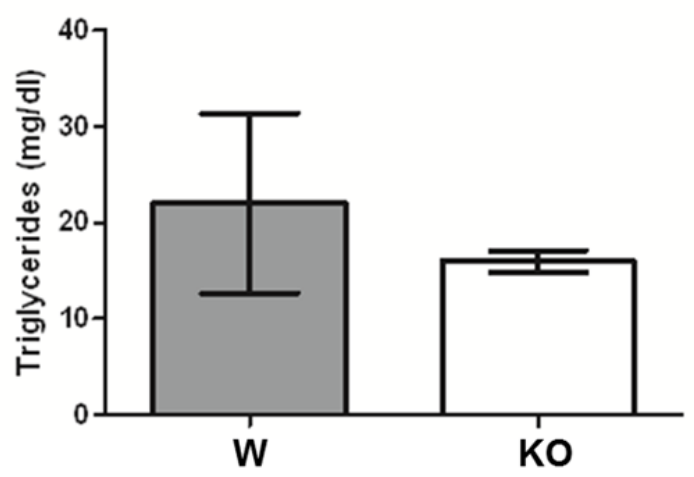

Fig. 15. Quantitative measurement of triglyceride content in the liver tissue: (A) Liver tissue of PrPC knockout mice (KO) showed significnatly higher amount of triglycerides content as compared to the wild type (W) at old age (14 months). (B) No significant differences in the triglycerides content was observed in the liver of PrPC knockout mice as compared to the wild type in 9 months old age group.

\subsubsection{Fat globules in PrPC knockout mice liver}

Further, we investigated the fat content by Sudan III staining in the liver of 14 months old mice. We detected fat globules in PrPC knockout mice liver, which confirmed the presence of liver steatosis in the liver of PrPC knockout mice (Fig.16). Notably, fat globules were almost negligible in the liver of male PrPC knockout mice while some fat rich specific cells (Fig.17) were present in both male and female PrPC knockout mice liver as compared to the wild type. It is evident that these specific fat laden cells could be hepatic stellate cells (HSCs) because HSCs are known to be rich in fat and it needs specific marker stainings for further confirmation.

\subsubsection{Liver pathology:}

Liver steatiosis could be associated with the increased cell death due to apoptosis and inflammation, which are the indicators of non-alcoholic steatohepatitis (NASH), an advanced stage of fatty liver disease (Wieckowska et al., 2006). First, we investigated, if there was any evidence of apoptosis in the liver of PrPC knockout as compared to the wild type. The imbalance of pro-apoptotic protein Bax and antiapoptotic protein $\mathrm{Bcl} 2$ has been reported to contribute to hepatocyte apoptosis during the pathogenesis of NASH (Wang et al., 2008). 

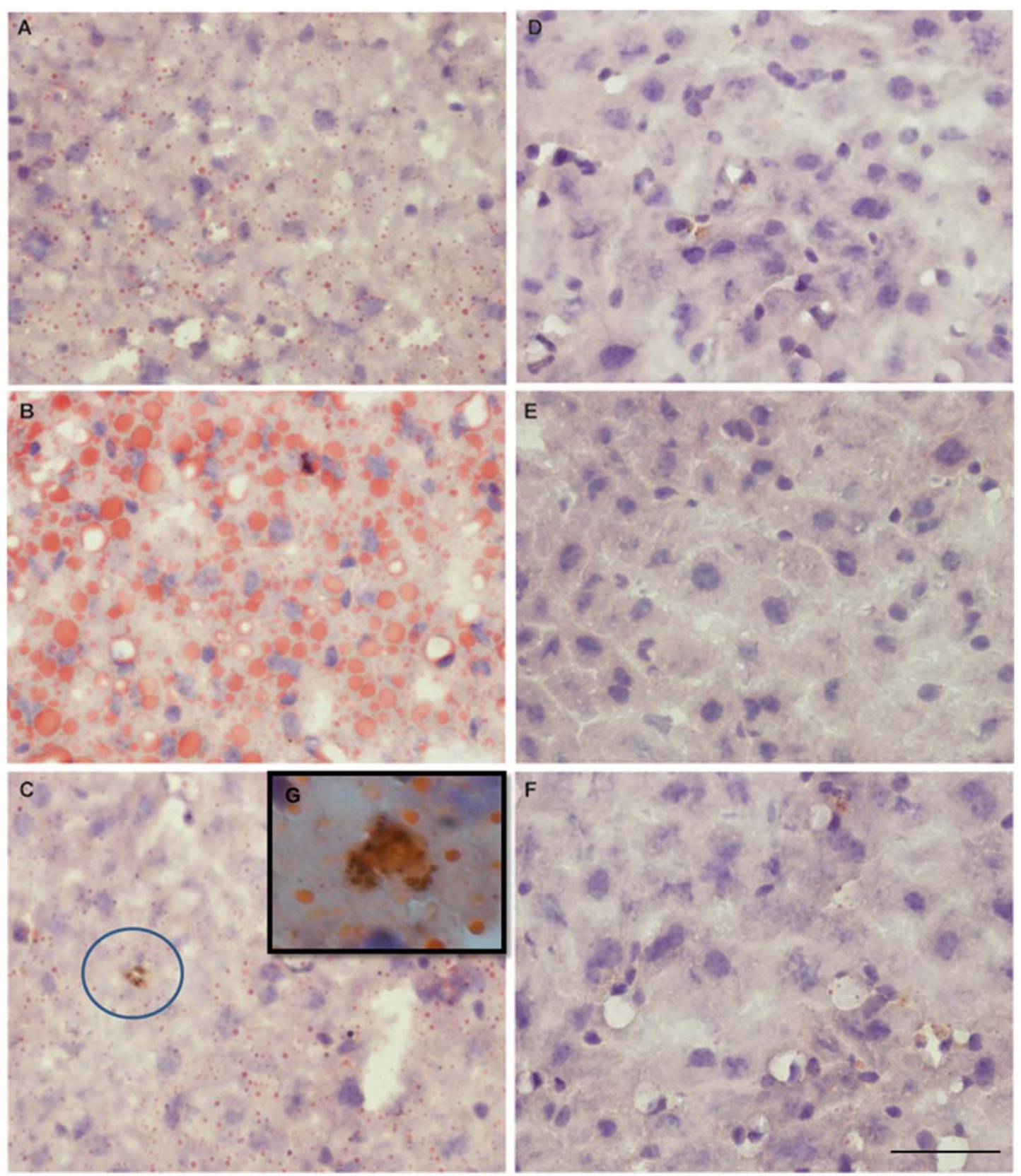

Fig. 17. Liver disease pathology (female): Liver tissue stained with Sudan III staining indicating a higher fat content in the liver of 14 months old PrPC knockout mice (A, B and C) as compared to the wild type mice (D, E and F), where no pathological phenotypes were observed. (G) indicating a magnified image of specfic fat rich cell. Nucleus was stained with hematoxylin. Scale bar $-20 \mu \mathrm{m}$ 

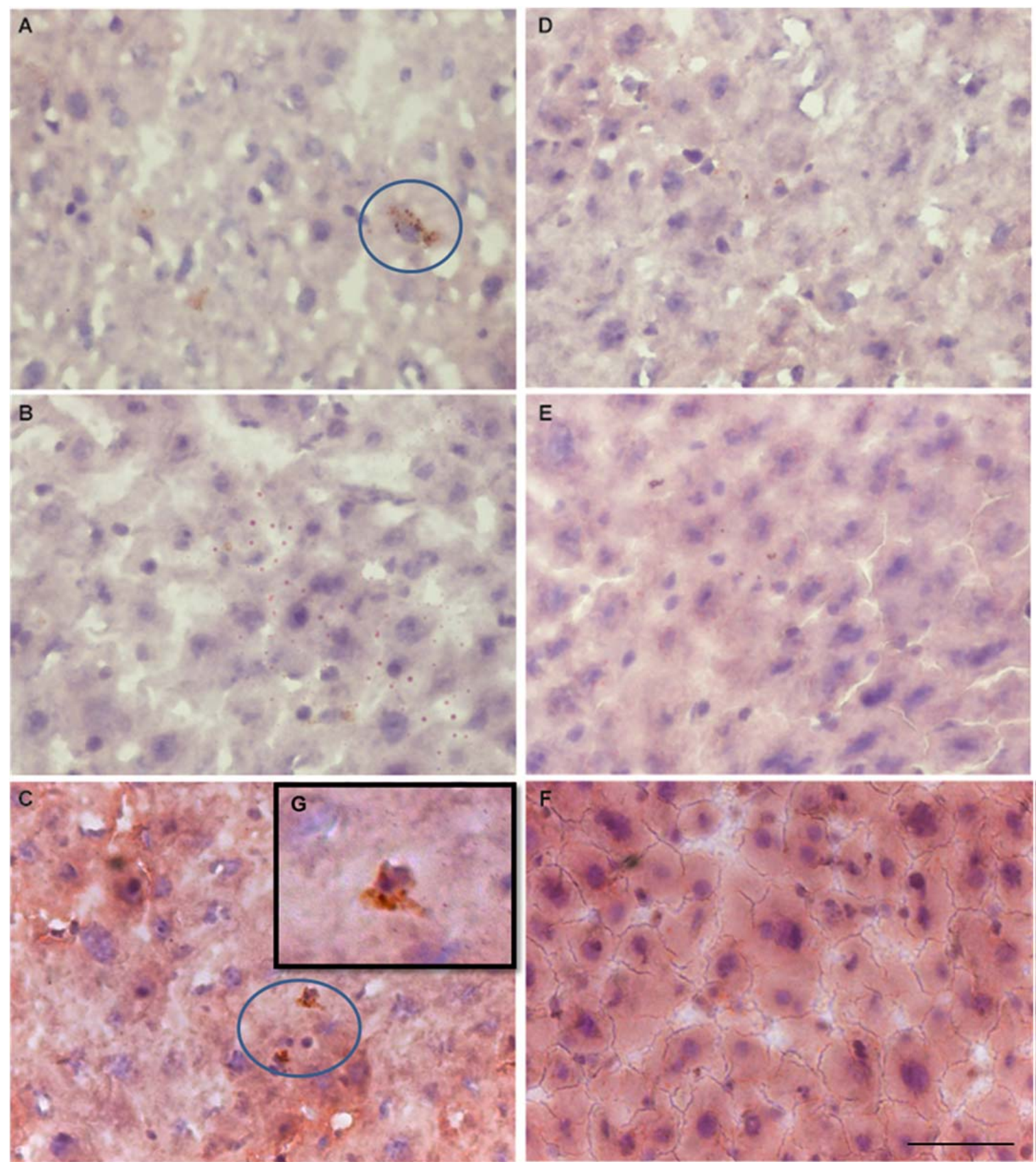

Fig. 17. Liver disease pathology (Male): Liver tissue stained with Sudan III staining indicating a higher fat content in the liver of 14 months old PrPC knockout mice (A, B and C) as compared to the wild type mice (D, E and F), where no pathological phenotypes were observed. (G) indicating a magnified image of specfic fat rich cell. Nucleus was stained with hematoxylin. Scale bar $-20 \mu \mathrm{m}$

Therefore, further we analyzed the expression of Bax and $\mathrm{Bcl} 2$ in the liver of PrPC knockout female mice by Western blot because severe fatty liver disease pathology was observed only in the female group. We observed an increased Bax to Bcl2 ratio (Fig.18A and 18B), which indicated that the liver steatosis might be associated with apoptosis in the liver of PrPC knockout female mice. It evidenced the presence of $\mathrm{NASH}$, an advanced stage of fatty liver disease. 
A

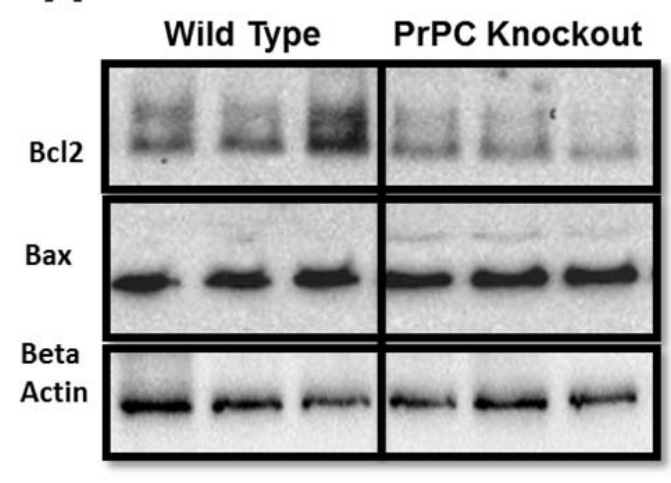

B

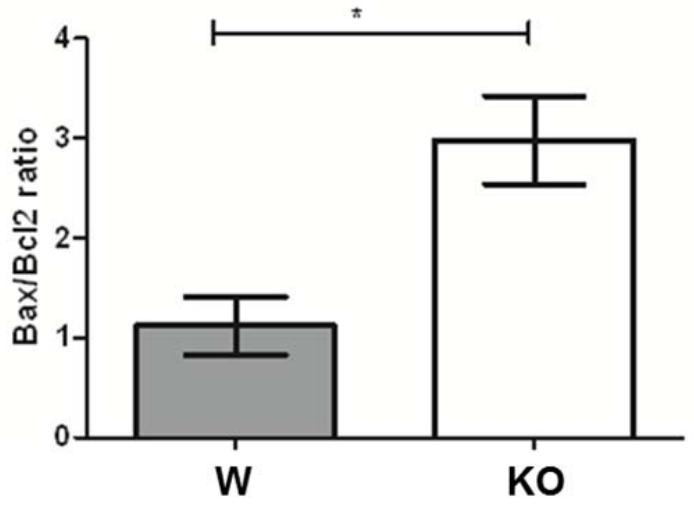

Fig. 18. Bax/Bcl2 protein expression in 14 months old female mice liver: (A); Western blot analysis shows the down-regulation of $\mathrm{Bcl} 2$ expression in the liver of PrPC knockout mice in comparison to the wild type mice, while the expression of Bax was not regulated in either groups. (B); Bar graph shows the significant up-regulation of $\mathrm{Bax}$ to $\mathrm{Bcl} 2$ ratio in the liver of PrPC knockout mice (KO) as compared to the wild type mice (W).

\subsubsection{IPA analysis (Brain as a reference tissue)}

As mentioned earlier, most of the PrPC functional studies with Zürich I model has been done in the brain only. Therefore, the networks linked with PrPC function were totally undiscovered in the liver. Hence, we decided to analyze the liver proteomics dataset by IPA software again but selected other tissues such as brain as well, which provided a better opportunity to get functional networks with broader literature information stored in IPKB. Results revealed the involvement of 8 different functional networks (Index - Table 4), which were linked to the cellular development, cell signaling, cellular growth and proliferation. Interestingly, the investigation of networks built with reference tissue as brain revealed the regulation of many proteins such as cytoskeleton associated microtubule associated protein tau (MAPT) which has been linked with alzheimer disease pathways. The relation of PrPC and tau function has already been described in the brain and also in the context of neurodegeneration. In addition, recent studies from our group using PrPC knockout mice, has described the role of PrPC in regulating the tau and ptau expressions in the different regions of brain (Schmitz et al., 2014). The previous proteomics and genomics reports in the brain of PrPC knockout mice has also linked PrPC functional networks with alzheimer disease pathways (Benvegnù et al., 2011). Our proteomics dataset also showed the down-regulation of cytoskeleton proteins like actin - cytoplasmic, actin - aortic smooth muscle (number 1 and 54, Table 3 ) in the liver of PrPC knockout mice. Further, as we showed liver steatosis in the liver of PrPC knockout mice and interestingly liver steatosis has also been reported to be associated with the 
increased expression and formation of cytoskeleton protein aggregates of keratins and tau (Zatloukal et al., 1995). Authers also suggested that disturbance of cytoskeleton may be linked to the accumulation of triglycerides due to defects in molecular transport.

Therefore, in order to understand the link between age related pathological outcome in liver and alteration of cytoskeleton function, we analyzed the tau protein functional regulation in the liver of PrPC knockout as compared to the wild type. We analyzed the expression of tau and its phosphorylated form (ptau-199) in 3, 9 and 14 months old group. Further, we analyzed enzymes expression levels which have already been described to be involved in regulating tau phosphorylation.

\subsubsection{Altered Tau/Ptau expression in mice liver by Western blot}

The expression of tau decreased with age and was comparatively low in the liver of 14 months old age mice as compared to 3 and 9 months in both PrPC knockout as well as wild type mice. In 14 months, tau expression was up regulated in the PrPC knockout mice compared to the wild type but results were not significant (Fig. 19A and 19B). As there were no significant differences between male and female groups in the tau expression, therefore we combined the densitometric quantifications (Fig.19B). The expression of ptau was increased significantly with the age and was found to be maximum in the old age in both male and female wild type mice liver. Further, in comparison to the wild type we found significant down-regulation of ptau expression in the liver of aging PrPC knockout mice as compared to the wild type mice (Fig. 19A and 19C). Although not significantly, expression of ptau in male appears to be lower than female in the liver of PrPC knockout mice and there was no such regulation in the wild type mice. 


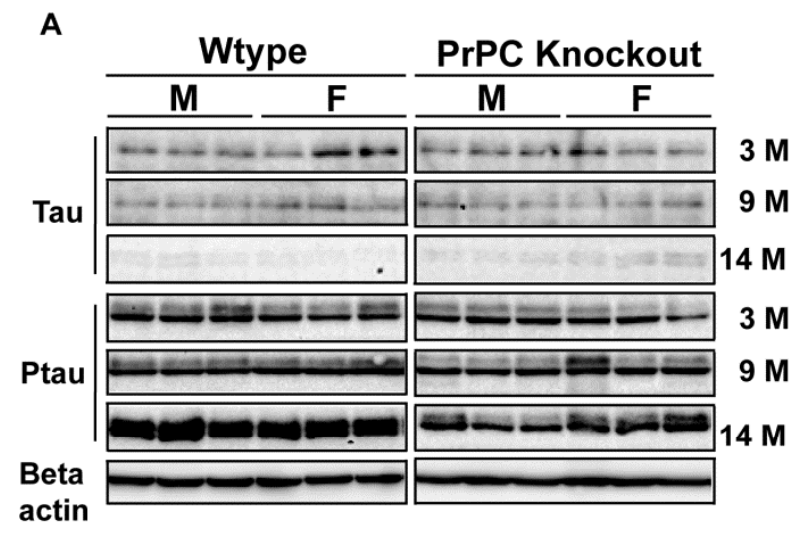

B

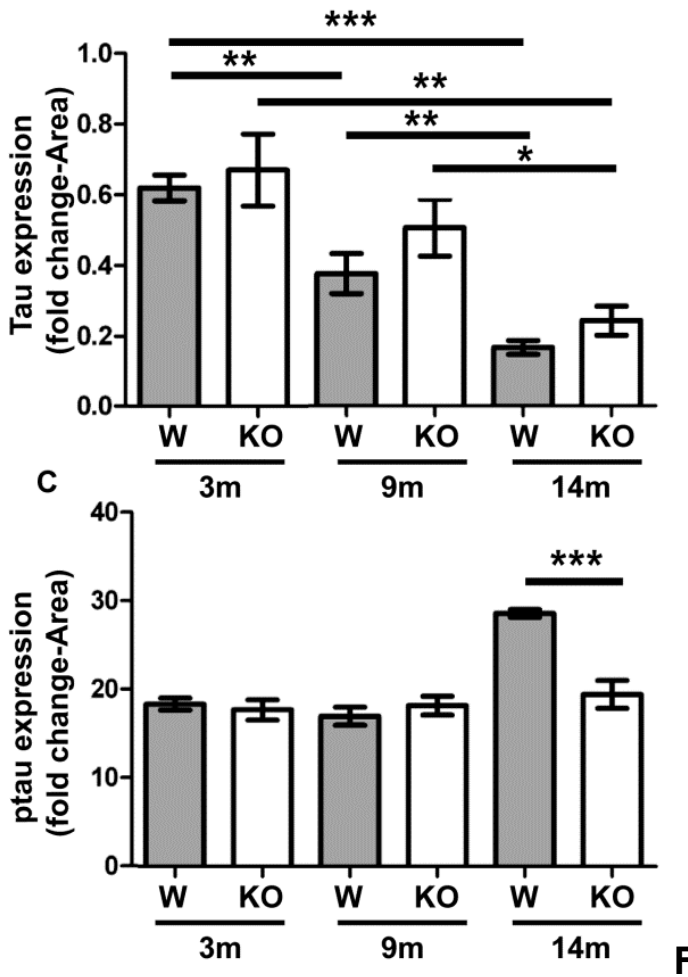

Fig.

19. Tau and Ptau expression: (A); Western blot analysis shows the expression of tau/ptau in the liver of 3,9 and 14 months old $(3 \mathrm{~m}, 9 \mathrm{~m}$ and $14 \mathrm{~m})$ male and female PrPC knockout mice (KO) as compared to wild type (W) mice. There was age dependent decrease of tau expression from 3 to 14 months old in both PrPC knockout and wild type mice liver. The expression of tau in the liver of 14 months old PrPC knockout was up-regulated as compared to the wild type, although results were not significant. The expression of ptau was significantly down-regulated in the liver of 14 months old PrPC knockout mice as compared to the wild type. (B) and (C); Densitometry quantification of tau/ptau expression bands show the significant fold change expressions of tau and ptau in the PrPC knockout mice liver as compared to the wild types group respectively.

\subsubsection{Altered Tau/Ptau expression in mice liver by immunofluorescence}

Further, we performed the immunofluorescence experiments to confirm the expressional regulation of tau/ptau. We found age dependent decrease of tau expression from 3 to 9 months in both wild type and PrPC knockout mice liver (Fig. $20 \mathrm{M}, 20 \mathrm{~N}, 200,20 \mathrm{P}$ ) while expression of tau is significantly up regulated in the liver of 14 months old PrPC knockout mice as compared to the wild type (Fig. 20R and 20Q). A similar trend has been observed in the Western blot experiments (Fig. 19A and 19B) but the results were not significant. So, the results from immunofluorescence has a similar expressional regulation as observed in Western blots. Further, there was down-regulation of ptau expression in the liver of PrPC 
knockout mice as compared to the wild type in 9 and 14 months old group (20I, 20J, $20 \mathrm{~K}, 20 \mathrm{~L}$ ) while there was not much differences in signal in 3 months (Fig. 20G and $20 \mathrm{H})$. Therefore, the results were correlated to the ptau expression in the 14 months old Western blot experiments (Fig. 19C).

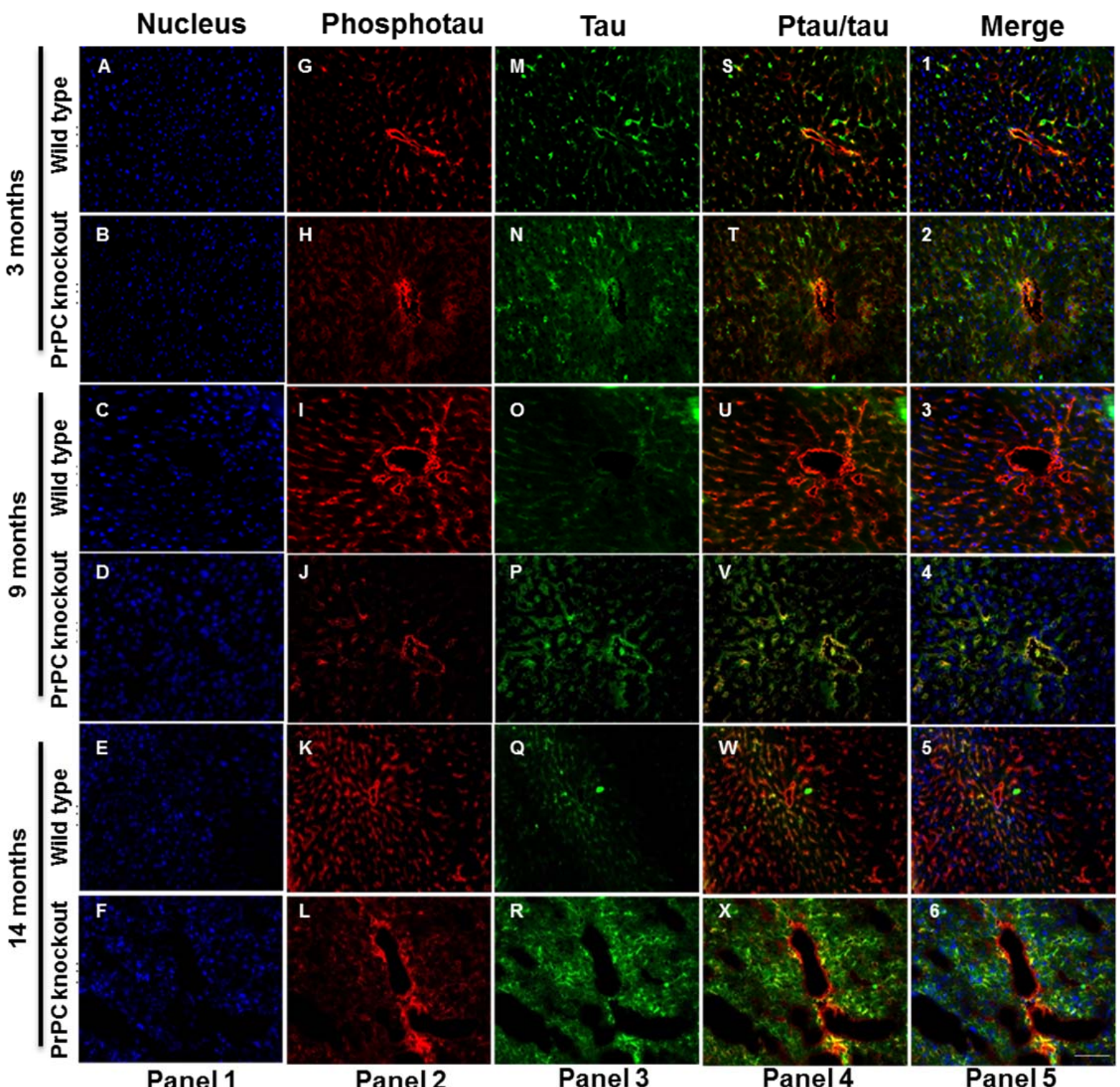

Fig. 20. Ptau/Tau expression in 3, 9 and 14 months old age mice: Panel 3 shows an age dependent decrease of tau expression from 3 to 9 months old in both PrPC knockout (N, P) and wild type mice liver (M, $\mathbf{O})$. The expression of tau in the liver of 14 months old PrPC knockout (R) was significantly up-regulated as compared to the wild type mice (Q). Panel 2 shows the expression of ptau in 3 (G), 9 (I) and 14 months old (K) wild type mice liver and PrPC knockout mice liver $(\mathbf{H}, \mathbf{J}$, and $\mathbf{L})$. The expression of ptau was significantly downregulated in the liver of 9 and 14 months old $\operatorname{PrPC}$ knockout mice $(\mathbf{J}, \mathbf{L})$ as compared to the wild type mice (I, K). Panel 4 shows the co-localization of Tau and ptau expression and nucleus was stained with DAPI (panel 1). 


\subsubsection{Cyclin dependent kinase 5 (CDK5)/p25 fragment expression by Western blot}

Cdk5 is known to catalyze the phosphorylation of tau protein. Its activation depends on its interaction with p25 fragment, so along with expression of Cdk5 itself, the expression p25 dictates the activation of Cdk5. We analyzed its expression levels in the 14 months group. We found an up-regulation of p25/Cdk5 in the liver of PrPC knockout female, but no regulation in the male group (Fig. 21).

A

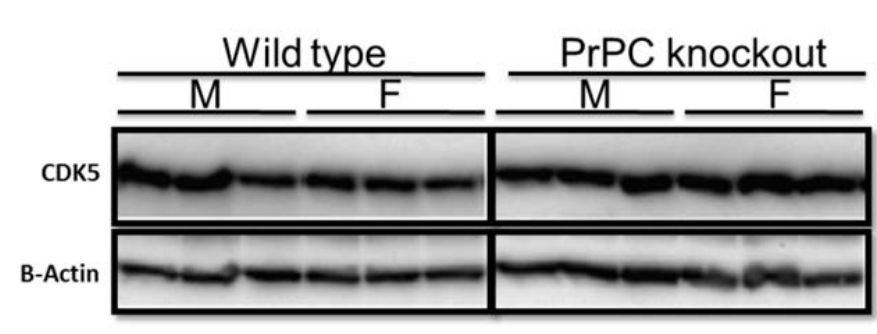

B

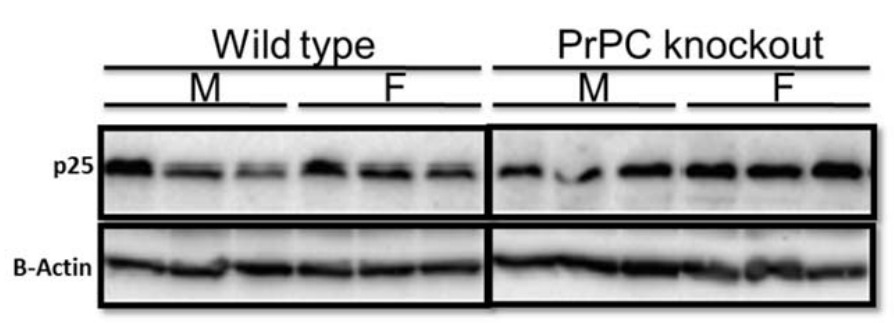

C

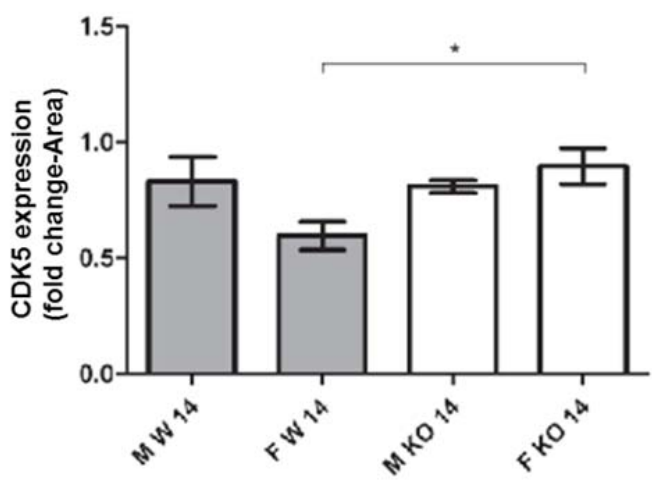

D

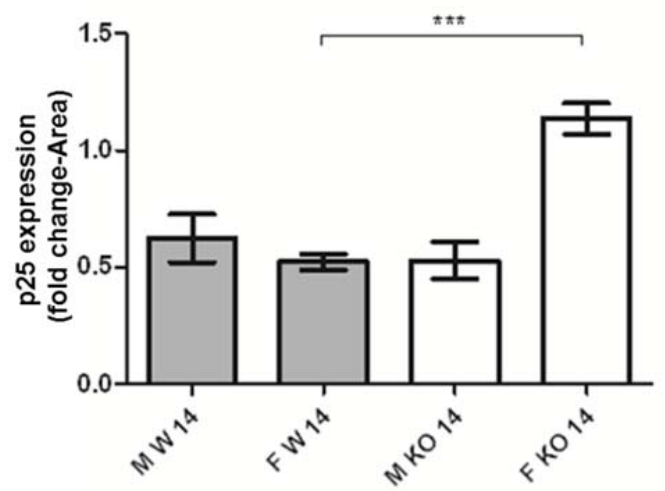

Fig. 21. Cdk5/p25 expression: (A) and (B); Western blot analysis shows the expression of Cdk5 and p25 in the liver of 14 months old PrPC knockout female (F KO) and male (M KO) mice as compared to the wild type female $(F W)$ and male mice $(F W)$ respectively. $(C)$ and (D); Densitometry quantification of Cdk5/p25 expression shows the significant up-regulation of p25 expression in the liver of female PrPC knockout mice (14 months old) compared to the wild type.

\subsubsection{Gsk3Beta/P-gsk3Beta expression by Western blot}

We further analyzed the enzyme expressional regulations of gsk3beta and its phosphorylated (active -Tyr216) form, pgsk3beta in the 14 months old group. The expression of gsk3beta was down-regulated in the liver of PrPC knockout male mice as compared to the wild type (Fig. 22A and 22C). Gsk3beta enzyme is known to be 
activated by the phosphorylation of Tyr216 residue. Therefore, the amounts of pgsk3beta (phosphorylation at Ty216) determines the activation of gsk3beta. Therefore, we further analyzed the expression of pgsk3beta (at Tyr216) by using pgsk3beta antibody which was specific for the phosphoTyr216 epitope. The expression of pgsk3beta was significantly down-regulated in the liver of aging PrPC knockout mice (14 months) as compared to the wild type mice (Fig. 22B and 22D). It showed that pgsk3beta might be involved in the regulation of tau phosphorylation, as we have observed the similar down-regulation of ptau expressions by Western blot as well as by immunofluorescence (Fig. 19C, 20L and 20K).

A

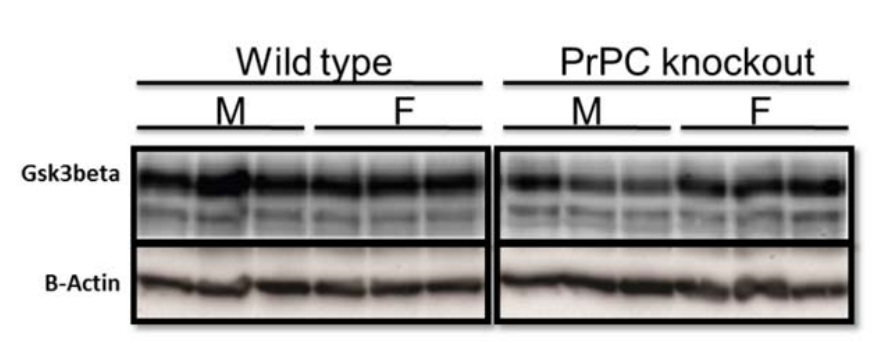

B

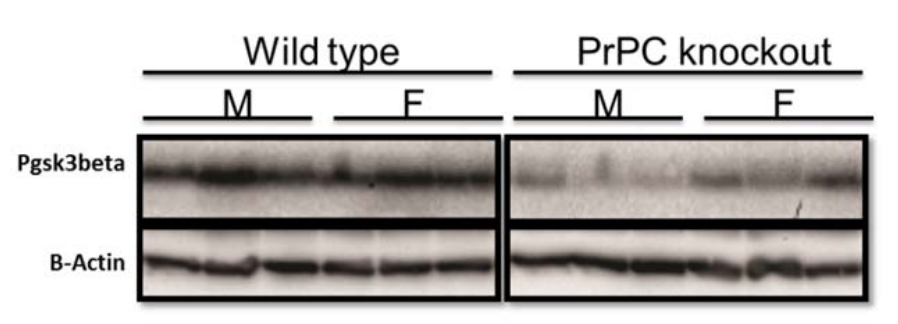

C

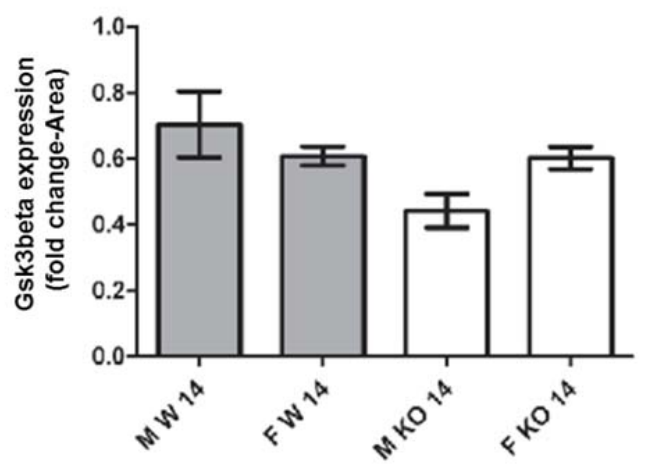

D

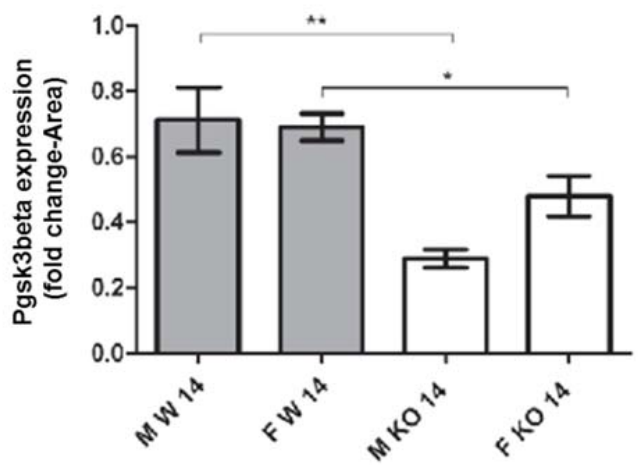

Fig. 22. Gsk3beta/p-gsk3beta expression: (A) and (B); Western blot analysis shows the expression of gsk3beta and p-gsk3beta in the liver of 14 months old PrPC knockout female ( $F \mathrm{KO}$ ) and male ( $\mathrm{M} \mathrm{KO}$ ) mice as compared to the wild type female $(F \mathrm{~W})$ and male mice ( $F$ W) respectively. (C) and (D); Densitometry quantification of gsk3beta/pgsk3beta expression shows the significant down-regulation of pgsk3beta in the liver of male and female PrPC knockout mice (14 months old) as compared to the wild type. 


\section{Discussion}

Liver is physiologically and functionally linked with all other organs of the body and is vital for the survival. Although few reports have been published to analyze the expression of PrPC in liver, but surprisingly, only two reports have been published till date to understand the role of PrPC in liver (Raeber et al., 1999, Ikeda et al., 1998). To characterize the function of PrPC in the liver, first challenge was to obtain the expressional profile of PrPC. As mentioned previously, the expression of PrPC in the liver has been reported to be very low, may be therefore all of the previous reports were based on embryonic, young and adult mice (Ford et al., 2002, Horiuchi et al., 1995; Moudjou et al., 2001; Peralta et al., 2012). Therefore, we tried to obtain the detailed expressional profile of PrPC from adult to aging, male and female wild type mice liver. To improve the detection of PrPC, we employed a highly sensitive method based on capillary electrophoresis (CE) along with the standard techniques. Furthermore, altered proteome associated with PrPC expressional regulation was uncovered by using 2D gel electrophoresis which was followed by bioinformatics software based functional analysis.

\subsection{PrPC expressional profile in liver}

The detection of PrPC by capillary electrophoresis (CE) immunoassay has already been demonstrated in the previous reports (Yang et al., 2005). Additional advancement of the method by the use of carboxymethyl- $\beta$-cyclodextrin (CM- $\beta-C D$ ) aided separation, PrPC specific FITC-peptide and PrPC specific rabbit Rb70 have provided further improvements to detect the subtle changes in PrPC expression. The sensitivity of the method $(1 \mathrm{pg})$ has already been reported to be much higher (approximately 10 fold) than the standard techniques such as Western blot.

Interestingly, the higher expression of $\mathrm{PrPC}$ in the old age compared to the young and adult age mice has already been described in the brain (Williams et al., 2004) as well as in the human peripheral blood leukocytes (Politopoulou et al., 2000). The reports have linked the higher expression of PrPC in the old age to increase in oxidative stress as a part of aging mechanism (Gasperini et al., 2014). Therefore, in order to understand the role of PrPC during aging in liver, it seems critical to measure its expressional profile from young adult to aging mice. We have shown the higher expression of PrPC in the 14 months old mice by Western blot. Further, the 
expression of PrPC was higher in the liver of female wild type mice as compared to the male. But we could not find any subtle differences in the adult (3 months) or advanced adult age ( 9 months) by using Western blot technique. Interestingly, by CIE we found similar gender dependent up-regulated expression of PrPC in the liver of 9 months old female wild type mice. Further, there was an age dependent regulation of PrPC expression in the liver of 14 months old wild type mice as compared to the 3 and 9 months. Furthermore, the PrPC expression at the transcriptional level showed a similar age and gender dependent expression of PrPC mRNA by qPCR.

The SCJD disease has been reported to occur in humans in the 7 th decade and its prevalence in women is higher than in males across the countries (Appleby et al., 2007). The link between the amount of PrPC and the susceptibility of the disease is not fully understood. There are some experiments that demonstrate that the incubation period of the disease might depend on the levels of PrPC in the peripheral tissues due to the fact that PrPC/PrPSc molecules may potentially be released into the extracellular environment (Fevrier et al., 2004, Molloy et. al., 2005). Hence, we hypothesized that the higher expression of PrPC during aging in brain and peripheral tissues such as liver along with the effect of gender might be important factors to dictate the susceptibility and incubation period of the disease.

Hence, with the help of CIE and Western blotting, we showed a higher expression of PrPC in the females and in addition, the significant up-regulation of PrPC in the aging wild type mice liver as compared to the 3 and 9 months. It could be associated with the role of PrPC during aging and oxidative stress. Therefore, the up-regulation of PrPC in the liver of aging wild type mice might be linked with the activation of hepatic stellate cells (HSCs) because the activation of HSCs has already been reported to be associated with the up-regulation of PrPC expression (Ikeda et al., 1998).

\subsection{Functional proteome analysis}

To understand the role of PrPC in liver in detail, we used 2D gel based proteomics approach. The proteins which were differentially regulated (Proteomics dataset) in the liver of PrPC knockout mice as compared to the wild type was classified by based on their functions (Index - Fig. 1). The clusters of proteins with highest percentage (24\%) belong to protein/Amino acid metabolism, followed by energy (17\%) and lipid metabolism (11\%), mRNA splicing/gene regulation (9\%) and cytoskeleton (9\%). 


\subsubsection{Protein/Amino acid metabolism}

This group constituted the highest percentage of total proteins (24\%). The protein/amino acid metabolism is a set of critically regulated biochemical reactions, which involve the synthesis and breakdown of protein/amino acids to maintain the constant turnover rate. Liver tissue is of central importance because large numbers of physiologically important proteins are synthesized in the liver and secreted into circulation. Among various proteins that have been found in this category, following were of particular interest in context of defining the PrPC function:

\subsubsection{3-hydroxyanthranilate 3, 4-dioxygenase (HAAO-3)}

This enzyme is the part of tryptophan metabolism which catalyzes the conversion of 3-hydroxyanthranilate into quinolinic acid (QUIN) from 3-hydroxyanthranilic acid. The quinolinic acid may serve as a precursor for $\mathrm{NAD}(+)$ and has also been described as a neurotoxic compound (Sahm et al., 2013). The reports have suggested that the secretion of quinolinic acid from liver into circulation might further be passed through blood brain barrier (Basile et al., 1995). Further, quinolinic acid mediated toxicity has also been described to be involved in the neurodegeneration (Sahm et al., 2013). In the differential proteome dataset (Table 3) of both male and female group, we have observed the up-regulation of HAAO-3 in the liver of PrPC knockout mice as compared to the wild type. The above evidences showed that the up-regulation of HAAO-3 consequently may cause the accumulation of toxic quinolinic acid in the liver. Further, it might be linked with its levels in the brain of PrPC knockout mice which still needs to be determined. In addition to its role in tryptophan metabolism, the regulation of HAAO-3 in PrPC knockout mice liver has highlighted a possible insight into role of PrPC in liver-brain functional axis in relevance to the prion diseases.

\subsubsection{Capthepsin Z}

Cysteine cathepsins are the group of lysosomal proteases, which degrade polypeptides with their specific mechanisms (Wiederanders et al., 2003). Cathepsin Z is a carboxypeptidase which has the specificity to a single catalytic site with cysteine thiol group (Guncar et al., 2000). The role of cathepsins in autocatalytic conversion of normal cellular PrPC into protease $\mathrm{K}$ resistant PrPSc in scrapie-infected Neuro2a cells has already been described (Zhang et al., 2003). Further, the up-regulation of various cathepsins subtypes including cathepsin $z$ have been reported in scrapie- 
infected mice brains (booth et al., 2004). However, we found 2.14 fold downregulation of cathepsin $z$ in the 3 months PrPC knockout mice liver as compared to the wild type. Although needs further investigations, however above evidences showed that PrPC might be involved in regulating the expression of cathepsins in mice liver, which could further be associated with the regulation of prion infection or its sporadic conversion into PrPSc.

\subsubsection{Bioenergetics/Glucose metabolism}

This group constituted $17 \%$ of the total proteins and is considered as an important group because all the cellular processes are linked with bioenergetics. The important proteins of this group included: NADH dehydrogenase [ubiquinone] flavoprotein 2, mitochondrial, transaldolase, L-xylulose reductase, isocitrate dehydrogenase [NAD] subunit alpha, mitochondrial, L-xylulose reductase, 39S ribosomal protein L12, mitochondrial, sorbitol dehydrogenase, alcohol dehydrogenase class-3 and malate dehydrogenase.

The key enzymes involved in bioenergetics are the components of NADH dehydrogenase [ubiquinone], isocitrate and malate dehydrogenase. All are the important mitochondrial enzyme components which have been associated with electron transport chain and citric acid cycle.

These enzyme components were found to be down regulated in the liver of PrPC knockout mice as compared to the wild type mice. In addition, there was downregulation of mitochondrial ribosomal protein $39 S$ ribosomal protein L12 protein. Interestingly, the alterations in the expression of mitochondrial proteins, DNA, RNA and lipid content due to increase in oxidative stress have already been described (Crawford et al., 1996, Fariss et al., 2005). Further, the down-regulation of mitochondrial RNA levels have been reported as a response mechanism in liver cells to protect against oxidative stress (Crawford et al., 1996). Moreover, the role of PrPC against oxidative stress has already been very well documented from the studies in neuronal tissue (Brown et al., 1999). The above evidences showed that PrPC might have an important role in modulating the mitochondrial activity in response to oxidative stress in liver. 


\subsubsection{Transaldolase}

It is a key enzyme of reversible non-oxidative branch of pentose phosphate pathway, which regulates the reduced state of glutathione (GSH) by regulating the NADPH levels. Prnp knock down based approach in human embryonic kidney (HEK), has reported the down-regulation of transaldolase expression (Ramljak et al., 2007). An additional report showed that the down-regulation of transaldolase in jurkat human $T$ cells resulted into reduced apoptosis and increased levels of glutathione (Banki et al., 1996). Further, a study performed in cirrhotic liver patients has reported the increased cell death due to the deficiency of transaldolase (Perl et al., 2007). In concordance with the previous reports, we have observed similar down-regulation of transaldolase in the liver of PrPC knockout male as compared to the wild type. It showed an important role of $\operatorname{PrPC}$ in maintaining the levels of glutathione and also regulating the apoptosis. The elucidation of detailed pathways involved, needs further investigation.

\subsubsection{Malate dehydrogenase (MDH)}

Malate dehydrogenase is an enzyme of citric acid cycle, which catalyzes the reversible conversion of malate into oxaloacetate. The regulation of $\mathrm{MDH}$ has critical biological significance because several catabolic pathways of macromolecules such as carbohydrates, lipids and proteins converge on the citric acid cycle (TCA) to produce ATP. A report has shown the down-regulation of MDH in the brain of SCJD patients (Xiang et al., 2005). Further, the proteomics dataset from our study also showed the down-regulation of malate dehydrogenase in the liver of 14 months old PrPC knockout female mice. It further supports that the loss of PrPC function due to its conversion into PrPSc in SCJD might be linked with the down-regulation of energy metabolism as a part of the disease mechanism.

\subsubsection{Lipid metabolism}

This group constituted the $11 \%$ of the total PrPC dependent regulated proteins. Proteins included in this group included:

\subsubsection{Farnesyl pyrophosphate synthase}

It is an important enzyme of lipid/steroid metabolism, which catalyzes the synthesis of farnesyl diphosphate (FPP) and latter acts a precursor for many metabolites including, dolichols, sterols, ubiquinones and carotenoids. In addition, the farnesyl 
diphosphate also acts as a substrate for farnesylation and geranylgeranylation of proteins. We have found the down-regulation of FPP synthase in the liver of 3 months PrPC knockout mice as compared to the wild type. This showed a role of PrPC in regulating the cholesterol levels. Recently, the depletion of cholesterol from the membrane lipid rafts has been demonstrated as a causative factor to the increased susceptibility of PrPC misfolding (Sarnataro et al., 2004). The downregulation of FPP synthase in the liver of PrPC knockout suggests that PrPC may regulate cholesterol synthesis and could be linked with the correct folding of the PrPC protein itself. In conclusion, according to the loss of function hypothesis, the conversion of PrPC into PrPSc might be linked with the cholesterol metabolism and modulating the further susceptibility of PrPC misfolding.

\subsubsection{Apolipoprotein A-I (ApoA-I)}

It is another protein linked with the cholesterol metabolism. 14 months old PrPC knockout mice liver has shown an up-regulation of ApoA-I (proteomics dataset). ApoA-I is required for the reverse transport of cholesterol from the body into the liver for excreting out of the body (Zhang et al., 2003). Therefore, the up-regulation of Apolipoprotein A1 in the PrPC knockout mice might be involved in cholesterol depletion or deficiency and as described earlier, which has been a crucial factor for the proper folding of PrPC within the lipid rafts.

Physiologically, liver critically regulates the cholesterol levels of all other organs. PrPC seems to possess physiological importance by regulating the enzymes and transport proteins of cholesterol metabolism in the liver.

\subsubsection{Delta(3,5)-Delta(2,4)-dienoyl-CoA isomerase(DI)}

It is an enzyme of beta-oxidation of fatty acids, which catalyzes the isomerization of 3-trans,5-cis-dienoyl-CoA to 2-trans,4-trans-dienoyl-CoA. Proteomics dataset has shown the up-regulation of $\mathrm{DI}$ in all three age groups of PrPC knockout male mice liver. Therefore, the up-regulation of DI may trigger higher FFAs beta oxidation and subsequently, the increased generation of reactive oxygen species (ROS) in the liver diseases such as NASH (Sanyal et al., 2001). The up-regulation of DI indicated that the liver of PrPC knockout mice might have higher oxidative stress due to the increased beta oxidation of fatty acids. It showed an antioxidant role of PrPC in the liver, which has been in correlation with the previous discussion. 


\subsection{7 mRNA splicing/gene regulation}

We have obtained a cluster of proteins ( $9 \%$ of the dataset), which are the components for mRNA splicing and all proteins were regulated in the male group. Proteins were down regulated in the liver of PrPC knockout mice compared to the wild type which revealed an important function of PrPC in regulating the gene expression at transcriptional level. Proteins classified to this group were: Serinethreonine kinase receptor-associated protein, U5 small nuclear ribonucleoprotein 200 $\mathrm{kDa}$ helicase and Pre-mRNA-processing-splicing factor 8, a U5 small nuclear ribonucleoprotein component.

\subsubsection{Serine-threonine kinase receptor-associated protein (STRAP)}

It is ubiquitously expressed in all the mouse tissues with the highest expression in the liver and testes but it is less abundant in the spleen (Kashikar et al., 2012). It has been involved in TFG- $\beta$ signaling, mRNA transport, PDK signaling and U SnRNA assembly. We have found the down-regulation of STRAP in the liver of 3 months old PrPC knockout male mice. Although, the implication of STRAP in diverse functions reflects a role of PrPC in the cell proliferation, gene regulation and PKB/AKT signaling but the elucidation of the detailed mechanisms needs further investigation.

\subsubsection{U5 small nuclear ribonucleoprotein $200 \mathrm{kDa}$ helicase}

It is an enzyme associated with the tri-snRNP RNA helicase that plays a role in the pre-mRNA splicing as a component of U5 snRNP and U4/U6-U5 tri-snRNP complexes. One study described that the dominant negative and the transient expression of this gene in the mammalian cell causes defects in the cell cycle (Ehsani et al., 2013). We have observed the down-regulation of this protein in the liver of 14 months old PrPC knockout male as compared to the wild type. Hence, PrPC appears to be involved in the cell cycle and the cell proliferative pathways.

\subsubsection{Pre-mRNA-processing-splicing factor 8}

Pre-mRNA-processing-splicing factor 8 is known for its role in ordering the assemblies of spliceosomal proteins and snRNAs. The mutation of Prpf8 factor affects the splicing, cell survival and myeloid differentiation (Keightley et al., 2013). We have found the down-regulation of Prpf8 in the 14 months old PrPC knockout male mice as compared to the wild type. 


\subsubsection{4 $116 \mathrm{kDa}$ U5 small nuclear ribonucleoprotein component}

It is another component of U5 snRNP and U4/U6-U5 tri-snRNP complexes. It has been observed to be down-regulated in the liver of 14 months old PrPC knockout male in comparison to the wild type.

In conclusion, we have found a cluster of proteins which are associated with mRNA splicing and found to be down-regulated in the liver of PrPC knockout mice liver as compared to the wild type. The defects associated with the mutations of these splicing gene components have been linked with the cell cycle and proliferation. The above evidences indicated that aging PrPC knockout mice liver might have altered regulation of liver cell proliferative pathways which could be in response to the liver injury that we have reported in the same 14 months PrPC knockout group due to liver steatosis. It might also directly be linked the function of PrPC, because the role of PrPC in cell growth and proliferation is already known (llorenz et al., 2013). Therefore, the above evidences showed that PrPC play an important role in cell proliferation in the aging mice liver. To understand the pathways involved needs further investigations.

\subsubsection{Structural/Cytoskeleton}

This group constitutes the $9 \%$ of the total PrPC dependent regulated proteins. The selected proteins in this group include:

\subsubsection{Annexin 5 (Anxa V)}

Annexin 5 belongs to the family of calcium-dependent phospholipid binding proteins. Although the precise function of this protein is unknown, but it is believed to inhibit the phospholipase $A 2$ and protein kinase $C$ enzyme activities, calcium channel activity, involved in inflammation, cellular signal transduction and differentiation (Hammill et al., 1999, Reutelingsperger et al., 1997). It has been demonstrated that the overexpression of PrPC in the HEK293 cells results into the up-regulation of Anxa $\checkmark$ (Ramljak et al., 2007) and another study based on gene expression profiling showed its up-regulation in frontal cortex of sporadic CJD patients (Xiang et al., 2005). In liver, its role has been illustrated against ischemia and reperfusion injury following the rat liver transplantation (Shen et al., 2007). We have shown the downregulation of annexin 5 in the liver of 3 months old PrPC knockout female mice. This 
outcome suggested that PrPC might be regulating the annexin $\mathrm{V}$ levels against the cell injury during the pathophysiological conditions.

\subsubsection{Annexin A4 and calponin 3}

Similar to annexin 5 , annexin A4 and calponin 3 are also calcium binding proteins associated with the cytoskeleton, which were down-regulated in the liver of 3 months old PrPC knockout mice as compared to the wild type. One study based on gene microarray in ME7 and RML mouse strain of prion has shown the up-regulation of annexin A4 and calponin 3 (Xiang et al., 2004). It showed a role of PrPC in regulating the cytoarchitecture of the cell and loss of its function might be linked with disease phenotype.

\subsubsection{Cell proliferation}

\subsubsection{Putative hydrolase RBBP9}

Putative hydrolase has been reported to be involved in the proliferation of tumor cells by suppressing the TGF- $\beta$ mediated anti-proliferative signaling (Shields et al., 2009). We showed a down-regulation of RBBP9 protein in the liver of 14 months old PrPC knockout female mice. It showed that PrPC might be involved in the cell proliferation signaling during aging liver. As we have also observed fatty liver disease in the 14 months old PrPC knockout female mice. It could further be relevant in terms of its role during the fatty liver disease because the fatty liver disease has also been linked to the cell proliferation signaling (Sydor et al., 2013). The increased mitochondrial oxidation and the esterification of excessive FFA provide substrates and signaling for the cell proliferation. The above evidences suggests that the down-regulation of RBBP9 in the liver of 14 months old PrPC knockout female mice might have been involved in stimulating the cell proliferation by the activation of TGF- $\beta$ signaling, which might be the part of response mechanism to the reported liver injury due to fatty liver disease. The understanding of the detailed regulated signaling linked with cell proliferative pathways needs further in detailed investigations.

\subsubsection{P27/cyclin dependent kinase inhibitor 1B}

$\mathrm{P} 27 /$ cyclin dependent kinase inhibitor $1 \mathrm{~B}$ is a cell cycle inhibitor, which negatively regulates the progression of $\mathrm{G} 1$ cell cycle phase by suppressing the cyclin dependent kinase (CDK) activity (Coats et al., 1996; Soos et al., 1996, Toyoshima et al., 1994, Chu et al., 2008). The expression of P27 upreglates during Go phase and 
declines when cells enter the cell cycle (Poon et al., 1995; Agrawal et al., 1996; Polyak et al., 1994). We have observed the up-regulation of P27/cyclin dependent kinase inhibitor 1B in the liver of 9 months old PrPC knockout female as compared to the wild type. In support of previous evidences, it has further been suggested that PrPC seems to be involved in the cell proliferative pathways.

\subsection{Fatty liver disease}

Liver steatosis is also known as fatty liver disease (FLD) and caused by the abnormal deposition of lipids within the liver cells. It is pathologicaly recognized by the large vacuoles of triglycerides deposition within the liver cells. Liver steatosis can be caused by the intra- as well as extrahepatic mechanisms (Boer et al., 2003). The deposition of the higher fat in the liver of PrPC knockout mice showed the involvement of PrPC in regulating the lipid metabolism such as the enhanced release of non-esterified fatty acids from adipose tissue (lipolysis), increased de novo fatty acid synthesis (lipogenesis) or decreased beta-oxidation of fatty acids (Boer et al., 2003).

The information regarding the role of PrPC in liver diseases was predicted by IPA software analysis of proteomics dataset. The detailed chart (Table -4$)$ of functional network 1 (gastroinestinal disease, hepatic system disease and liver steatosis) showed the involvement of various protein clusters in the liver disease pathology. Notably, the protein called glutathione-S-transferase zeta 1 (or Maleylacetoacetate isomerase) has been predicted to be involved in hepatic steatosis as well as change in morphological features of liver tissue as observed in the Sudan III staining. Contradictorily, GSTZ1 has been found to be upregulated in 9 months PrPC knockout mice liver while the disease pathology has been observed in the 14 months. This indicated that the up-regulation of GSTZ1, only in 9 months could be protective against steatosis because the deficiency (but not up-regulation) of GSTZ1 has been reported to be involved in the liver steatosis (Lim CE et al., 2004). As we have observed no regulation of GSTZ1 in the liver of 14 months old mice, which might be one of the factor that liver steatosis has been observed only in the liver of 14 months old PrPC knockout mice. Other than GSTZ1, several markers of liver steatosis have been found in 14 months old female mice liver as well, which are discussed in detail in section (5.3.3). 
As a confirmatory finding, the higher levels of triglycerides in the liver of 14 months old PrPC knockout mice have been observed by the biochemical test. IPA analysis has predicted the 12 protein molecules (Table 4 - Column 6) in the network linked with the excessive deposition of triglycerides including glucose-6-phosphotase, Peroxisome proliferator-activated receptor alpha (PPAR $\alpha$ ), Acetyl-CoA acetyltransferase1, Insulin receptor and leptin. Out of 12 proteins, PPARa is of particular importance (Fig. 23A) because it is a transcriptional factor which regulates the various enzymes of lipogenesis as well as beta oxidation of free fatty acids (FFAs) (Kersten et al., 2000).

The understanding of the exact mechanisms which lead to the deposition of triglycerides in the liver of PrPC knockout mice needs further investigation.

Table - 4: Enzymes/proteins involved in liver steatosis (predicted by IPA software analysis)

\begin{tabular}{|c|c|c|c|c|c|}
\hline & Categories & $\begin{array}{l}\text { Diseases or } \\
\text { Functional } \\
\text { Annotations }\end{array}$ & $P$-value & Molecules & Number \\
\hline 1 & $\begin{array}{l}\text { Lipid Metabolism, } \\
\text { Molecular } \\
\text { Transport, Small } \\
\text { Molecule } \\
\text { Biochemistry }\end{array}$ & $\begin{array}{l}\text { Concentration } \\
\text { of cholesterol }\end{array}$ & $3,13 E-13$ & $\begin{array}{l}\text { ACAT1,ATP7B,CYP7A1,G6 } \\
\text { PC,INSR,LDLR,LEP,LPL,NR } \\
1 \mathrm{H} 3, N R 1 H 4, P O R, P P A R \alpha, S \\
\text { IRT3,THRB }\end{array}$ & 14 \\
\hline 2 & $\begin{array}{l}\text { Gastrointestinal } \\
\text { Disease, Hepatic } \\
\text { System Disease, } \\
\text { Liver Steatosis }\end{array}$ & $\begin{array}{l}\text { Hepatic } \\
\text { steatosis }\end{array}$ & $1,42 \mathrm{E}-12$ & $\begin{array}{l}\text { G6PC,GPD1,GSTZ1,INSR,L } \\
\text { DLR,LEP,LPL,NR1H3,NR1H } \\
\text { 4,POR,PPAR } \boldsymbol{\alpha}, \text { PPARGC1A, } \\
\text { SIRT3 }\end{array}$ & 13 \\
\hline 3 & $\begin{array}{l}\text { Lipid Metabolism, } \\
\text { Small Molecule } \\
\text { Biochemistry, } \\
\text { Vitamin and } \\
\text { Mineral } \\
\text { Metabolism }\end{array}$ & $\begin{array}{l}\text { Synthesis of } \\
\text { bile acid }\end{array}$ & $5,24 \mathrm{E}-12$ & $\begin{array}{l}\text { CYP7A1,LDLR,NR1H3,NR1 } \\
\text { H4,POR,PPAR } \boldsymbol{\alpha}, \text { PPARGC1 } \\
\text { A }\end{array}$ & 7 \\
\hline 4 & $\begin{array}{l}\text { Digestive System } \\
\text { Development and } \\
\text { Function, Hepatic } \\
\text { System } \\
\text { Development and } \\
\text { Function, Organ } \\
\text { Morphology }\end{array}$ & Mass of liver & $6,66 \mathrm{E}-12$ & $\begin{array}{l}\text { G6PC,GSTZ1,LDLR,LEP,NF } \\
\text { E2L2,NR1H3,NR1H4,POR, } \\
\text { PPAR } \boldsymbol{\alpha}, T H R B\end{array}$ & 10 \\
\hline
\end{tabular}




\begin{tabular}{|c|c|c|c|c|c|}
\hline 5 & $\begin{array}{l}\text { Lipid Metabolism, } \\
\text { Molecular } \\
\text { Transport, Small } \\
\text { Molecule } \\
\text { Biochemistry }\end{array}$ & $\begin{array}{l}\text { Accumulation } \\
\text { of lipid }\end{array}$ & $1,13 \mathrm{E}-11$ & $\begin{array}{l}\text { ACAT1,CYP7A1,INSR,LDLR } \\
\text {,LEP,LPL,MAPK14,NFE2L2, } \\
\text { NR1H3,NR1H4,PPAR } \alpha, P P \\
\text { ARGC1A,THRB }\end{array}$ & 13 \\
\hline 6 & $\begin{array}{l}\text { Lipid Metabolism, } \\
\text { Molecular } \\
\text { Transport, Small } \\
\text { Molecule } \\
\text { Biochemistry }\end{array}$ & $\begin{array}{l}\text { Concentration } \\
\text { of } \\
\text { triacylglycerol }\end{array}$ & $2,01 \mathrm{E}-10$ & $\begin{array}{l}\text { G6PC,INSR,LDLR,LEP,LPL, } \\
\text { NR1H3,NR1H4,POR,PPAR } \\
\boldsymbol{\alpha}, \text { PPARGC1A,SIRT3,THRB }\end{array}$ & 12 \\
\hline
\end{tabular}

\subsubsection{Pathology associated with liver steatosis}

Fatty liver disease has been classified into two main categories: alcoholic (ALD) and non-alcoholic liver disease (NALD), as no alcohol treatment dose was given, so fatty liver disease in this study is NALD. NALD is associated with the multiple pathological outcomes ranging from the simple steatosis, nonalcoholic steatohepatitis (NASH), fibrosis to liver cirrhosis (Wieckowska et al., 2006).

Severity of the disease depends on the extent of liver injury such as the involvement of cell death due to apoptosis, formation of cytoskeleton protein aggregates called Mallory bodies (MD). The formation of MB indicates the progression of the disease into the second NASH stage from the simple NALD (Feldstein et al., 2003). Further, the increased formation of fibrous scar tissue around the liver cells and the blood vessels causes fibrosis and the final advanced stage is called cirrhosis, which is marked by the shrinkage of the liver, when tissue becomes lumpsy.

Sudan III staining has shown the dense fat globules in the liver of 14 months old PrPC knockout mice, which is a typical feature of liver steatosis. In addition, the density of hepatocytes has been observed less and more spaces in the liver of PrPC knockout mice as compared to the wild type. The decrease in the number of hepatocytes in the steatotic liver of PrPC knockout mice could be because of increased cell death due to apoptosis. To confirm the progression of the disease, we further analyzed the expressional regulation of apoptotic markers. Apoptosis can be caused by the extrinsic or death receptor pathway and the intrinsic or mitochondrial pathway. The induction of apoptosis in the fatty liver disease, activated by the 
production of ROS due to increased oxidation of free fatty acids is already known (Wang et al., 2014).

In liver steatosis, increased de novo fatty acid synthesis or uptake of free fatty acids (FFAs) by liver from the adipose tissues triggers the synthesis of triglycerides and subsequently, the excessive amounts of fatty acids enter into the mitochondria for beta oxidation (Gusdon et al., 2014). The increased rate of free fatty acids (FFAs) mitochondrial beta-oxidation during liver steatosis has already been described (Lazarin et al., 2011). It leads to the increased transport of the substrates (i.e $\mathrm{NADH} /$ acetyl CoA) to electron transport chain (ETC) and subsequently, results into the higher production of reactive oxygen species (ROS), which may further cause ETC dysfunction. Interestingly, we have found the up-regulation of mitochondrial enzyme called Delta(3,5)-Delta(2,4)-dienoyl-CoA isomerase (DI) in the liver of 14 months old PrPC knockout mice. DI is involved in the beta oxidation of free fatty acids. Additionally, the dysfunction of ETC is indicated by the down-regulation of TCA enzymes which were discussed in the section 5.2.2. The current evidences suggest that there has been higher production of ROS in the liver of 14 months old PrPC knockout mice due to increased fatty acid oxidation.

The role of ROS in regulating the levels of anti-apoptotic protein bcl2 due to increased oxidative stress is very well known (Hildeman et. al., 2003). Bax and Bcl-2 are anti- and pro-apoptotic members, respectively of the bcl-2 family (Gross et al., 1999). Additionally, it has been reported that Bax to $\mathrm{Bcl}-2$ ratio increases during the fatty liver disease progression due to apoptosis (Walsh et al., 2004). We have shown the down-regulation of bcl-2 protein in the liver of 14 months old PrPC knockout mice as compared to the wild type by Western blot. There was no significant regulation of Bax protein in PrPC knockout mice liver as compared to wild type. Hence, increase in Bax to Bcl-2 ratio in the PrPC knockout mice liver confirmed the involvement of apoptosis in liver injury associated with the NALD. Thus, it is evident that liver steatosis might have been progressed into NASH. Interestingly, the up-regulation of bcl2 expression in the brain of PrPC knockout mice has already been described (Brown et al., 2002), which evidenced that the down-regulation of bcl2 specifically in liver could be a secondary effect due to liver steatosis. 


\subsubsection{Change in cytoskeleton function in liver disease}

As discussed previously that the progression of liver steatosis into NASH is marked by the apoptosis and formation of cytoskeleton aggregates called Mallory bodies. Mallory bodies contain the de-regulated cytoskeleton proteins like keratin and tau. The up-regulation of tau protein in the liver steatosis with marked presence of Mallory bodies has already been reported (Zatloukal et al., 1995). We have also shown the up-regulation of tau in the liver of 14 months old PrPC knockout female mice as compared to the wild type by Western blot and immunofluorescence, the evidence which supported the progression of NALD. Further, $\alpha$-smooth muscle actin is known as an early marker of hepatic stellate cell activation that plays a role in the induction of fibrosis and which could be associated with the progression of liver steatosis (Washington et al., 2000, Macdonald et al., 2001, Nouchi et al., 1991). Our proteomics dataset has shown 4.96 fold up-regulation of the alpha smooth muscle actin in the liver of 14 months old PrPC knockout female mice as compared to the wild type. The up-regulation of tau protein and alpha smooth muscle actin in the PrPC knockout mice showed that the liver steatosis might have been progressed with the advanced cytoskeleton pathology like Mallory body's formation and liver fibrosis (Fig. 23D).

\subsubsection{Markers of liver steatosis (Proteomics dataset)}

\subsubsection{Sorbitol dehydrogenase (SDH)}

Sorbitol dehydrogenase is an enzyme of carbohydrate metabolism. It catalyzes the conversion of sorbitol into fructose. We have observed the up-regulation of SDH in the liver of 14 months old PrPC knockout mice as compared to the wild type from our proteomics dataset. The higher expression of SDH may increase the synthesis of fructose. Interestingly, the reports based on high fed fructose mice have shown the induction of liver steatosis by the activation of PPARa (Chan et al., 2012, Zhang et al., 2008). Notably, PPARa is an important transcriptional factor (also predicted by IPA software analysis - Table 4) which has been known to regulate the expression of many enzymes involved in lipid metabolism (Kersten et al., 2000). Additionally, the up-regulation of $\mathrm{SDH}$ has also been associated with the liver disease pathology (Gröhn et. al., 2010). Therefore, it has been evidenced that the up-regulation of SDH might be linked with the increased de novo synthesis of fatty acids by the activation of PPARa (Fig. 23A and 23E). 


\subsubsection{Amine sulfotransferase (SULT1A3)}

Amine sulfotransferases have been known to catalyze the sulfonation of xenobiotics such as dopamine, norepinephrine, catechols, monocyclic phenols and aromatic molecules and also regulate the hormonal levels (Jancova et al., 2010).

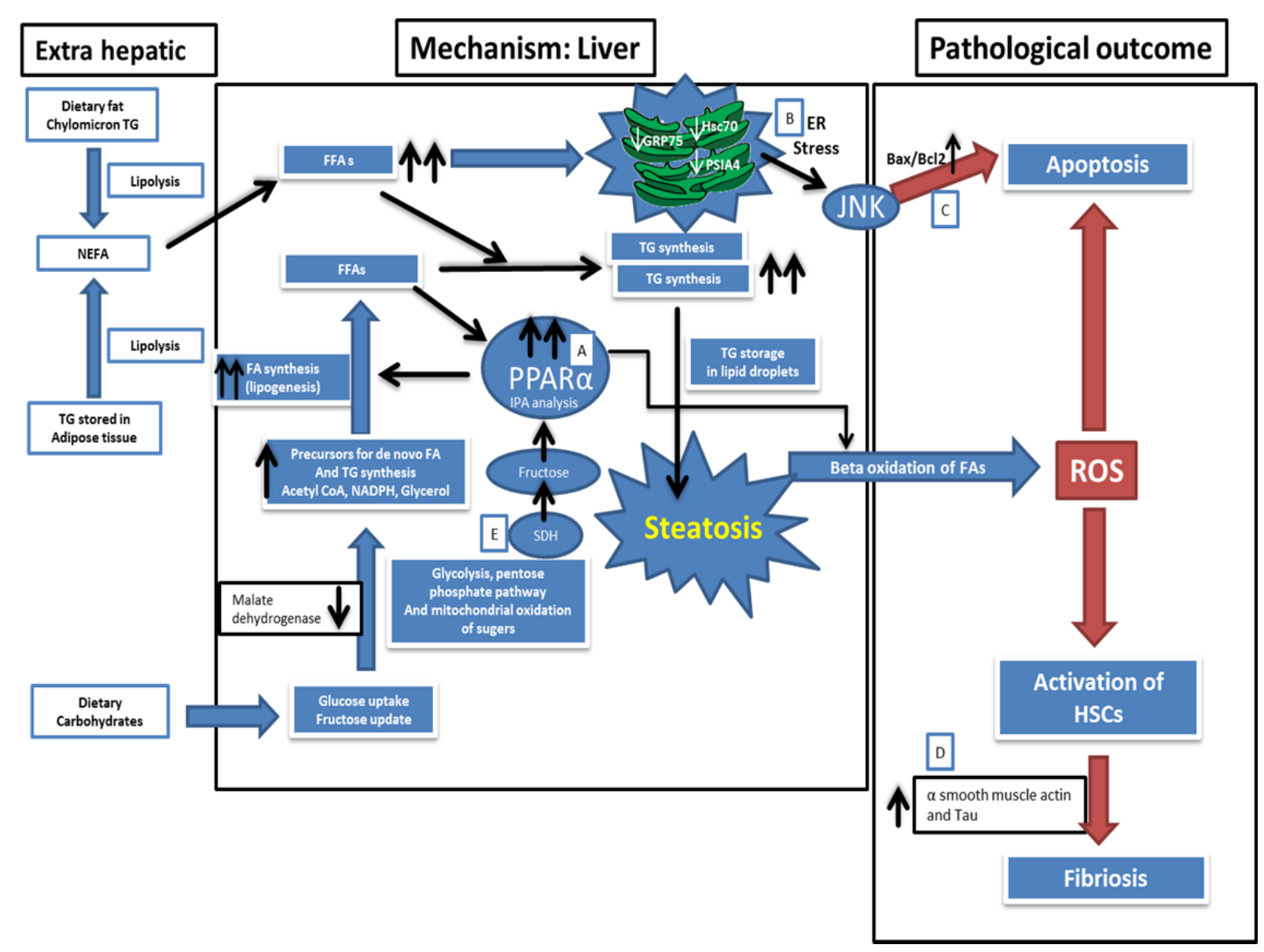

Fig. 23. Liver steatosis: possible biochemical defects and pathological outcome in the liver of 14 months old PrPC knockout mice. (A) PPARa, a transcriptional factor regulating the enzymes involved in the lipid metabolism (predicted by IPA analysis), (B) ER stress, caused by the down-regulation of chaperone activity (GRP75), (C) The induction of apoptosis by Bax/Bcl2, (D) The cytoskeleton disturbance during progression of steatosis caused by the regulation of tau and alpha smooth muscle actin, (E) The role of sorbitol dehydrogenase and malate dehydrogenase in liver steatosis.

The sulfonation of xenobiotics increases their polarity and solubility which is required for their transport out of the cell. Although the exact role of sult1a3 in liver steatosis is not known, but recently, the reduced levels of various forms of sulfotransferase including (SULT1A3) in the liver of patients with steatosis and cirrhosis has been reported (Yalcin et al., 2013). Interestingly, we have found 3.01 fold down-regulation of sult1a3 in the liver of 14 months old PrPC knockout female mice. The downregulation of sulfotransferase may alter its function to detoxify its various substrates 
and could result into the increased hepatotoxicity associated with the liver steatosis in the liver of 14 months old PrPC knockout mice.

\subsubsection{Apolipoprotein A-1(Marker)}

ApoA-I has already been discussed in the context of PrPC function (section - 5.2.5). It is a component of high density lipoprotein (HDL) in the plasma. ApoA-I has been involved in the efflux of fat such as cholesterol from the peripheral tissues to the liver, which is then excreted out of the body. Although, the role of Apolipoprotein A-1 in the development of liver disease is not clear but the co-localization of Apo-A1 with fat globules in the liver steatosis has been described in an $\mathrm{H}$-ras12V transgenic model (Wang et al., 2011). We have found the up-regulation of Apo-A1 in the liver of 14 months old PrPC knockout mice as compared to the wild type. Hence, the upregulation Apo-A1 in the liver of PrPC knockout mice indicated that it might be involved in the development of fatty liver disease pathology.

\subsubsection{Malate dehydrogenase (Marker)}

As already discussed in the bioenergetics section (section 5.2.2.2), it is an enzyme of citric acid metabolism and has been found to be down regulated in the liver of 14 months old PrPC knockout female mice. The down-regulation of $\mathrm{MDH}$ could lead to the slowing down of biochemical reactions in the TCA cycle and subsequently, may cause the accumulation of citrate and acetyl CoA. Acetyl CoA is also a substrate of de novo fatty acid synthesis. The up-regulation of lipogenesis due to allosteric activation of acetyl CoA carboxylase (Munday et al., 2002, first rate limiting enzyme of lipogenesis) by citrate might be part of the mechanism of the observed fatty liver disease in the liver of 14 months old PrPC knockout group (Fig. 23E).

\subsubsection{Proteins with chaperone activity}

All three proteins are the enzymes known to have chaperone activity along with the role against oxidative stress. This cluster of proteins have been observed to be 1.56 fold down regulated in the liver of 14 months old PrPC knockout female mice as compared to the wild type.

\subsection{Protein disulfide-isomerase}

It is involved in protein folding by re-arranging the disulfide bonds (B. Wilkinson et al., 2004). A proteomics based study from chang's group has shown the down-regulation of protein disulfide-isomerase A4 in the liver of obese CP rat (hypertensive/NIH - 
corpulent rat SHR/NDmcr-cp) as compared to the control groups (Chang et al., 2012). Hence, the down-regulation of protein disulfide-isomerase A4 in the liver of 14 months old PrPC knockout mice correlated with the previous finding that it might be linked with the lipid metabolism. Therefore, the down-regulation of protein disulfideisomerase A4 could generate the higher endoplasmic reticulum (ER) stress and subsequent increased unfolded protein responses (UPR) which may further induce apoptosis (Davenport et al., 2007, Arsenovic et al., 2012). The alteration of the lipid metabolism due to ER stress has already been described in several liver diseases including the fatty liver disease (Malhi et al., 2011). The Knockout of PrPC appears to be linked with endoplasmic reticulum (ER) stress induced liver steatosis hypothesis, which needs further investigation.

\subsection{Stress-70 (GRP75)}

It has been known to be involved in the multiple functions such as chaperone activity, mitochondrial transporter, and regulation of the lipid pathways and exist in multiple locations within the cell (Wadhwa et al., 2002, Mizzen et al., 1991). We have found the down-regulation of GRP75 in the proteomics dataset and also validated its regulation at the gene level by qPCR (Index - Fig. 2). GRP75 has been demonstrated to be an interacting partner of GRP94 (Takano et al 2001) and GRP94 is further known to be regulated by PPARa (Macdonald et al., 2000). As discussed previously, PPARa is a transcriptional factor which regulates various enzymes of lipid metabolism (Fig. 23A). The above evidences indicated that the down-regulation of GRP75 might be linked with the change of genes expressions which regulate the lipid metabolism.

In liver, both in in vivo and in vitro studies based on $\mathrm{CCl}_{4}$ induced liver injury have shown that the over-expression of GRP75 expression protects against oxidative damage by the inhibition of cytochrome $C$ release, improve cell viability, ATP concentrations and decreasing the serum levels of alanine transaminase and aspartate aminotransferase (Qiukai et al., 2013). As progression of liver steatosis leads to liver injury, increase in oxidative stress and tissue fibrosis. The downregulation of GRP75 suggests its involvement in liver disease pathology in the liver of 14 months old PrPC knockout mice.

Additionally, GRP75 has also been demonstrated to be an interacting partner of p53 and described to inactivate the p53 activity (Wadhwa et al., 2002). P53 is a very well- 
known protein which generates the death signals to mitochondria and cause apoptosis (Marchenko et al 2000). Hence, the activation of p53 could be favored by the down-regulation of GRP75 and subsequently may cause the induction of hepatic apoptosis in the liver of 14 months old PrPC knockout mice.

The above evidences showed that the function of GRP75 as an anti-oxidant, as an anti-apoptotic factor and its probable role in the lipid metabolism could be modulated by the PrPC expression in the old age liver. The down-regulation of GRP75 in the liver of 14 months old PrPC knockout female mice seems, at least partially be responsible of the observed pathological phenotype in the PrPC knockout mice liver.

\subsection{Heat shock cognate 71 kDa protein (HSC 71)}

It is an important protein which has chaperone properties and regulates the protein maturation (Beckmann et al., 1990; Beckmann et al., 1992). It also plays a role in the translocation of the proteins into endoplasmic reticulum (ER) and mitochondria (Chirico et al., 1998, Sheffield et al., 1990). Hsc70 has already been described as an interactive partner of recombinant PrP as well as native PrP (Wilkins et al., 2010). Similar to the disulfide isomerase A4 and stress-70 proteins, the down-regulation of hsc70 might be a causative factor for endoplasmic reticulum (ER) stress, apparently because of its reduced chaperone activity. As mentioned previously, the endoplasmic reticulum (ER) stress has been known to be linked to ROS mediated liver injury and thereby, further involved in the progression of the liver steatosis into NASH.

\subsection{Age and PrPC dependent altered tau/ptau pathway}

As we have discussed previously, that the regulation of tau protein has been known to be linked with the cytoskeleton disturbance during liver steatosis. It was one of our interests to describe the tau protein function in detail because of very well established role of PrPC in regulating tau function in prion diseases (Benvegnù et al., 2011, Reiniger et al., 2011). In addition, IPA software analysis of liver proteomics dataset also predicted the involvement of tau function (additional analysis with brain as a reference tissue). Tau is a microtubule associated protein, which stabilizes the microtubule. The hyperphosphorylation of tau causes its dissociation from the microtubules which eventually lead to its destablization and imbalance of the cytoskeleton (Illenberger et al., 1998). The role of PrPC in regulating the tau function has already been described in the brain hippocampus using PrPC knockout mouse model and also during neurodegnerative diseases (Benvegnù et al., 2011, Reiniger 
et al., 2011). A report showed that the treatment of neurotoxic prion synthetic peptide (106-126) to cultured neurons induced the cell death and in parallel caused the upregulation of tau phosphorylation by the activation of gsk3beta activity (Perez et al., 2003).

First, we showed the age dependent decrease of total tau protein expression in the liver of PrPC knockout mice as well as in the wild type mice. Secondly, we showed the significant up-regulation of ptau expression in the liver of 14 months old compared to 3 and 9 months old wild type mice. However, the increased phosphorylation of tau could be a mechanism linked with the higher degradation of tau protein in the old age (Shimura et al., 2004), which has been indicated by no parallel significant decrease in mRNA expression of tau gene (Data not shown) as compared to the protein expression of total tau with aging. Interestingly, we observed the down-regulation of ptau expression in the liver of 14 months old PrPC knockout mice as compared to the wild type mice. Therefore, the higher tau protein degradation due to phosphorylation of tau protein in the aging mice could be a PrPC dependent mechanism to regulate the cytoskeleton functions in the liver tissue.

Further, gsk3beta and Cdk5 are among the well characterized enzymes which catalyzes the phosphorylation of tau in various neurodegenerative pathways (Ishiguro K, et al., 1993, Takashima A, et al., 2006). The activation of gsk3beta depends on its phosphorylation at Tyr216 residue while the activation of Cdk5 depends on its interaction with the p25 fragment. Hence, we analyzed the expressional regulation of gsk3beta/pgsk3beta and Cdk5/p25 proteins. We showed the down-regulation of pgsk3beta/gsk3beta enzyme (phospho-Tyr216) expression in the liver of 14 months old PrPC knockout mice while there was no such regulation in p25/Cdk5 expressions. As described before, the expression of ptau was also downregulated in the liver of 14 months old PrPC knockout mice liver. Therefore, it indicated that PrPC might be involved in the tau protein phosphorylation in the liver of 14 months old mice by regulating the gsk3beta enzyme activation. Alterations in the phosphorylation of tau modulates its cytoskeleton function, because binding of tau protein to the microtubule, stabilizes the microtubule assemblies. The increased phosphorylation of tau protein decreases its binding to the microtubules while decrease in phosphorylation causes increased binding. 
Current evidences showed a role of PrPC in the regulation of age related alterations of cytoskeleton by modulating the tau protein function. 


\section{Conclusions}

- $\operatorname{PrPC}$ seems to play an important role in the liver of aging mice which is indicated by the significant up-regulation of PrPC expression in the liver of aging wild type mice as compared to the adult or advanced adult age mice.

- The evidences of the observed fatty liver disease pathology in the liver of aging PrPC knockout mice were provided by the implication of $2 \mathrm{D}$ gel proteome profiling.

- Current study revealed a new role of PrPC in regulating the pathways linked with the lipid/glucose metabolism in the liver. The manifestation of apoptosis in the damaged tissue as indicated by the higher $\mathrm{Bax} / \mathrm{Bc} / 2$ ratio along with the markers of liver steatosis found in the proteomics dataset, revealed a possible progression of the disease into non-alcoholic steatohepatitis (NASH).

- The regulation of G6PC, GPD1, GSTZ1, INSR, LDLR, LEP, LPL, NR1H3, NR1H4, POR, PPARa, PPARGCA, and SIRT3 (predicted by the bioinformatics IPA software analysis) proteins shows an imbalance of the complex metabolic pathways in the liver of aging PrPC knockout mice.

- The above outcome revealed that the regulations of the lipid or glucose metabolism in the intra- or extra-hepatic tissues are among the causative factors of the observed liver disease phenotypes, which needs further in detailed investigations.

- Interestingly, the expression of PrPC was higher in the liver of aging wild type female mice than male and the observed liver disease also affects more to the female group after knock out of PrPC gene. It indicates that, possibly due to the hormonal influence, gender seems to play a differential role in regulating the PrPC function in the liver.

- Additionally, the down-regulation of ptau expression in the liver of aging PrPC knockout mice via gsk3beta showed a role of PrPC in regulating the cytoskeleton function in the aging mice liver.

- In the current study, with the help of proteomics approach, a new role of PrPC in regulating the glucose/lipid metabolic pathways has been described, which also further seems be linked with the cytoskeleton functions in the aging liver. The elucidation of the whole disease mechanisms needs further investigation. 


\section{Take home message}

The finding of fatty liver disease along with the alteration of cytoskeleton protein tau function in the liver of aging PrPC knockout mice revealed an important metabolic role of PrPC in the aging mice liver. 


\section{References}

1. Agostini, F., Dotti, C.G., Perez-Canamas, A., Ledesma, M.D., Benetti, F., and Legname, G. (2013). Prion protein accumulation in lipid rafts of mouse aging brain. PLoS One 8, e74244.

2. Agrawal, D., Hauser, P., McPherson, F., Dong, F., Garcia, A., and Pledger, W.J. (1996). Repression of p27kip1 synthesis by platelet-derived growth factor in BALB/C 3 T3 cells. Mol Cell Biol 16, 4327-4336.

3. Aine, C.J., Sanfratello, L., Adair, J.C., Knoefel, J.E., Qualls, C., Lundy, S.L., Caprihan, A., Stone, D., and Stephen, J.M. (2014). Characterization of a normal control group: are they healthy? Neuroimage $84,796-809$.

4. Alexander Mironov Jr, Diane Latawiec, Holger Wille, Essia Bouzamondo-Bernstein, Giuseppe Legname, R. Anthony Williamson, Dennis Burton, Stephen J. DeArmond, Stanley B. Prusiner, and Peter J. Peters. (2003). Cytosolic Prion protein in neurons. The Journal of Neuroscience. 23(18), 7183-7193

5. Arsenovic, P.T., Maldonado, A.T., Colleluori, V.D., and Bloss, T.A. (2012). Depletion of the $C$. elegans NAC engages the unfolded protein response, resulting in increased chaperone expression and apoptosis. PLoS One 7, e44038.

6. Asante, E.A., Li, Y.G., Gowland, I., Jefferys, J.G., and Collinge, J. (2004). Pathogenic human prion protein rescues PrP null phenotype in transgenic mice. Neurosci Lett 360, 33-36.

7. Ballerini, C., Gourdain, P., Bachy, V., Blanchard, N., Levavasseur, E., Gregoire, S., Fontes, P., Aucouturier, P., Hivroz, C., and Carnaud, C. (2006). Functional implication of cellular prion protein in antigen-driven interactions between $T$ cells and dendritic cells. J Immunol 176, 7254-7262.

8. Bandaru, V.V., Troncoso, J., Wheeler, D., Pletnikova, O., Wang, J., Conant, K., and Haughey, N.J. (2009). ApoE4 disrupts sterol and sphingolipid metabolism in Alzheimer's but not normal brain. Neurobiol Aging 30, 591-599.

9. Banki, K., Hutter, E., Colombo, E., Gonchoroff, N.J., and Perl, A. (1996). Glutathione levels and sensitivity to apoptosis are regulated by changes in transaldolase expression. J Biol Chem 271, 32994-33001.

10. Basler, K., Oesch, B., Scott, M., Westaway, D., Walchli, M., Groth, D.F., McKinley, M.P., Prusiner, S.B., and Weissmann, C. (1986). Scrapie and cellular PrP isoforms are encoded by the same chromosomal gene. Cell 46, 417-428.

11. Beach, T.G. (2008). Physiologic origins of age-related beta-amyloid deposition. Neurodegener Dis 5, 143-145. 
12. Beckmann, R.P., Lovett, M., and Welch, W.J. (1992). Examining the function and regulation of hsp 70 in cells subjected to metabolic stress. J Cell Biol 117, 1137-1150.

13. Beckmann, R.P., Mizzen, L.E., and Welch, W.J. (1990). Interaction of Hsp 70 with newly synthesized proteins: implications for protein folding and assembly. Science 248, 850-854.

14. Benvegnu, S., Poggiolini, I., and Legname, G. (2010). Neurodevelopmental expression and localization of the cellular prion protein in the central nervous system of the mouse. J Comp Neurol 518, 1879-1891.

15. Bonney Wilkinson, Hiram F Gilbert. (2004). Protein disulfide isomerase. Biochim. Biophys. Acta, 1699, 35.

16. Booth, S., Bowman, C., Baumgartner, R., Sorensen, G., Robertson, C., Coulthart, M., Phillipson, C., and Somorjai, R.L. (2004). Identification of central nervous system genes involved in the host response to the scrapie agent during preclinical and clinical infection. J Gen Virol 85, 3459-3471.

17. Brown, D.R. (2002). Mayhem of the multiple mechanisms: modelling neurodegeneration in prion disease. J Neurochem 82, 209-215.

18. Brown, D.R., and Besinger, A. (1998). Prion protein expression and superoxide dismutase activity. Biochem J 334 ( Pt 2), 423-429.

19. Brown, D.R., Qin, K., Herms, J.W., Madlung, A., Manson, J., Strome, R., Fraser, P.E., Kruck, T., von Bohlen, A., Schulz-Schaeffer, W., et al. (1997). The cellular prion protein binds copper in vivo. Nature 390, 684-687.

20. Brown, D.R., Wong, B.S., Hafiz, F., Clive, C., Haswell, S.J., and Jones, I.M. (1999). Normal prion protein has an activity like that of superoxide dismutase. Biochem $\mathrm{J} 344$ Pt 1, 1-5.

21. Brown, W.R., and Thore, C.R. (2011). Review: cerebral microvascular pathology in ageing and neurodegeneration. Neuropathol Appl Neurobiol 37, 56-74.

22. Bueler, H., Fischer, M., Lang, Y., Bluethmann, H., Lipp, H.P., DeArmond, S.J., Prusiner, S.B., Aguet, M., and Weissmann, C. (1992). Normal development and behaviour of mice lacking the neuronal cell-surface PrP protein. Nature 356, 577-582.

23. Caiati MD1, Safiulina VF, Fattorini G, Sivakumaran S, Legname G, Cherubini E. (2013). PrPC controls via protein kinase A the direction of synaptic plasticity in the immature hippocampus. J Neurosci 13;33(7), 2973-83.

24. Carleton, A., Tremblay, P., Vincent, J.D., and Lledo, P.M. (2001). Dose-dependent, prion protein (PrP)-mediated facilitation of excitatory synaptic transmission in the mouse hippocampus. Pflugers Arch 442, 223-229.

25. Casadesus, G., Smith, M.A., and Perry, G. (2005). Commentary: "Ceramide and cholesterol: possible connections between normal aging of the brain and Alzheimer's 
disease. Just hypotheses or molecular pathways to be identified?" by Claudio Costantini, Rekha M.K. Kolasani, and Luigi Puglielli. Alzheimers Dement 1, 51-52.

26. Chang, J., Oikawa, S., Ichihara, G., Nanpei, Y., Hotta, Y., Yamada, Y., Tada-Oikawa, S., Iwahashi, H., Kitagawa, E., Takeuchi, I., et al. (2012). Altered gene and protein expression in liver of the obese spontaneously hypertensive/NDmcr-cp rat. Nutr Metab (Lond) 9, 87.

27. Chirico, W.J., Markey, M.L., and Fink, A.L. (1998). Conformational changes of an Hsp70 molecular chaperone induced by nucleotides, polypeptides, and $\mathrm{N}$ ethylmaleimide. Biochemistry 37, 13862-13870.

28. Christopher J Johnson, Joel A Pedersen, Rick J Chappell, Debbie McKenzie, Judd M Aiken. (2007). Oral transmissibility of prion disease is enhanced by binding to soil particles. PLoS Pathog 3(7), e93. doi:10.1371.

29. Chu, I.M., Hengst, L., and Slingerland, J.M. (2008). The Cdk inhibitor p27 in human cancer: prognostic potential and relevance to anticancer therapy. Nat Rev Cancer 8 , 253-267.

30. Coats, S., Flanagan, W.M., Nourse, J., and Roberts, J.M. (1996). Requirement of p27Kip1 for restriction point control of the fibroblast cell cycle. Science 272, 877-880.

31. Coitinho, A.S., Dietrich, M.O., Hoffmann, A., Dall'Igna, O.P., Souza, D.O., Martins, V.R., Brentani, R.R., Izquierdo, I., and Lara, D.R. (2002). Decreased hyperlocomotion induced by MK-801, but not amphetamine and caffeine in mice lacking cellular prion protein $(\operatorname{PrP}(\mathrm{C}))$. Brain Res Mol Brain Res 107, 190-194.

32. Coitinho, A.S., Roesler, R., Martins, V.R., Brentani, R.R., and Izquierdo, I. (2003). Cellular prion protein ablation impairs behavior as a function of age. Neuroreport 14 , 1375-1379.

33. Colling, S.B., Khana, M., Collinge, J., and Jefferys, J.G. (1997). Mossy fibre reorganization in the hippocampus of prion protein null mice. Brain Res 755, 28-35.

34. Collinge, J., Whittington, M.A., Sidle, K.C., Smith, C.J., Palmer, M.S., Clarke, A.R., and Jefferys, J.G. (1994). Prion protein is necessary for normal synaptic function. Nature 370, 295-297.

35. Crawford, D.R., Schools, G.P., and Davies, K.J. (1996). Oxidant-inducible adapt 15 RNA is associated with growth arrest- and DNA damage-inducible gadd153 and gadd45. Arch Biochem Biophys 329, 137-144.

36. Criado, J.R., Sanchez-Alavez, M., Conti, B., Giacchino, J.L., Wills, D.N., Henriksen, S.J., Race, R., Manson, J.C., Chesebro, B., and Oldstone, M.B. (2005). Mice devoid of prion protein have cognitive deficits that are rescued by reconstitution of $\operatorname{PrP}$ in neurons. Neurobiol Dis 19, 255-265. 
37. Curtis, J., Errington, M., Bliss, T., Voss, K., and MacLeod, N. (2003). Age-dependent loss of PTP and LTP in the hippocampus of PrP-null mice. Neurobiol Dis 13, 55-62.

38. Davenport, E.L., Moore, H.E., Dunlop, A.S., Sharp, S.Y., Workman, P., Morgan, G.J., and Davies, F.E. (2007). Heat shock protein inhibition is associated with activation of the unfolded protein response pathway in myeloma plasma cells. Blood 110, 26412649.

39. de Almeida, C.J., Chiarini, L.B., da Silva, J.P., PM, E.S., Martins, M.A., and Linden, R. (2005). The cellular prion protein modulates phagocytosis and inflammatory response. J Leukoc Biol 77, 238-246.

40. de Haan, J.B., Tymms, M.J., Cristiano, F., and Kola, I. (1994). Expression of copper/zinc superoxide dismutase and glutathione peroxidase in organs of developing mouse embryos, fetuses, and neonates. Pediatr Res 35, 188-196.

41. DeArmond, S.J., Mobley, W.C., DeMott, D.L., Barry, R.A., Beckstead, J.H., and Prusiner, S.B. (1987). Changes in the localization of brain prion proteins during scrapie infection. Neurology 37, 1271-1280.

42. den Boer, M., Voshol, P.J., Kuipers, F., Havekes, L.M., and Romijn, J.A. (2004). Hepatic steatosis: a mediator of the metabolic syndrome. Lessons from animal models. Arterioscler Thromb Vasc Biol 24, 644-649.

43. Dhungana, H., Rolova, T., Savchenko, E., Wojciechowski, S., Savolainen, K., Ruotsalainen, A.K., Sullivan, P.M., Koistinaho, J., and Malm, T. (2013). Western-type diet modulates inflammatory responses and impairs functional outcome following permanent middle cerebral artery occlusion in aged mice expressing the human apolipoprotein E4 allele. J Neuroinflammation 10, 102.

44. E, Q., Liu, X., Liu, Y., Liu, W., and Zuo, J. (2013). Over-expression of GRP75 inhibits liver injury induced by oxidative damage. Acta Biochim Biophys Sin (Shanghai) 45 , 129-134.

45. Ehsani, A., Alluin, J.V., and Rossi, J.J. (2013). Cell cycle abnormalities associated with differential perturbations of the human U5 snRNP associated U5-200kD RNA helicase. PLoS One 8, e62125.

46. Everest, S.J., Ramsay, A.M., Chaplin, M.J., Everitt, S., Stack, M.J., Neale, M.H., Jeffrey, M., Moore, S.J., Bellworthy, S.J., and Terry, L.A. (2011). Detection and localisation of $\operatorname{PrP}(\mathrm{Sc})$ in the liver of sheep infected with scrapie and bovine spongiform encephalopathy. PLoS One 6, e19737.

47. Fariss, M.W., Chan, C.B., Patel, M., Van Houten, B., and Orrenius, S. (2005). Role of mitochondria in toxic oxidative stress. Mol Interv 5, 94-111. 
48. Feldstein, A.E., Canbay, A., Angulo, P., Taniai, M., Burgart, L.J., Lindor, K.D., and Gores, G.J. (2003). Hepatocyte apoptosis and fas expression are prominent features of human nonalcoholic steatohepatitis. Gastroenterology 125, 437-443.

49. Flechsig, E., Hegyi, I., Leimeroth, R., Zuniga, A., Rossi, D., Cozzio, A., Schwarz, P., Rulicke, T., Gotz, J., Aguzzi, A., et al. (2003). Expression of truncated PrP targeted to Purkinje cells of PrP knockout mice causes Purkinje cell death and ataxia. EMBO J 22, 3095-3101.

50. Fontes, P., Alvarez-Martinez, M.T., Gross, A., Carnaud, C., Kohler, S., and Liautard, J.P. (2005). Absence of evidence for the participation of the macrophage cellular prion protein in infection with Brucella suis. Infect Immun 73, 6229-6236.

51. Ford, M.J., Burton, L.J., Morris, R.J., and Hall, S.M. (2002). Selective expression of prion protein in peripheral tissues of the adult mouse. Neuroscience 113, 177-192.

52. Foster, T.C. (2006). Biological markers of age-related memory deficits: treatment of senescent physiology. CNS Drugs 20, 153-166.

53. Fournier JG1, Escaig-Haye F, Billette de Villemeur T, Robain O, Lasmézas Cl, Deslys JP, Dormont D, Brown P (1998). Distribution and submicroscopic immunogold localization of cellular prion protein (PrPc) in extracerebral tissues Cell Tissue Res. 292(1), 77-84.

54. Gains, M.J., Roth, K.A., and LeBlanc, A.C. (2006). Prion protein protects against ethanol-induced Bax-mediated cell death in vivo. Neuroreport 17, 903-906.

55. Gasperini, L., and Legname, G. (2014). Prion protein and aging. Front Cell Dev Biol $2,44$.

56. Goh, A.X., Li, C., Sy, M.S., and Wong, B.S. (2007). Altered prion protein glycosylation in the aging mouse brain. $\mathrm{J}$ Neurochem 100, 841-854.

57. Grohn, Y., Lindberg, L.A., Bruss, M.L., and Farver, T.B. (1983). Fatty infiltration of liver in spontaneously ketotic dairy cows. J Dairy Sci 66, 2320-2328.

58. Gross, A., McDonnell, J.M., and Korsmeyer, S.J. (1999). BCL-2 family members and the mitochondria in apoptosis. Genes Dev 13, 1899-1911.

59. Gusdon, A.M., Song, K.X., and Qu, S. (2014). Nonalcoholic Fatty liver disease: pathogenesis and therapeutics from a mitochondria-centric perspective. Oxid Med Cell Longev 2014, 637027.

60. Hammill, A.K., Uhr, J.W., and Scheuermann, R.H. (1999). Annexin V staining due to loss of membrane asymmetry can be reversible and precede commitment to apoptotic death. Exp Cell Res 251, 16-21.

61. Harris, D.A. (2003). Trafficking, turnover and membrane topology of PrP. Br Med Bull $66,71-85$. 
62. Herms, J.W., Kretzchmar, H.A., Titz, S., and Keller, B.U. (1995). Patch-clamp analysis of synaptic transmission to cerebellar purkinje cells of prion protein knockout mice. Eur J Neurosci 7, 2508-2512.

63. Herms, J.W., Tings, T., Dunker, S., and Kretzschmar, H.A. (2001). Prion protein affects Ca2+-activated $\mathrm{K}+$ currents in cerebellar purkinje cells. Neurobiol Dis $8,324-$ 330.

64. Horiuchi, M., Yamazaki, N., Ikeda, T., Ishiguro, N., and Shinagawa, M. (1995). A cellular form of prion protein (PrPC) exists in many non-neuronal tissues of sheep. $\mathrm{J}$ Gen Virol 76 ( Pt 10), 2583-2587.

65. Hoshino, S., Inoue, K., Yokoyama, T., Kobayashi, S., Asakura, T., Teramoto, A., and Itohara, S. (2003). Prions prevent brain damage after experimental brain injury: a preliminary report. Acta Neurochir Suppl 86, 297-299.

66. Hottman, D.A., Chernick, D., Cheng, S., Wang, Z., and Li, L. (2014). HDL and cognition in neurodegenerative disorders. Neurobiol Dis 72 Pt A, 22-36.

67. Hutter, G., Heppner, F.L., and Aguzzi, A. (2003). No superoxide dismutase activity of cellular prion protein in vivo. Biol Chem 384, 1279-1285.

68. Ikeda, K., Kawada, N., Wang, Y.Q., Kadoya, H., Nakatani, K., Sato, M., and Kaneda, K. (1998). Expression of cellular prion protein in activated hepatic stellate cells. Am J Pathol 153, 1695-1700.

69. Illenberger, S., Zheng-Fischhofer, Q., Preuss, U., Stamer, K., Baumann, K., Trinczek, B., Biernat, J., Godemann, R., Mandelkow, E.M., and Mandelkow, E. (1998). The endogenous and cell cycle-dependent phosphorylation of tau protein in living cells: implications for Alzheimer's disease. Mol Biol Cell 9, 1495-1512.

70. Isaacs, J.D., Jackson, G.S., and Altmann, D.M. (2006). The role of the cellular prion protein in the immune system. Clin Exp Immunol 146, 1-8.

71. Ishiguro, K., Shiratsuchi, A., Sato, S., Omori, A., Arioka, M., Kobayashi, S., Uchida, T., and Imahori, K. (1993). Glycogen synthase kinase 3 beta is identical to tau protein kinase I generating several epitopes of paired helical filaments. FEBS Lett 325, $167-$ 172.

72. Jancova, P., Anzenbacher, P., and Anzenbacherova, E. (2010). Phase II drug metabolizing enzymes. Biomed Pap Med Fac Univ Palacky Olomouc Czech Repub $154,103-116$.

73. Jian-Zhi Wang, Zhi-Hao Wang, Qing Tian (2014). Tau hyperphosphorylation induces apoptotic escape and triggers neurodegeneration in Alzheimer's disease. Neurosci Bull 30(2),359-366. 
74. Kay Washington, Kelly Wright, Yu Shyr, Ellen B. Hunter, Sandy Olson, David S. Raiford. (2000). Hepatic stellate cell activation in nonalcoholic steatohepatitis and fatty liver. Hum Pathol 31(7), 822-8.

75. Keightley, M.C., Crowhurst, M.O., Layton, J.E., Beilharz, T., Markmiller, S., Varma, S., Hogan, B.M., de Jong-Curtain, T.A., Heath, J.K., and Lieschke, G.J. (2013). In vivo mutation of pre-mRNA processing factor 8 (Prpf8) affects transcript splicing, cell survival and myeloid differentiation. FEBS Lett 587, 2150-2157.

76. Kellett, K.A., and Hooper, N.M. (2009). Prion protein and Alzheimer disease. Prion 3, 190-194.

77. Kersten, S., and Wahli, W. (2000). Peroxisome proliferator activated receptor agonists. EXS 89, 141-151.

78. Khalili-Shirazi, A., Summers, L., Linehan, J., Mallinson, G., Anstee, D., Hawke, S., Jackson, G.S., and Collinge, J. (2005). PrP glycoforms are associated in a strainspecific ratio in native PrPSc. J Gen Virol 86, 2635-2644.

79. Kim, B.H., Lee, H.G., Choi, J.K., Kim, J.I., Choi, E.K., Carp, R.I., and Kim, Y.S. (2004). The cellular prion protein (PrPC) prevents apoptotic neuronal cell death and mitochondrial dysfunction induced by serum deprivation. Brain Res Mol Brain Res $124,40-50$.

80. Klamt, F., Dal-Pizzol, F., Conte da Frota, M.L., Jr., Walz, R., Andrades, M.E., da Silva, E.G., Brentani, R.R., Izquierdo, I., and Fonseca Moreira, J.C. (2001). Imbalance of antioxidant defense in mice lacking cellular prion protein. Free Radic Biol Med 30, 1137-1144.

81. Knight, R. (2004). Prion diseases. Vox Sang 87 Suppl1, 104-106.

82. Komatsubara, A.T., Asano, T., Tsumoto, H., Shimizu, K., Nishiuchi, T., Yoshizumi, M., and Ozawa, K. (2012). Proteomic analysis of S-nitrosylation induced by 1-methyl-4phenylpyridinium (MPP+). Proteome Sci 10, 74.

83. Koschack, J., Lutjohann, D., Schmidt-Samoa, C., and Irle, E. (2009). Serum 24Shydroxycholesterol and hippocampal size in middle-aged normal individuals. Neurobiol Aging 30, 898-902.

84. Kralovicova, S., Fontaine, S.N., Alderton, A., Alderman, J., Ragnarsdottir, K.V., Collins, S.J., and Brown, D.R. (2009). The effects of prion protein expression on metal metabolism. Mol Cell Neurosci 41, 135-147.

85. Kristiansen, M., Messenger, M.J., Klohn, P.C., Brandner, S., Wadsworth, J.D., Collinge, J., and Tabrizi, S.J. (2005). Disease-related prion protein forms aggresomes in neuronal cells leading to caspase activation and apoptosis. J Biol Chem 280, 38851-38861. 
86. Kubosaki, A., Nishimura-Nasu, Y., Nishimura, T., Yusa, S., Sakudo, A., Saeki, K., Matsumoto, Y., Itohara, S., and Onodera, T. (2003). Expression of normal cellular prion protein $(\operatorname{PrP}(\mathrm{c}))$ on $\mathrm{T}$ lymphocytes and the effect of copper ion: Analysis by wildtype and prion protein gene-deficient mice. Biochem Biophys Res Commun 307, 810813.

87. Lalanza, J.F., Caimari, A., del Bas, J.M., Torregrosa, D., Cigarroa, I., Pallas, M., Capdevila, L., Arola, L., and Escorihuela, R.M. (2014). Effects of a post-weaning cafeteria diet in young rats: metabolic syndrome, reduced activity and low anxiety-like behaviour. PLoS One 9, e85049.

88. Lawson, V.A., Collins, S.J., Masters, C.L., and Hill, A.F. (2005). Prion protein glycosylation. J Neurochem 93, 793-801.

89. Lazarin Mde, O., Ishii-Iwamoto, E.L., Yamamoto, N.S., Constantin, R.P., Garcia, R.F., da Costa, C.E., Vitoriano Ade, S., de Oliveira, M.C., and Salgueiro-Pagadigorria, C.L. (2011). Liver mitochondrial function and redox status in an experimental model of non-alcoholic fatty liver disease induced by monosodium L-glutamate in rats. Exp Mol Pathol 91, 687-694.

90. Leritz, E.C., Salat, D.H., Williams, V.J., Schnyer, D.M., Rudolph, J.L., Lipsitz, L., Fischl, B., McGlinchey, R.E., and Milberg, W.P. (2011). Thickness of the human cerebral cortex is associated with metrics of cerebrovascular health in a normative sample of community dwelling older adults. Neuroimage 54, 2659-2671.

91. Lewis, M., and Howdle, P.D. (2003). The neurology of liver failure. QJM 96, 623-633.

92. Li, A., Sakaguchi, S., Shigematsu, K., Atarashi, R., Roy, B.C., Nakaoke, R., Arima, K., Okimura, N., Kopacek, J., and Katamine, S. (2000). Physiological expression of the gene for PrP-like protein, PrPLP/Dpl, by brain endothelial cells and its ectopic expression in neurons of PrP-deficient mice ataxic due to Purkinje cell degeneration. Am J Pathol 157, 1447-1452.

93. Li, L., Cao, D., Kim, H., Lester, R., and Fukuchi, K. (2006). Simvastatin enhances learning and memory independent of amyloid load in mice. Ann Neurol 60, 729-739.

94. Liu, C.C., Kanekiyo, T., Xu, H., and Bu, G. (2013). Apolipoprotein E and Alzheimer disease: risk, mechanisms and therapy. Nat Rev Neurol 9, 106-118.

95. Lledo, P.M., Tremblay, P., DeArmond, S.J., Prusiner, S.B., and Nicoll, R.A. (1996). Mice deficient for prion protein exhibit normal neuronal excitability and synaptic transmission in the hippocampus. Proc Natl Acad Sci U S A 93, 2403-2407.

96. Llorens, F., Carulla, P., Villa, A., Torres, J.M., Fortes, P., Ferrer, I., and del Rio, J.A. (2013). $\operatorname{Pr} P(C)$ regulates epidermal growth factor receptor function and cell shape dynamics in Neuro2a cells. J Neurochem 127, 124-138. 
97. Lobao-Soares, B., Bianchin, M.M., Linhares, M.N., Carqueja, C.L., Tasca, C.I., Souza, M., Marques, W., Jr., Brentani, R., Martins, V.R., Sakamoto, A.C., et al. (2005). Normal brain mitochondrial respiration in adult mice lacking cellular prion protein. Neurosci Lett 375, 203-206.

98. MacDonald, G.A., Bridle, K.R., Ward, P.J., Walker, N.I., Houglum, K., George, D.K., Smith, J.L., Powell, L.W., Crawford, D.H., and Ramm, G.A. (2001). Lipid peroxidation in hepatic steatosis in humans is associated with hepatic fibrosis and occurs predominately in acinar zone 3. J Gastroenterol Hepatol 16, 599-606.

99. Maglio, L.E., Martins, V.R., Izquierdo, I., and Ramirez, O.A. (2006). Role of cellular prion protein on LTP expression in aged mice. Brain Res 1097, 11-18.

100. Maglio, L.E., Perez, M.F., Martins, V.R., Brentani, R.R., and Ramirez, O.A. (2004). Hippocampal synaptic plasticity in mice devoid of cellular prion protein. Brain Res Mol Brain Res 131, 58-64.

101. Malhi, H., and Kaufman, R.J. (2011). Endoplasmic reticulum stress in liver disease. J Hepatol 54, 795-809.

102. Manson, J., West, J.D., Thomson, V., McBride, P., Kaufman, M.H., and Hope, J. (1992). The prion protein gene: a role in mouse embryogenesis? Development 115 , 117-122.

103. Manson, J.C., Clarke, A.R., Hooper, M.L., Aitchison, L., McConnell, I., and Hope, J. (1994). 129/Ola mice carrying a null mutation in PrP that abolishes mRNA production are developmentally normal. Mol Neurobiol 8, 121-127.

104. Manson, J.C., Hope, J., Clarke, A.R., Johnston, A., Black, C., and MacLeod, N. (1995). PrP gene dosage and long term potentiation. Neurodegeneration 4, 113-114.

105. Marchenko, N.D., Zaika, A., and Moll, U.M. (2000). Death signal-induced localization of p53 protein to mitochondria. A potential role in apoptotic signaling. J Biol Chem 275, 16202-16212.

106. Martin, M., Dotti, C.G., and Ledesma, M.D. (2010). Brain cholesterol in normal and pathological aging. Biochim Biophys Acta 1801, 934-944.

107. Mawal-Dewan M1, Henley J, Van de Voorde A, Trojanowski JQ, Lee VM. (1994).The phosphorylation state of tau in the developing rat brain is regulated by phosphoprotein phosphatases. J Biol Chem 269(49), 30981-7.

108. McCulloch, L., Brown, K.L., and Mabbott, N.A. (2013). Ablation of the cellular prion protein, PrPC, specifically on follicular dendritic cells has no effect on their maturation or function. Immunology 138, 246-257.

109. McLennan, N.F., Brennan, P.M., McNeill, A., Davies, I., Fotheringham, A., Rennison, K.A., Ritchie, D., Brannan, F., Head, M.W., Ironside, J.W., et al. (2004). Prion protein 
accumulation and neuroprotection in hypoxic brain damage. Am J Pathol 165, $227-$ 235.

110. Mead, S., Gandhi, S., Beck, J., Caine, D., Gajulapalli, D., Carswell, C., Hyare, H., Joiner, S., Ayling, H., Lashley, T., et al. (2013). A novel prion disease associated with diarrhea and autonomic neuropathy. N Engl J Med 369, 1904-1914.

111. Miele, G., Jeffrey, M., Turnbull, D., Manson, J., and Clinton, M. (2002). Ablation of cellular prion protein expression affects mitochondrial numbers and morphology. Biochem Biophys Res Commun 291, 372-377.

112. Mizzen, L.A., Kabiling, A.N., and Welch, W.J. (1991). The two mammalian mitochondrial stress proteins, grp 75 and hsp 58, transiently interact with newly synthesized mitochondrial proteins. Cell Regul 2, 165-179.

113. Moore, R.C., Lee, I.Y., Silverman, G.L., Harrison, P.M., Strome, R., Heinrich, C., Karunaratne, A., Pasternak, S.H., Chishti, M.A., Liang, Y., et al. (1999). Ataxia in prion protein (PrP)-deficient mice is associated with upregulation of the novel PrP-like protein doppel. J Mol Biol 292, 797-817.

114. Moudjou, M., Frobert, Y., Grassi, J., and La Bonnardiere, C. (2001). Cellular prion protein status in sheep: tissue-specific biochemical signatures. J Gen Virol 82, 20172024.

115. Munday, M.R. (2002). Regulation of mammalian acetyl-CoA carboxylase. Biochem Soc Trans 30, 1059-1064.

116. Nguyen, K., D'Mello, C., Le, T., Urbanski, S., and Swain, M.G. (2012). Regulatory T cells suppress sickness behaviour development without altering liver injury in cholestatic mice. J Hepatol 56, 626-631.

117. Nico, P.B., Lobao-Soares, B., Landemberger, M.C., Marques, W., Jr., Tasca, C.I., de Mello, C.F., Walz, R., Carlotti, C.G., Jr., Brentani, R.R., Sakamoto, A.C., et al. (2005). Impaired exercise capacity, but unaltered mitochondrial respiration in skeletal or cardiac muscle of mice lacking cellular prion protein. Neurosci Lett 388, 21-26.

118. Nouchi, T., Tanaka, Y., Tsukada, T., Sato, C., and Marumo, F. (1991). Appearance of alpha-smooth-muscle-actin-positive cells in hepatic fibrosis. Liver 11, 100-105.

119. Oliveira, T.G., and Di Paolo, G. (2010). Phospholipase D in brain function and Alzheimer's disease. Biochim Biophys Acta 1801, 799-805.

120.Pan, T., Li, R., Wong, B.S., Liu, T., Gambetti, P., and Sy, M.S. (2002). Heterogeneity of normal prion protein in two- dimensional immunoblot: presence of various glycosylated and truncated forms. J Neurochem 81, 1092-1101.

121.Parkin, E.T., Watt, N.T., Hussain, I., Eckman, E.A., Eckman, C.B., Manson, J.C., Baybutt, H.N., Turner, A.J., and Hooper, N.M. (2007). Cellular prion protein regulates 
beta-secretase cleavage of the Alzheimer's amyloid precursor protein. Proc Natl Acad Sci U S A 104, 11062-11067.

122. Peralta, O.A., Huckle, W.R., and Eyestone, W.H. (2012). Developmental expression of the cellular prion protein $(\operatorname{PrP}(\mathrm{C}))$ in bovine embryos. Mol Reprod Dev 79, 488498.

123. Perez, M., Rojo, A.I., Wandosell, F., Diaz-Nido, J., and Avila, J. (2003). Prion peptide induces neuronal cell death through a pathway involving glycogen synthase kinase 3 . Biochem J 372, 129-136.

124. Perl, A. (2007). The pathogenesis of transaldolase deficiency. IUBMB Life 59, 365373.

125. Petit, C.S., Barreau, F., Besnier, L., Gandille, P., Riveau, B., Chateau, D., Roy, M., Berrebi, D., Svrcek, M., Cardot, P., et al. (2012). Requirement of cellular prion protein for intestinal barrier function and mislocalization in patients with inflammatory bowel disease. Gastroenterology 143, 122-132 e115.

126. Politopoulou G, Seebach JD, Schmugge M, Schwarz HP, Aguzzi A. (2000). Agerelated expression of cellular. prion protein in human peripheral blood leukocytes. Haematologica 85, 580-587.

127.Polyak, K., Kato, J.Y., Solomon, M.J., Sherr, C.J., Massague, J., Roberts, J.M., and Koff, A. (1994). p27Kip1, a cyclin-Cdk inhibitor, links transforming growth factor-beta and contact inhibition to cell cycle arrest. Genes Dev 8, 9-22.

128. Poon, R.Y., Toyoshima, H., and Hunter, T. (1995). Redistribution of the CDK inhibitor p27 between different cyclin.CDK complexes in the mouse fibroblast cell cycle and in cells arrested with lovastatin or ultraviolet irradiation. Mol Biol Cell 6, 1197-1213.

129. Portet, F., Brickman, A.M., Stern, Y., Scarmeas, N., Muraskin, J., Provenzano, F.A., Berr, C., Bonafe, A., Artero, S., Ritchie, K., et al. (2012). Metabolic syndrome and localization of white matter hyperintensities in the elderly population. Alzheimers Dement 8, S88-95 e81.

130. Rachidi, W., Vilette, D., Guiraud, P., Arlotto, M., Riondel, J., Laude, H., Lehmann, S., and Favier, A. (2003). Expression of prion protein increases cellular copper binding and antioxidant enzyme activities but not copper delivery. J Biol Chem 278, 90649072.

131. Radovanovic, I., Braun, N., Giger, O.T., Mertz, K., Miele, G., Prinz, M., Navarro, B., and Aguzzi, A. (2005). Truncated prion protein and Doppel are myelinotoxic in the absence of oligodendrocytic PrPC. J Neurosci 25, 4879-4888.

132. Reed, B.R., Marchant, N.L., Jagust, W.J., DeCarli, C.C., Mack, W., and Chui, H.C. (2012). Coronary risk correlates with cerebral amyloid deposition. Neurobiol Aging 33, 1979-1987. 
133. Reiniger, L., Lukic, A., Linehan, J., Rudge, P., Collinge, J., Mead, S., and Brandner, S. (2011). Tau, prions and Abeta: the triad of neurodegeneration. Acta Neuropathol $121,5-20$.

134. Reutelingsperger, C.P., and van Heerde, W.L. (1997). Annexin V, the regulator of phosphatidylserine-catalyzed inflammation and coagulation during apoptosis. Cell Mol Life Sci 53, 527-532.

135. Roesler, R., Walz, R., Quevedo, J., de-Paris, F., Zanata, S.M., Graner, E., Izquierdo, I., Martins, V.R., and Brentani, R.R. (1999). Normal inhibitory avoidance learning and anxiety, but increased locomotor activity in mice devoid of $\operatorname{Pr}(\mathrm{C})$. Brain Res Mol Brain Res 71, 349-353.

136. Roucou, X., and LeBlanc, A.C. (2005). Cellular prion protein neuroprotective function: implications in prion diseases. J Mol Med (Berl) 83, 3-11.

137. Sakaguchi, S., Katamine, S., Nishida, N., Moriuchi, R., Shigematsu, K., Sugimoto, T., Nakatani, A., Kataoka, Y., Houtani, T., Shirabe, S., et al. (1996). Loss of cerebellar Purkinje cells in aged mice homozygous for a disrupted PrP gene. Nature 380, 528531.

138. Sakurai-Yamashita, Y., Sakaguchi, S., Yoshikawa, D., Okimura, N., Masuda, Y., Katamine, S., and Niwa, M. (2005). Female-specific neuroprotection against transient brain ischemia observed in mice devoid of prion protein is abolished by ectopic expression of prion protein-like protein. Neuroscience 136, 281-287.

139. Sanyal, A.J., Campbell-Sargent, C., Mirshahi, F., Rizzo, W.B., Contos, M.J., Sterling, R.K., Luketic, V.A., Shiffman, M.L., and Clore, J.N. (2001). Nonalcoholic steatohepatitis: association of insulin resistance and mitochondrial abnormalities. Gastroenterology 120, 1183-1192.

140. Sarnataro, D., Campana, V., Paladino, S., Stornaiuolo, M., Nitsch, L., and Zurzolo, C. (2004). PrP(C) association with lipid rafts in the early secretory pathway stabilizes its cellular conformation. Mol Biol Cell 15, 4031-4042.

141. Schmitz M, Wulf K, Signore SC, Schulz-Schaeffer WJ, Kermer P, Bähr M, Wouters FS, Zafar S, Zerr I (2014). Impact of the cellular prion protein on amyloid- $\beta$ and 3POtau processing. J Alzheimers Dis. 38(3), 551-65.

142.Schmitz, M., Zafar, S., Silva, C.J., and Zerr, I. (2014). Behavioral abnormalities in prion protein knockout mice and the potential relevance of $\operatorname{PrP}(C)$ for the cytoskeleton. Prion 8, 381-386.

143. Schneider, K., Korkmaz, Y., Addicks, K., Lang, H., and Raab, W.H. (2007). Prion protein (PrP) in human teeth: an unprecedented pointer to PrP's function. J Endod 33, 110-113. 
144.Sheffield, W.P., Shore, G.C., and Randall, S.K. (1990). Mitochondrial precursor protein. Effects of 70-kilodalton heat shock protein on polypeptide folding, aggregation, and import competence. J Biol Chem 265, 11069-11076.

145. Shen, X.D., Ke, B., Zhai, Y., Tsuchihashi, S.I., Gao, F., Duarte, S., Coito, A., Busuttil, R.W., Allison, A.C., and Kupiec-Weglinski, J.W. (2007). Diannexin, a novel annexin V homodimer, protects rat liver transplants against cold ischemia-reperfusion injury. Am J Transplant 7, 2463-2471.

146. Shields, D.J., Niessen, S., Murphy, E.A., Mielgo, A., Desgrosellier, J.S., Lau, S.K., Barnes, L.A., Lesperance, J., Bouvet, M., Tarin, D., et al. (2010). RBBP9: a tumorassociated serine hydrolase activity required for pancreatic neoplasia. Proc Natl Acad Sci U S A 107, 2189-2194.

147. Shimura, H., Miura-Shimura, Y., and Kosik, K.S. (2004). Binding of tau to heat shock protein 27 leads to decreased concentration of hyperphosphorylated tau and enhanced cell survival. J Biol Chem 279, 17957-17962.

148. Shmerling, D., Hegyi, I., Fischer, M., Blattler, T., Brandner, S., Gotz, J., Rulicke, T., Flechsig, E., Cozzio, A., von Mering, C., et al. (1998). Expression of amino-terminally truncated PrP in the mouse leading to ataxia and specific cerebellar lesions. Cell 93, 203-214.

149. Silverman GL, Qin K, Moore RC et al. Doppel is an N-glycosylated, glycosylphosphatidylinositol-anchored protein (2000). Expression in testis and ectopic production in the brains of Prnpo/o mice predisposed to Purkinje cell loss. J Biol Chem 275, 26834-41.

150. Singal, A., Tirkey, N., Pilkhwal, S., and Chopra, K. (2006). Green tea (Camellia sinensis) extract ameliorates endotoxin induced sickness behavior and liver damage in rats. Phytother Res 20, 125-129.

151.Soos, T.J., Kiyokawa, H., Yan, J.S., Rubin, M.S., Giordano, A., DeBlasio, A., Bottega, S., Wong, B., Mendelsohn, J., and Koff, A. (1996). Formation of p27-CDK complexes during the human mitotic cell cycle. Cell Growth Differ 7, 135-146.

152. Spudich, A., Frigg, R., Kilic, E., Kilic, U., Oesch, B., Raeber, A., Bassetti, C.L., and Hermann, D.M. (2005). Aggravation of ischemic brain injury by prion protein deficiency: role of ERK-1/-2 and STAT-1. Neurobiol Dis 20, 442-449.

153. Stahl, N., Borchelt, D.R., Hsiao, K., and Prusiner, S.B. (1987). Scrapie prion protein contains a phosphatidylinositol glycolipid. Cell 51, 229-240.

154. Steele, A.D., Emsley, J.G., Ozdinler, P.H., Lindquist, S., and Macklis, J.D. (2006). Prion protein (PrPC) positively regulates neural precursor proliferation during developmental and adult mammalian neurogenesis. Proc Natl Acad Sci U S A 103, 3416-3421. 
155. Steele, A.D., Hutter, G., Jackson, W.S., Heppner, F.L., Borkowski, A.W., King, O.D., Raymond, G.J., Aguzzi, A., and Lindquist, S. (2008). Heat shock factor 1 regulates lifespan as distinct from disease onset in prion disease. Proc Natl Acad Sci U S A 105, 13626-13631.

156. Steele, A.D., Lindquist, S., and Aguzzi, A. (2007). The prion protein knockout mouse: a phenotype under challenge. Prion 1, 83-93.

157. Sutcliffe, J.G., Hedlund, P.B., Thomas, E.A., Bloom, F.E., and Hilbush, B.S. (2011). Peripheral reduction of beta-amyloid is sufficient to reduce brain beta-amyloid: implications for Alzheimer's disease. J Neurosci Res 89, 808-814.

158. Sydor, S., Gu, Y., Schlattjan, M., Bechmann, L.P., Rauen, U., Best, J., Paul, A., Baba, H.A., Sowa, J.P., Gerken, G., et al. (2013). Steatosis does not impair liver regeneration after partial hepatectomy. Lab Invest 93, 20-30.

159. Takano, S., Wadhwa, R., Mitsui, Y., and Kaul, S.C. (2001). Identification and characterization of molecular interactions between glucose-regulated proteins (GRPs) mortalin/GRP75/peptide-binding protein 74 (PBP74) and GRP94. Biochem J 357, 393-398.

160. Thackray, A.M., Madec, J.Y., Wong, E., Morgan-Warren, R., Brown, D.R., Baron, T., and Bujdoso, R. (2003). Detection of bovine spongiform encephalopathy, ovine scrapie prion-related protein (PrPSc) and normal PrPC by monoclonal antibodies raised to copper-refolded prion protein. Biochem J 370, 81-90.

161. Thackray, A.M., Ryder, S.J., and Bujdoso, R. (2005). Modification of blood cell PrP epitope exposure during prion disease. Biochem J 390, 563-571.

162. Tobler, I., Gaus, S.E., Deboer, T., Achermann, P., Fischer, M., Rulicke, T., Moser, M., Oesch, B., McBride, P.A., and Manson, J.C. (1996). Altered circadian activity rhythms and sleep in mice devoid of prion protein. Nature 380, 639-642.

163. Toyoshima, H., and Hunter, T. (1994). p27, a novel inhibitor of G1 cyclin-Cdk protein kinase activity, is related to p21. Cell 78, 67-74.

164. Valenti, P., Cozzio, A., Nishida, N., Wolfer, D.P., Sakaguchi, S., and Lipp, H.P. (2001). Similar target, different effects: late-onset ataxia and spatial learning in prion protein-deficient mouse lines. Neurogenetics 3, 173-184.

165. Vassallo, N., and Herms, J. (2003). Cellular prion protein function in copper homeostasis and redox signalling at the synapse. J Neurochem 86, 538-544.

166. Wadhwa, R., Yaguchi, T., Hasan, M.K., Mitsui, Y., Reddel, R.R., and Kaul, S.C. (2002). Hsp70 family member, mot-2/mthsp70/GRP75, binds to the cytoplasmic sequestration domain of the p53 protein. Exp Cell Res 274, 246-253. 
167. Waggoner, D.J., Drisaldi, B., Bartnikas, T.B., Casareno, R.L., Prohaska, J.R., Gitlin, J.D., and Harris, D.A. (2000). Brain copper content and cuproenzyme activity do not vary with prion protein expression level. J Biol Chem 275, 7455-7458.

168. Walhovd, K.B., Storsve, A.B., Westlye, L.T., Drevon, C.A., and Fjell, A.M. (2014). Blood markers of fatty acids and vitamin D, cardiovascular measures, body mass index, and physical activity relate to longitudinal cortical thinning in normal aging. Neurobiol Aging 35, 1055-1064.

169. Walsh, M.J., Vanags, D.M., Clouston, A.D., Richardson, M.M., Purdie, D.M., Jonsson, J.R., and Powell, E.E. (2004). Steatosis and liver cell apoptosis in chronic hepatitis C: a mechanism for increased liver injury. Hepatology 39, 1230-1238.

170.Walz, R., Amaral, O.B., Rockenbach, I.C., Roesler, R., Izquierdo, I., Cavalheiro, E.A., Martins, V.R., and Brentani, R.R. (1999). Increased sensitivity to seizures in mice lacking cellular prion protein. Epilepsia 40, 1679-1682.

171.Wang, A.G., Moon, H.B., Chae, J.I., Kim, J.M., Kim, Y.E., Yu, D.Y., and Lee, D.S. (2011). Steatosis induced by the accumulation of apolipoprotein A-I and elevated ROS levels in H-ras12V transgenic mice contributes to hepatic lesions. Biochem Biophys Res Commun 409, 532-538.

172. Wang, K. (2014). Molecular mechanisms of hepatic apoptosis. Cell Death Dis 5, e996.

173. Watarai, M., Kim, S., Erdenebaatar, J., Makino, S., Horiuchi, M., Shirahata, T., Sakaguchi, S., and Katamine, S. (2003). Cellular prion protein promotes Brucella infection into macrophages. J Exp Med 198, 5-17.

174. Watt, N.T., Taylor, D.R., Gillott, A., Thomas, D.A., Perera, W.S., and Hooper, N.M. (2005). Reactive oxygen species-mediated beta-cleavage of the prion protein in the cellular response to oxidative stress. J Biol Chem 280, 35914-35921.

175.Waxman, D.J., and Holloway, M.G. (2009). Sex differences in the expression of hepatic drug metabolizing enzymes. Mol Pharmacol 76, 215-228.

176. Weise, J., Sandau, R., Schwarting, S., Crome, O., Wrede, A., Schulz-Schaeffer, W., Zerr, I., and Bahr, M. (2006). Deletion of cellular prion protein results in reduced Akt activation, enhanced postischemic caspase-3 activation, and exacerbation of ischemic brain injury. Stroke 37, 1296-1300.

177. Whittington, M.A., Sidle, K.C., Gowland, I., Meads, J., Hill, A.F., Palmer, M.S., Jefferys, J.G., and Collinge, J. (1995). Rescue of neurophysiological phenotype seen in PrP null mice by transgene encoding human prion protein. Nat Genet 9, 197-201.

178. Wilkins, S., Choglay, A.A., Chapple, J.P., van der Spuy, J., Rhie, A., Birkett, C.R., and Cheetham, M.E. (2010). The binding of the molecular chaperone Hsc70 to the prion protein PrP is modulated by $\mathrm{pH}$ and copper. Int J Biochem Cell Biol 42, 1226-1232. 
179. Williams, V.J., Leritz, E.C., Shepel, J., McGlinchey, R.E., Milberg, W.P., Rudolph, J.L., Lipsitz, L.A., and Salat, D.H. (2013). Interindividual variation in serum cholesterol is associated with regional white matter tissue integrity in older adults. Hum Brain Mapp 34, 1826-1841.

180. Williams, W.M., Stadtman, E.R., and Moskovitz, J. (2004). Ageing and exposure to oxidative stress in vivo differentially affect cellular levels of $\operatorname{PrP}$ in mouse cerebral microvessels and brain parenchyma. Neuropathol Appl Neurobiol 30, 161-168.

181.Wong, B.S., Brown, D.R., Pan, T., Whiteman, M., Liu, T., Bu, X., Li, R., Gambetti, P., Olesik, J., Rubenstein, R., et al. (2001a). Oxidative impairment in scrapie-infected mice is associated with brain metals perturbations and altered antioxidant activities. $\mathrm{J}$ Neurochem 79, 689-698.

182. Wong, B.S., Liu, T., Li, R., Pan, T., Petersen, R.B., Smith, M.A., Gambetti, P., Perry, G., Manson, J.C., Brown, D.R., et al. (2001b). Increased levels of oxidative stress markers detected in the brains of mice devoid of prion protein. J Neurochem 76, 565572.

183.Xiang, W., Windl, O., Westner, I.M., Neumann, M., Zerr, I., Lederer, R.M., and Kretzschmar, H.A. (2005). Cerebral gene expression profiles in sporadic CreutzfeldtJakob disease. Ann Neurol 58, 242-257.

184. Xiang, W., Windl, O., Wunsch, G., Dugas, M., Kohlmann, A., Dierkes, N., Westner, I.M., and Kretzschmar, H.A. (2004). Identification of differentially expressed genes in scrapie-infected mouse brains by using global gene expression technology. J Virol 78, 11051-11060.

185. Yalcin, E.B., More, V., Neira, K.L., Lu, Z.J., Cherrington, N.J., Slitt, A.L., and King, R.S. (2013). Downregulation of sulfotransferase expression and activity in diseased human livers. Drug Metab Dispos 41, 1642-1650.

186.Zeng, X.Y., Zhou, X., Xu, J., Chan, S.M., Xue, C.L., Molero, J.C., and Ye, J.M. (2012). Screening for the efficacy on lipid accumulation in 3T3-L1 cells is an effective tool for the identification of new anti-diabetic compounds. Biochem Pharmacol 84, 830-837.

187.Zhang, C.C., Steele, A.D., Lindquist, S., and Lodish, H.F. (2006). Prion protein is expressed on long-term repopulating hematopoietic stem cells and is important for their self-renewal. Proc Natl Acad Sci U S A 103, 2184-2189.

188. Zhang, L., Perdomo, G., Kim, D.H., Qu, S., Ringquist, S., Trucco, M., and Dong, H.H. (2008). Proteomic analysis of fructose-induced fatty liver in hamsters. Metabolism 57, 1115-1124. 
189.Zhang, M., Wang, X., Jiang, F., Wang, W., Vincent, I., and Bu, B. (2010). Mitotic epitopes are incorporated into age-dependent neurofibrillary tangles in Niemann-Pick disease type C. Brain Pathol 20, 367-377.

190.Zhang, Y., Spiess, E., Groschup, M.H., and Burkle, A. (2003a). Up-regulation of cathepsin B and cathepsin L activities in scrapie-infected mouse Neuro2a cells. J Gen Virol 84, 2279-2283.

191.Zhang, Y., Zanotti, I., Reilly, M.P., Glick, J.M., Rothblat, G.H., and Rader, D.J. (2003b). Overexpression of apolipoprotein A-I promotes reverse transport of cholesterol from macrophages to feces in vivo. Circulation 108, 661-663.

192.Zomosa-Signoret, V., Arnaud, J.D., Fontes, P., Alvarez-Martinez, M.T., and Liautard, J.P. (2008). Physiological role of the cellular prion protein. Vet Res 39, 9. 


\section{INDEX}

\section{Table 1 - Network 1 liver}

\begin{tabular}{|c|c|c|c|c|}
\hline Symbol & Entrez Gene Name & $\begin{array}{l}\text { GenPept/UniProt/Sw } \\
\text { iss-Prot Accession }\end{array}$ & $\begin{array}{c}\text { Fold } \\
\text { Change }\end{array}$ & Location \\
\hline ATP7B & ATPase, $\mathrm{Cu}++$ transporting, beta polypeptide & & & Cytoplasm \\
\hline ECH1 & enoyl CoA hydratase 1 , peroxisomal & O35459 & 6.71 & Cytoplasm \\
\hline FDPS & farnesyl diphosphate synthase & Q920E5 & -2.28 & Cytoplasm \\
\hline FTH1 & ferritin, heavy polypeptide 1 & P09528 & 2.08 & Cytoplasm \\
\hline G6PC & glucose-6-phosphatase, catalytic subunit & & & Cytoplasm \\
\hline GPD1 & $\begin{array}{l}\text { glycerol-3-phosphate dehydrogenase } 1 \\
\text { (soluble) }\end{array}$ & & & Cytoplasm \\
\hline $\begin{array}{l}\text { GSTT2/GSTT2 } \\
\text { B }\end{array}$ & glutathione S-transferase theta 2 & & & Cytoplasm \\
\hline GSTZ1 & glutathione S-transferase zeta 1 & Q9WVL0 & 2.3 & Cytoplasm \\
\hline HIST1H1C & histone cluster $1, \mathrm{H} 1 \mathrm{c}$ & P15864 & -2.48 & Nucleus \\
\hline IDH3A & isocitrate dehydrogenase $3(\mathrm{NAD}+)$ alpha & Q9D6R2 & -2.29 & Cytoplasm \\
\hline INSR & insulin receptor & & & $\begin{array}{l}\text { Plasma } \\
\text { Membrane }\end{array}$ \\
\hline LEP & Leptin & & & $\begin{array}{l}\text { Extracellul } \\
\text { ar Space }\end{array}$ \\
\hline MAPK14 & mitogen-activated protein kinase 14 & & & Cytoplasm \\
\hline MDH2 & malate dehydrogenase 2, NAD (mitochondrial) & & & Cytoplasm \\
\hline MRPL12 & mitochondrial ribosomal protein $\mathrm{L} 12$ & Q9DB15 & 2.07 & Cytoplasm \\
\hline NDUFV2 & $\begin{array}{l}\text { NADH dehydrogenase (ubiquinone) } \\
\text { flavoprotein } 2,24 \mathrm{kDa}\end{array}$ & Q9D6J6 & -1.8 & Cytoplasm \\
\hline NFE2L2 & nuclear factor, erythroid 2-like 2 & & & Nucleus \\
\hline NR1H4 & $\begin{array}{l}\text { nuclear receptor subfamily } 1 \text {, group } \mathrm{H} \text {, } \\
\text { member } 4\end{array}$ & & & Nucleus \\
\hline POR & P450 (cytochrome) oxidoreductase & & & Cytoplasm \\
\hline PPA1 & pyrophosphatase (inorganic) 1 & & & Cytoplasm \\
\hline PPARA & $\begin{array}{l}\text { peroxisome proliferator-activated receptor } \\
\text { alpha }\end{array}$ & & & Nucleus \\
\hline PPARGC1A & $\begin{array}{l}\text { peroxisome proliferator-activated receptor } \\
\text { gamma, coactivator } 1 \text { alpha }\end{array}$ & & & Nucleus \\
\hline PSMA7 & $\begin{array}{l}\text { proteasome (prosome, macropain) subunit, } \\
\text { alpha type, } 7\end{array}$ & & & Cytoplasm \\
\hline PSMB4 & $\begin{array}{l}\text { proteasome (prosome, macropain) subunit, } \\
\text { beta type, } 4\end{array}$ & & & Cytoplasm \\
\hline PSMC3 & $\begin{array}{l}\text { proteasome (prosome, macropain) } 26 \mathrm{~S} \\
\text { subunit, ATPase, } 3\end{array}$ & & & Nucleus \\
\hline
\end{tabular}




\begin{tabular}{|llll|}
\hline PSMD14 & $\begin{array}{l}\text { proteasome (prosome, macropain) 26S } \\
\text { subunit, non-ATPase, 14 }\end{array}$ & Cytoplasm \\
\hline PSMD7 & $\begin{array}{l}\text { proteasome (prosome, macropain) 26S } \\
\text { subunit, non-ATPase, }\end{array}$ & Cytoplasm \\
\hline RICTOR & $\begin{array}{l}\text { RPTOR independent companion of MTOR, } \\
\text { complex 2 }\end{array}$ & & Cytoplasm \\
\hline RPLP0 & ribosomal protein, large, P0 & P97351 & Cytoplasm \\
\hline Rps3a1 & ribosomal protein S3A1 & 2.15 & Cytoplasm \\
\hline SERPINB1 & $\begin{array}{l}\text { serpin peptidase inhibitor, clade B (ovalbumin), } \\
\text { member 1 }\end{array}$ & Q9D154 & Cytoplasm \\
\hline SIRT3 & sirtuin 3 & & Cytoplasm \\
\hline TALDO1 & transaldolase 1 & Q93092 & Cytoplasm \\
\hline THRB & thyroid hormone receptor, beta & & Nucleus \\
\hline TPI1 & triosephosphate isomerase 1 & P17751 & Cytoplasm \\
\hline
\end{tabular}

\section{Table 2 - Network 2 liver}

\begin{tabular}{|c|c|c|c|c|}
\hline Symbol & Entrez Gene Name & $\begin{array}{l}\text { GenPept/UniProt/Sw } \\
\text { iss-Prot Accession }\end{array}$ & $\begin{array}{l}\text { Fold } \\
\text { Change }\end{array}$ & Location \\
\hline ATP7B & $\begin{array}{l}\text { ATPase, Cu++ transporting, beta } \\
\text { polypeptide }\end{array}$ & & & Cytoplasm \\
\hline $\mathrm{ECH} 1$ & enoyl CoA hydratase 1 , peroxisomal & O35459 & 6.71 & Cytoplasm \\
\hline FDPS & farnesyl diphosphate synthase & Q920E5 & -2.28 & Cytoplasm \\
\hline FTH1 & ferritin, heavy polypeptide 1 & P09528 & 2.08 & Cytoplasm \\
\hline G6PC & glucose-6-phosphatase, catalytic subunit & & & Cytoplasm \\
\hline GPD1 & $\begin{array}{l}\text { glycerol-3-phosphate dehydrogenase } 1 \\
\text { (soluble) }\end{array}$ & & & Cytoplasm \\
\hline GSTT2/GSTT2B & glutathione S-transferase theta 2 & & & Cytoplasm \\
\hline GSTZ1 & glutathione S-transferase zeta 1 & Q9WVL0 & 2.3 & Cytoplasm \\
\hline HIST1H1C & histone cluster $1, \mathrm{H} 1 \mathrm{c}$ & P15864 & -2.48 & Nucleus \\
\hline IDH3A & $\begin{array}{l}\text { isocitrate dehydrogenase } 3(\mathrm{NAD}+) \\
\text { alpha }\end{array}$ & Q9D6R2 & -2.29 & Cytoplasm \\
\hline INSR & insulin receptor & & & $\begin{array}{l}\text { Plasma } \\
\text { Membrane }\end{array}$ \\
\hline LEP & Leptin & & & $\begin{array}{l}\text { Extracellul } \\
\text { ar Space }\end{array}$ \\
\hline MAPK14 & mitogen-activated protein kinase 14 & & & Cytoplasm \\
\hline MDH2 & $\begin{array}{l}\text { malate dehydrogenase } 2, \text { NAD } \\
\text { (mitochondrial) }\end{array}$ & & & Cytoplasm \\
\hline MRPL12 & mitochondrial ribosomal protein $\mathrm{L} 12$ & Q9DB15 & 2.07 & Cytoplasm \\
\hline
\end{tabular}




\begin{tabular}{|c|c|c|c|c|}
\hline NDUFV2 & $\begin{array}{l}\text { NADH dehydrogenase (ubiquinone) } \\
\text { flavoprotein } 2,24 \mathrm{kDa}\end{array}$ & Q9D6J6 & -1.8 & Cytoplasm \\
\hline NFE2L2 & nuclear factor, erythroid 2-like 2 & & & Nucleus \\
\hline NR1H4 & $\begin{array}{l}\text { nuclear receptor subfamily } 1 \text {, group } \mathrm{H} \text {, } \\
\text { member } 4\end{array}$ & & & Nucleus \\
\hline POR & P450 (cytochrome) oxidoreductase & & & Cytoplasm \\
\hline PPA1 & pyrophosphatase (inorganic) 1 & & & Cytoplasm \\
\hline PPARA & $\begin{array}{l}\text { peroxisome proliferator-activated } \\
\text { receptor alpha }\end{array}$ & & & Nucleus \\
\hline PPARGC1A & $\begin{array}{l}\text { peroxisome proliferator-activated } \\
\text { receptor gamma, coactivator } 1 \text { alpha }\end{array}$ & & & Nucleus \\
\hline PSMA7 & $\begin{array}{l}\text { proteasome (prosome, macropain) } \\
\text { subunit, alpha type, } 7\end{array}$ & & & Cytoplasm \\
\hline PSMB4 & $\begin{array}{l}\text { proteasome (prosome, macropain) } \\
\text { subunit, beta type, } 4\end{array}$ & & & Cytoplasm \\
\hline PSMC3 & $\begin{array}{l}\text { proteasome (prosome, macropain) } 26 \mathrm{~S} \\
\text { subunit, ATPase, } 3\end{array}$ & & & Nucleus \\
\hline PSMD14 & $\begin{array}{l}\text { proteasome (prosome, macropain) } 26 \mathrm{~S} \\
\text { subunit, non-ATPase, } 14\end{array}$ & & & Cytoplasm \\
\hline PSMD7 & $\begin{array}{l}\text { proteasome (prosome, macropain) } 26 \mathrm{~S} \\
\text { subunit, non-ATPase, } 7\end{array}$ & & & Cytoplasm \\
\hline RICTOR & $\begin{array}{l}\text { RPTOR independent companion of } \\
\text { MTOR, complex } 2\end{array}$ & & & Cytoplasm \\
\hline RPLP0 & ribosomal protein, large, P0 & & & Cytoplasm \\
\hline Rps3a1 & ribosomal protein S3A1 & P97351 & -2.15 & Cytoplasm \\
\hline SERPINB1 & $\begin{array}{l}\text { serpin peptidase inhibitor, clade B } \\
\text { (ovalbumin), member } 1\end{array}$ & Q9D154 & 2.23 & Cytoplasm \\
\hline SIRT3 & sirtuin 3 & & & Cytoplasm \\
\hline TALD01 & transaldolase 1 & Q93092 & -1.82 & Cytoplasm \\
\hline THRB & thyroid hormone receptor, beta & & & Nucleus \\
\hline TPI1 & triosephosphate isomerase 1 & P17751 & 2.29 & Cytoplasm \\
\hline
\end{tabular}

\section{Table 3 - Network 3 liver}

\begin{tabular}{|lllll|}
\hline Symbol & Entrez Gene Name & $\begin{array}{l}\text { GenPept/UniProt/Sw } \\
\text { iss-Prot Accession }\end{array}$ & $\begin{array}{l}\text { Fold } \\
\text { Change }\end{array}$ & Location \\
\hline ACTA2 & actin, alpha 2, smooth muscle, aorta & P62737 & -4.96 & Cytoplasm \\
\hline ACY1 & aminoacylase 1 & Q99JW2 & -2.06 & Cytoplasm \\
\hline AHR & aryl hydrocarbon receptor & & Nucleus \\
\hline APOA4 & apolipoprotein A-IV & & $\begin{array}{l}\text { Extracellul } \\
\text { ar Space }\end{array}$ \\
\hline
\end{tabular}




\begin{tabular}{|c|c|c|c|c|}
\hline C6 & complement component 6 & & & $\begin{array}{l}\text { Extracellul } \\
\text { ar Space }\end{array}$ \\
\hline CCND1 & cyclin D1 & & & Nucleus \\
\hline CDKN1B & $\begin{array}{l}\text { cyclin-dependent kinase inhibitor 1B } \\
\text { (p27, Kip1) }\end{array}$ & P46414 & 2.32 & Nucleus \\
\hline CTNNB1 & $\begin{array}{l}\text { catenin (cadherin-associated protein), } \\
\text { beta } 1,88 \mathrm{kDa}\end{array}$ & & & Nucleus \\
\hline CYP1A2 & $\begin{array}{l}\text { cytochrome P } 450 \text {, family } 1 \text {, subfamily A, } \\
\text { polypeptide } 2\end{array}$ & & & Cytoplasm \\
\hline $\begin{array}{l}\text { Cyp2d9 (includes } \\
\text { others) }\end{array}$ & $\begin{array}{l}\text { cytochrome } \mathrm{P} 450 \text {, family } 2 \text {, subfamily } \mathrm{d} \text {, } \\
\text { polypeptide } 9\end{array}$ & & & Cytoplasm \\
\hline CYP2E1 & $\begin{array}{l}\text { cytochrome P } 450 \text {, family } 2 \text {, subfamily E, } \\
\text { polypeptide } 1\end{array}$ & & & Cytoplasm \\
\hline EFTUD2 & $\begin{array}{l}\text { elongation factor Tu GTP binding } \\
\text { domain containing } 2\end{array}$ & O08810 & -1.81 & Nucleus \\
\hline Gm4794/Sult3a1 & sulfotransferase family $3 \mathrm{~A}$, member 1 & O35403 & -3.01 & Cytoplasm \\
\hline IGFBP2 & $\begin{array}{l}\text { insulin-like growth factor binding protein } \\
2,36 \mathrm{kDa}\end{array}$ & & & $\begin{array}{l}\text { Extracellul } \\
\text { ar Space }\end{array}$ \\
\hline Igtp & interferon gamma induced GTPase & & & Cytoplasm \\
\hline Mt1 & metallothionein 1 & & & Cytoplasm \\
\hline PPARD & $\begin{array}{l}\text { peroxisome proliferator-activated } \\
\text { receptor delta }\end{array}$ & & & Nucleus \\
\hline RGN & Regucalcin & Q64374 & -1.59 & Nucleus \\
\hline SCD & $\begin{array}{l}\text { stearoyl-CoA desaturase (delta-9- } \\
\text { desaturase) }\end{array}$ & & & Cytoplasm \\
\hline SLC13A1 & $\begin{array}{l}\text { solute carrier family } 13 \text { (sodium/sulfate } \\
\text { symporter), member } 1\end{array}$ & & & $\begin{array}{l}\text { Plasma } \\
\text { Membrane }\end{array}$ \\
\hline Slco1a1 & $\begin{array}{l}\text { solute carrier organic anion transporter } \\
\text { family, member } 1 \mathrm{a} 1\end{array}$ & & & $\begin{array}{l}\text { Plasma } \\
\text { Membrane }\end{array}$ \\
\hline SMAD7 & SMAD family member 7 & & & Nucleus \\
\hline SORD & sorbitol dehydrogenase & Q64442 & 2.24 & Cytoplasm \\
\hline STAT1 & $\begin{array}{l}\text { signal transducer and activator of } \\
\text { transcription } 1,91 \mathrm{kDa}\end{array}$ & & & Nucleus \\
\hline VLDLR & very low density lipoprotein receptor & & & $\begin{array}{l}\text { Plasma } \\
\text { Membrane }\end{array}$ \\
\hline XBP1 & X-box binding protein 1 & & & Nucleus \\
\hline АСТВ & actin, beta & P60710 & $-2,480$ & Cytoplasm \\
\hline MAFB & $\begin{array}{l}\text { v-maf avian musculoaponeurotic } \\
\text { fibrosarcoma oncogene homolog B }\end{array}$ & -- & & Nucleus \\
\hline
\end{tabular}


Table 4 - Brain networks

\begin{tabular}{|c|c|c|c|c|}
\hline ID & Molecules in Network & Score & $\begin{array}{c}\text { Focus } \\
\text { Molecules }\end{array}$ & $\begin{array}{l}\text { Top Diseases and } \\
\text { Functions }\end{array}$ \\
\hline 1 & ACTB,NAPA,RARA,YWHAG & 7 & 3 & $\begin{array}{l}\text { Cellular Development, } \\
\text { Nervous System Development } \\
\text { and Function, Tissue } \\
\text { Development }\end{array}$ \\
\hline 2 & ADCYAP1,SERPINB1 & 2 & 1 & $\begin{array}{l}\text { Cancer, Cell Morphology, Cell- } \\
\text { To-Cell Signaling and } \\
\text { Interaction }\end{array}$ \\
\hline 3 & KMT2D,SORD & 2 & 1 & $\begin{array}{l}\text { Carbohydrate Metabolism, } \\
\text { Small Molecule Biochemistry, } \\
\text { Developmental Disorder }\end{array}$ \\
\hline 4 & CTSZ,PSEN1,PSEN2 & 2 & 1 & $\begin{array}{l}\text { Hereditary Disorder, Metabolic } \\
\text { Disease, Nervous System } \\
\text { Development and Function }\end{array}$ \\
\hline 5 & FDPS,NR1H2,NR1H3 & 2 & 1 & $\begin{array}{l}\text { Endocrine System } \\
\text { Development and Function, } \\
\text { Endocrine System Disorders, } \\
\text { Nervous System Development } \\
\text { and Function }\end{array}$ \\
\hline 6 & VPS29,VPS35,VPS26A,VPS26B & 2 & 1 & $\begin{array}{l}\text { Hereditary Disorder, } \\
\text { Neurological Disease, } \\
\text { Psychological Disorders }\end{array}$ \\
\hline 7 & $\begin{array}{l}\text { CCNB1,CDK2,CDKN1B,COPS5,FOXO1,GATA2,KCTD } \\
\text { 11,LGALS3,LMX1A,LMX1B,MAP1S,RB1,TSC1,TSC2, } \\
\text { ZIC1,ZIC2 }\end{array}$ & 1 & 1 & $\begin{array}{l}\text { Cellular Development, Cellular } \\
\text { Growth and Proliferation, } \\
\text { Embryonic Development }\end{array}$ \\
\hline 8 & $\begin{array}{l}\text { ABCA1,APOD,APOE,APP,CREB1,CREM,ESR2,GSK3 } \\
\text { B,IL1B,LCAT,LDLR,LPIN1,MAP2,MAPT,PPARG,PRNP } \\
\text {,SERPINA3,SYP }\end{array}$ & 1 & 1 & $\begin{array}{l}\text { Metabolic Disease, } \\
\text { Neurological Disease, } \\
\text { Psychological Disorders }\end{array}$ \\
\hline
\end{tabular}

Table 5 - Calculations for PrPC expression (Capillary electrophoreis)

\begin{tabular}{|c|c|c|c|c|c|c|c|c|c|c|c|}
\hline & & Female & & & & & Male & & & & \\
\hline & & & & & & $\begin{array}{c}\text { Relative } \\
\text { PrP }^{\mathrm{C}} \\
\text { Expression }\end{array}$ & & & & & \\
\hline \multirow[t]{5}{*}{$3 \mathrm{M}$} & No & $\begin{array}{l}\text { PrP }^{C} \\
\text { peak }\end{array}$ & $\begin{array}{c}\text { Free } \\
\text { Peptide }\end{array}$ & $\begin{array}{c}\mathrm{Ab} \\
\text { Control }\end{array}$ & Ratio & $\begin{array}{l}\text { Areax } \\
\text { Ratio }\end{array}$ & $\begin{array}{c}\text { Area } \\
\text { under } \\
\text { the peak }\end{array}$ & $\begin{array}{c}\text { F. } \\
\text { Peptide }\end{array}$ & $\begin{array}{c}\mathrm{Ab} \\
\text { Control }\end{array}$ & Ratio & $\begin{array}{c}\text { Areax } \\
\text { Ratio }\end{array}$ \\
\hline & 1 & 152177 & 281386 & 122857 & 2,29 & 348539,17 & 152668 & 281386 & 122857 & 2,29 & $\begin{array}{c}349663 \\
, 74\end{array}$ \\
\hline & 2 & 127967 & 281386 & 122857 & 2,29 & 293089,71 & 122926 & 281386 & 122857 & 2,29 & $\begin{array}{c}281544 \\
, 03\end{array}$ \\
\hline & 3 & 140734 & 281386 & 122857 & 2,29 & 322330,66 & 145240 & 281386 & 122857 & 2,29 & $\begin{array}{c}332650 \\
, 99\end{array}$ \\
\hline & 4 & 140970 & 281386 & 122857 & 2,29 & 322871,18 & 124735 & 281386 & 122857 & 2,29 & $\begin{array}{c}285687 \\
, 28 \\
\end{array}$ \\
\hline \multirow[t]{5}{*}{$9 M$} & & Female & & & & & Male & & & & \\
\hline & & $\begin{array}{l}\text { PrP }^{C} \\
\text { peak }\end{array}$ & $\begin{array}{c}\text { Free } \\
\text { Peptide }\end{array}$ & $\begin{array}{c}\mathrm{Ab} \\
\text { control }\end{array}$ & Ratio & $\begin{array}{l}\text { Areax } \\
\text { Ratio }\end{array}$ & & $\begin{array}{c}\text { F. } \\
\text { peptide }\end{array}$ & $\begin{array}{c}\mathrm{Ab} \\
\text { control }\end{array}$ & Ratio & $\begin{array}{c}\text { Areax } \\
\text { Ratio }\end{array}$ \\
\hline & 1 & 130441 & 253032 & 77815,77 & 3,25 & 424152,44 & 108443 & 253032 & 77815,8 & 3,25 & $\begin{array}{c}352621 \\
, 98\end{array}$ \\
\hline & 2 & 118011 & 253032 & 77815,77 & 3,25 & 383734,05 & 105078 & 253032 & 77815,8 & 3,25 & $\begin{array}{c}341680 \\
, 07 \\
\end{array}$ \\
\hline & 3 & 103925 & 253032 & 77815,77 & 3,25 & 337930,88 & 104728 & 253032 & 77815,8 & 3,25 & $\begin{array}{c}340541 \\
, 98\end{array}$ \\
\hline
\end{tabular}




\begin{tabular}{|c|c|c|c|c|c|c|c|c|c|c|c|}
\hline & 4 & 118494 & 253032 & 77815,77 & 3,25 & 385304,61 & 109282 & 253032 & 77815,8 & 3,25 & $\begin{array}{c}355350 \\
, 14\end{array}$ \\
\hline & 5 & 118813 & 253032 & 77815,77 & 3,25 & 386341,9 & 89887,8 & 253032 & 77815,8 & 3,25 & $\begin{array}{c}292286 \\
, 4\end{array}$ \\
\hline & 6 & 108398 & 253032 & 77815,77 & 3,25 & 352475,65 & 84926,5 & 253032 & 77815,8 & 3,25 & $\begin{array}{c}276153 \\
, 83\end{array}$ \\
\hline & 7 & 115977 & 253032 & 77815,77 & 3,25 & 377120,13 & 77627,4 & 253032 & 77815,8 & 3,25 & $\begin{array}{c}252419 \\
, 5\end{array}$ \\
\hline & 8 & 134676 & 253032 & 77815,77 & 3,25 & 437923,3 & 84872,9 & 253032 & 77815,8 & 3,25 & $\begin{array}{c}275979 \\
, 54\end{array}$ \\
\hline & 9 & 116750 & 253032 & 77815,77 & 3,25 & 379633,68 & & & & & \\
\hline & 10 & 105437 & 253032 & 77815,77 & 3,25 & 342847,42 & & & & & \\
\hline & 11 & 91018,8 & 253032 & 77815,77 & 3,25 & 295964,05 & & & & & \\
\hline
\end{tabular}



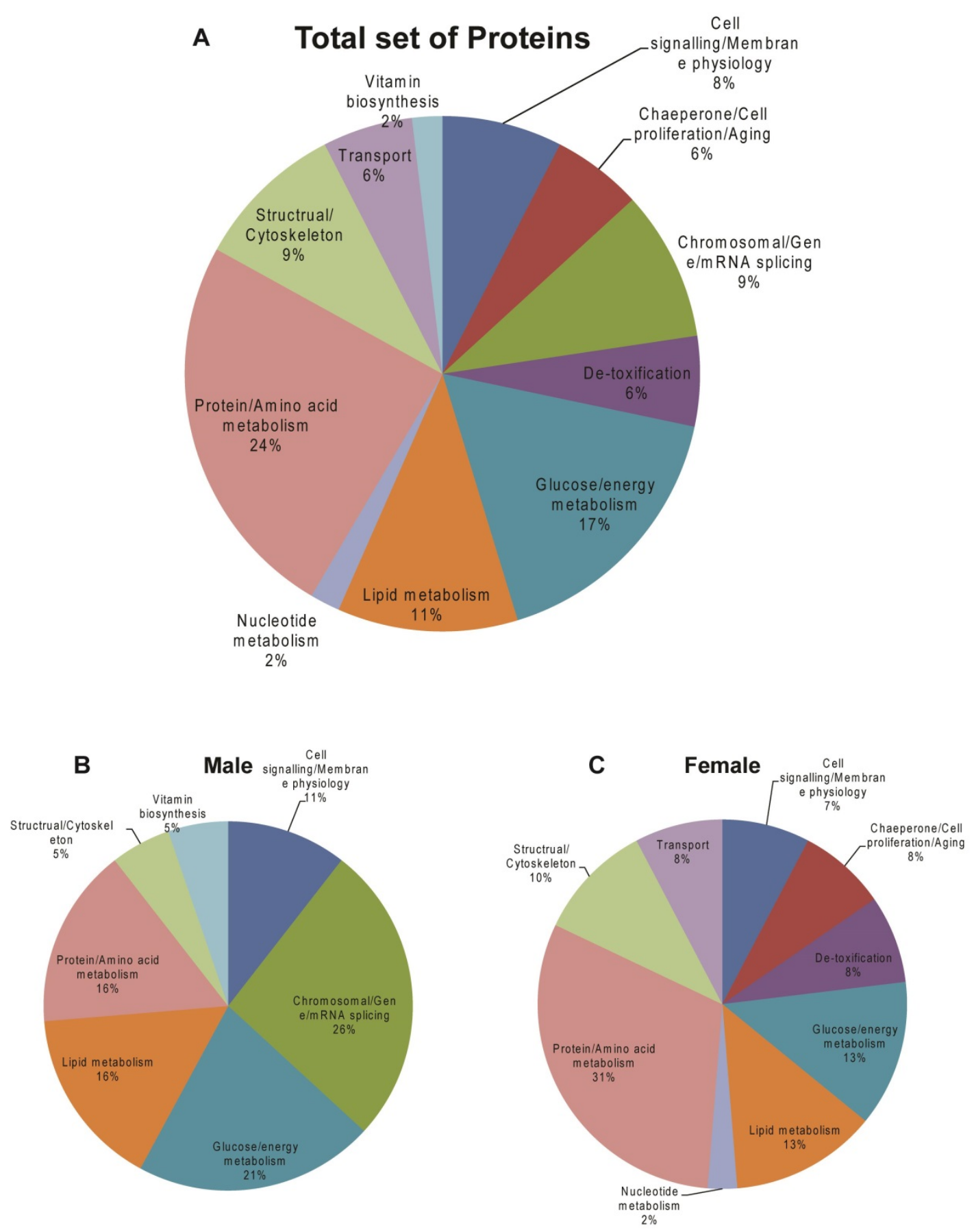

Fig.1. Functional classification based on PrPC dependent regulated proteins: (A) Total set of proteins regulated in PrP knockout mice liver as compared to wild type mice from all the groups. Major categories included Protein/Amino acid metabolism, lipid metabolism, and energy metabolism, gene/mRNA splicing. (B) and (C), sub-classification of regulated proteins from male and female groups respectively, shows a sex-dependent regulation of proteins from different categories with mRNA splicing group only present in male. 


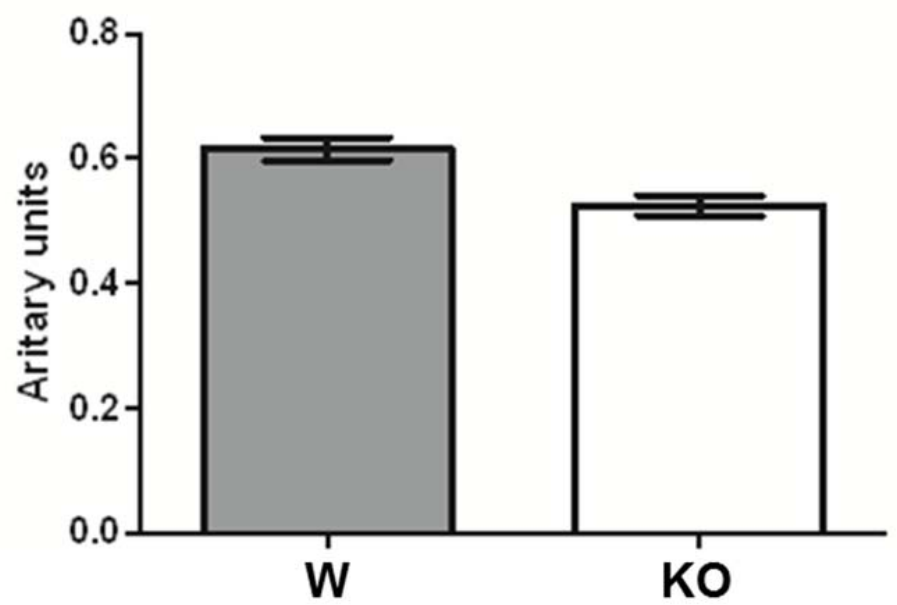

Fig. 2. Stress-70/GRP75 mRNA expression in 14 months old female mice liver: Significant higher expression of stress-70 mRNA in 14 months old female PrPC knockout mice liver has been correlated with identical regulation in proteomics data set. 
Chemicals

Methanol

Acetic acid

Sodium thiosulphate

Silver nitate

Formaldehyde

Sodium carbonate

Acetone

Triton X-100

PBS

BSA

Luminol

Dimehyl sulphate (DMSO)

p-Coumarsöure

Tris (Base)

Tris $(\mathrm{HCl})$

$\mathrm{HCl}$
Company

Milipore(MERCK)

Milipore(MERCK)

Sigma

milipore(MERCK)

Sigma

ROTH

Milipore(MERCK)

$\mathrm{ROTH}$

Milipore(MERCK)

ROTH

Sigma

Sigma

ROTH

ROTH

ROTH

Fluka

\section{ECL Solution}

Solution $1(10 \mathrm{ml})$

$100 \mu \mathrm{l}$ of $250 \mathrm{mM}$ Luminol (0.44g/10 ml DMSO)

$44 \mu \mathrm{l}$ of $90 \mathrm{mM}$ p-Coumarsäure (15g/10ml DMSO)

$1 \mathrm{ml}$ of 1.M Tris/HCL pH -8.5

$8.85 \mathrm{ml} \mathrm{H}_{2} \mathrm{O}$

Solution $2(10 \mathrm{ml})$

$6 \mu \mathrm{l}$ of $30 \% \mathrm{H}_{2} \mathrm{O}_{2}$

$1 \mathrm{ml}$ of Tris/HCL pH -8.5 


\section{Abbreviations}

\begin{tabular}{|ll|}
\hline Mouse age terminology & Years \\
\hline Aging mice & 14 months \\
\hline Advanced adult age mice & 9 months \\
\hline Adult age mice & 3 months \\
\hline \multicolumn{2}{|c|}{ Gasperini et al., 2014 } \\
\hline
\end{tabular}

\begin{tabular}{|lll|}
\hline Sr. No. & Abbreviation & Complete name \\
\hline $\mathbf{1}$ & $\mathrm{AD}$ & Alzheimer's disease \\
\hline $\mathbf{2}$ & $\mathrm{A} \beta$ & Amlyoid beta \\
\hline $\mathbf{3}$ & $\mathrm{BAX}$ & Bcl2-associated X protein \\
\hline $\mathbf{4}$ & $\mathrm{BCl} 2$ & B-cell lymphoma 2 \\
\hline $\mathbf{5}$ & $\mathrm{BSA}$ & Bovine serum albumin \\
\hline $\mathbf{6}$ & BSE & Bovine spongiform encephalopathy \\
\hline $\mathbf{7}$ & CCl 4 & Carbon tetrachloride \\
\hline $\mathbf{9}$ & CDK & Cyclin dependent kinase \\
\hline $\mathbf{1 0}$ & CDK5 & Cyclin dependent kinase 5 \\
\hline $\mathbf{1 1}$ & CFA & Capillary electrophoresis \\
\hline $\mathbf{1 2}$ & CHAPS & Cafeteria \\
& & $\begin{array}{l}\text { 3-[(3-Cholamidopropyl)dimethylammonio]-1- } \\
\text { propanesulfonate }\end{array}$ \\
\hline $\mathbf{1 3}$ & CJD & Creutzfeldt-Jakob disease \\
\hline $\mathbf{1 5}$ & DI & Delta(3,5)-Delta(2,4)-dienoyl-CoA isomerase \\
\hline $\mathbf{1 6}$ & Dpl & Dopple \\
\hline $\mathbf{1 7}$ & DTT & Dithiothreitol \\
\hline $\mathbf{1 8}$ & ELISA & Enzyme-linked immunosorbent assay \\
\hline $\mathbf{1 9}$ & ESI-Q-TOF & Electrospray ionization quadrupole time-of-flight \\
& & mass spectrometry \\
\hline $\mathbf{2 0}$ & ETC & Electron transport chain \\
\hline $\mathbf{2 1}$ & FDC & Follicular dendritic cells \\
\hline $\mathbf{2 2}$ & FFAs & Free Fatty acids \\
\hline & & \\
\hline
\end{tabular}




\begin{tabular}{|lll|}
\hline $\mathbf{2 3}$ & FFI & Fatal familial insomnia \\
\hline $\mathbf{2 4}$ & FITC & Fluorescein isothiocyanate \\
\hline $\mathbf{2 5}$ & FLD & Fatty liver disease \\
\hline $\mathbf{2 6}$ & FPP synthase & Farnesyl pyrophosphate synthase \\
\hline $\mathbf{2 7}$ & GPI & Glycosyl-phosphatidylinositol \\
\hline $\mathbf{2 8}$ & Gsk3Beta & Glycogen synthase kinase 3 beta \\
\hline $\mathbf{2 9}$ & GSTZ1 & Glutathione-S-transferase zeta 1 \\
\hline $\mathbf{3 0}$ & HAAO-3 & 3-hydroxyanthranilate 3, 4-dioxygenase \\
\hline $\mathbf{3 1}$ & HSC 71 & Heat shock cognate 71 kDa \\
\hline $\mathbf{3 2}$ & HSCs & Hepatic stellate cells \\
\hline $\mathbf{3 3}$ & INSR & Insulin receptor \\
\hline $\mathbf{3 4}$ & IPA & Ingenuity pathway analysis \\
\hline $\mathbf{3 5}$ & IPKB & Ingenuity Pathways Knowledge Base \\
\hline $\mathbf{3 6}$ & MAPT & Microtubule associated protein tau \\
\hline $\mathbf{3 7}$ & MD & Mallory bodies \\
\hline $\mathbf{3 8}$ & MDH & Malate dehydrogenase \\
\hline $\mathbf{3 9}$ & NALD & Non-alcoholic liver disease \\
\hline $\mathbf{4 0}$ & NASH & Non-alcoholic steatohepatitis \\
\hline $\mathbf{4 1}$ & ORF & Open reading frame \\
\hline $\mathbf{4 2}$ & p53 & Phosphoprotein 53 \\
\hline $\mathbf{4 3}$ & PAGE & Poly acrylamide gel electrophoresis \\
\hline $\mathbf{4 4}$ & P-gsk3Beta & Phospho - Glycogen synthase kinase 3 beta \\
\hline $\mathbf{4 5}$ & PPARa & Peroxisome proliferator-activated receptor alpha \\
\hline $\mathbf{4 6}$ & PrPC & Cellular prion protein \\
\hline $\mathbf{4 7}$ & PrPSc & Scrapie prion protein \\
\hline $\mathbf{4 8}$ & PVDF & Polyvinylidene fluoride \\
\hline $\mathbf{4 9}$ & RFU & Relative Fluorescent Units \\
\hline $\mathbf{5 0}$ & ROS & Reactive oxygen species \\
\hline $\mathbf{5 1}$ & SDH & Sorbitol dehydrogenase \\
\hline $\mathbf{5 2}$ & SDS & Sodium dodecyl sulfate \\
\hline
\end{tabular}




\begin{tabular}{|lll|}
\hline $\mathbf{5 5}$ & $\begin{array}{l}\text { Stress-70 } \\
(\text { GRP75) }\end{array}$ & Glucose-regulated protein 75 \\
\hline $\mathbf{5 6}$ & SULT1A3 & Sulfotransferase including \\
\hline $\mathbf{5 7}$ & TAP & $\begin{array}{l}\text { 3-[[1,3-dihydroxy-2-(hydroxymethyl)propan-2- } \\
\text { yl]amino]propane-1-sulfonic acid }\end{array}$ \\
\hline $\mathbf{5 8}$ & TGF- $\beta$ & Transforming growth factor beta \\
\hline $\mathbf{5 9}$ & TSEs & Transmissible spongiform encephalopathies \\
\hline
\end{tabular}




\section{Curriculum vitae}

Name - Amandeep Singh Arora

Born - 08-11-1983, Jalandhar (Punjab), India

Home address - House no. 310/Phase - 7, SAS Nagar - 160062 (INDIA)

Qualifications - Bachelors (BSc) and Masters of Science (MSc.) in (Hons) in

Biochemistry from Panjab University, Chandigarh. India.

\section{List of publications}

1. Cerebrospinal fluid tau levels are a marker for molecular subtype in sporadic Creutzfeldt-Jakob disease.

André Karch, Peter Hermann, Claudia Ponto, Matthias Schmitz, Amandeep Arora, Saima Zafar, Franc Llorens, Annika Müller-Heine, Inga Zerr. Neurobiology of Aging. 02/2015 (Published)

2. Age and Gender dependent regulated expression of PrPC in mice liver by capillary electrophoresis

Amandeep Singh Arora, Marry jo, Saima Zafar, Frank llorens, Waqas tahir, Sven vanselow, Prateek singh, Matthias Schmitz, Inga Zerr (Menuscript under preparation) 